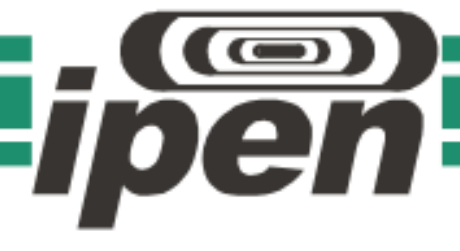

AUTARQUIA ASSOCIADA À UNIVERSIDADE DE SÃO PAULO

Degradação da resina de troca iônica utilizando o reagente de Fenton

Leandro Goulart de Araujo

Dissertação apresentada como parte dos requisitos para obtenção do Grau de Mestre em Ciências na Área de Tecnologia Nuclear - Aplicações

Orientador:

Prof. Dr. Júlio Takehiro Marumo 


\section{INSTITUTO DE PESQUISAS ENERGÉTICAS E NUCLEARES Autarquia associada à Universidade de São Paulo}

Degradação da resina de troca iônica utilizando o reagente de Fenton

Leandro Goulart de Araujo

Dissertação apresentada como parte dos requisitos para obtenção do Grau de Mestre em Ciências na Área de Tecnologia Nuclear - Aplicações

Orientador: Prof. Dr. Júlio Takehiro Marumo 
Dedico este trabalho principalmente ao meu pai, que me ajudou muito e infelizmente se foi antes que pudesse presenciar o fim deste trabalho. Também dedico a toda minha família, que sem seu apoio emocional, não teria sido possível. Ainda, dedico também a todos que, de alguma forma, contribuiram para 0 desenvolvimento e sua conclusão. Obrigado! 


\section{AGRADECIMENTOS}

Ao Prof. Dr. Júlio Takehiro Marumo, pela orientação e dedicação sempre presentes ao longo deste trabalho, com inúmeros conselhos profissionais e pessoais enquanto estive sob sua orientação.

Ao Marcos Maciel de Goes, pela imensa contribuição durante os ensaios laboratoriais, sempre à disposição para auxiliar no laboratório.

Aos laboratórios e centros de pesquisas (LAPOC-CNEN, POLI-USP, IQ/USP e LMM-CCTM-IPEN) que contribuíram com as análises e interpretações dos resultados.

Aos meus pais, irmã e namorada, Álvaro, Valdete, Luciana e Wanessa, pelo apoio nos momentos mais difíceis deste mestrado.

Aos amigos e colegas do GRR, Ana Paula, Bianca, Daiane, Eduardo, Heverton, Isis, Josenílson, Maria Eugênia, Maurício, Patrícia, Rafael, Vanessa e todos aqueles que me ajudaram na GRR, pelos inesquecíveis momentos juntos e pela grande amizade.

Ao IPEN, pelo auxílio financeiro durante o mestrado. 
"É muito melhor lançar-se em busca de conquistas grandiosas, mesmo expondo-se ao fracasso, do que alinhar-se aos pobres de espírito, que nem gozam muito nem sofrem muito, porque vivem numa penumbra cinzenta, onde não conhecem nem a vitória nem a derrota."

\section{Theodore Roosevelt}

"O conhecimento é o ato de entender a vida."

\section{Aristóteles}




\title{
DEGRADAÇÃO DA RESINA DE TROCA IÔNICA UTILIZANDO O REAGENTE DE FENTON
}

\section{Leandro Goulart de Araujo}

\begin{abstract}
RESUMO
O método mais comum de tratamento da resina de troca iônica radioativa é a imobilização em cimento, que reduz a liberação de radionuclídeos para o meio ambiente. Apesar de eficiente, esse método é custoso, pois a quantidade final de rejeito gerada é elevada, já que a capacidade de carga de imobilização é baixa. Este trabalho tem como objetivo desenvolver um método de degradação das resinas provenientes do reator de pesquisa nuclear do Instituto de Pesquisas Energéticas e Nucleares, utilizando o Processo Oxidativo Avançado (POA) com reagentes de Fenton. Isso permitiria uma incorporação maior no cimento. Três formas da resina foram avaliadas: catiônica, aniônica, e uma mistura de ambas as resinas. As reações foram realizadas variando a concentração do catalisador (25, 50, 100 e 150 mM), do volume de peróxido de hidrogênio (320 a $460 \mathrm{~mL}$ ), e de três temperaturas diferentes, 50,60 e $70{ }^{\circ} \mathrm{C}$. A solução de catalisador mais eficiente foi a de concentração de $50 \mathrm{mM}$ e volume de $330 \mathrm{~mL}$ de peróxido, degradando aproximadamente $98 \%$ da quantidade de resina. A temperatura mais eficiente foi a de $60 \circ \mathrm{C}$.
\end{abstract}




\title{
DEGRADATION OF ION SPENT RESIN USING THE FENTON'S REAGENT
}

\section{Leandro Goulart de Araujo}

\begin{abstract}
The most common method for spent radioactive ion exchange resin treatment is its immobilization in cement, which reduces the radionuclides release into the environment. Although this method is efficient, it increases considerably the final volume of the waste due to the low incorporation capacity. The objective of this work was to develop a degradation method of spent resins arising from the nuclear research reactor located at the Nuclear and Energy Research Institute (IPEN-CNEN/SP), using an Advanced Oxidation Process (AOP) with Fenton's reagents. This method would allow a higher incorporation in cement. Three different resins were evaluated: cationic, anionic and a mixture of both resins. The reactions were conducted varying the catalyst concentration $(25,50,100$ and 150 $\mathrm{mM}$ ), the volume of hydrogen peroxide (320 to $460 \mathrm{~mL}$ ), and three different temperatures, 50, 60 and $70 \stackrel{\circ}{\circ}$. Degradation of about $98 \%$ was achieved using a $50 \mathrm{mM}$ catalyst solution and $330 \mathrm{~mL}$ of hydrogen peroxide solution. The most efficient temperature was $60^{\circ} \mathrm{C}$.
\end{abstract}




\section{SUMÁRIO}

1 INTRODUÇÃO

2 OBJETIVO

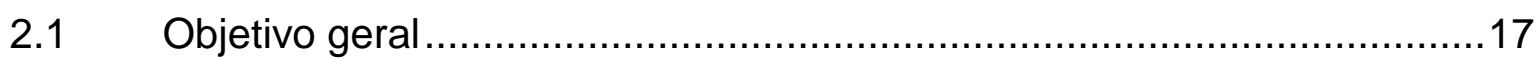

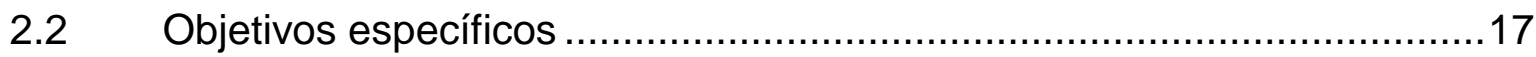

3 REVISÃO DA LITERATURA

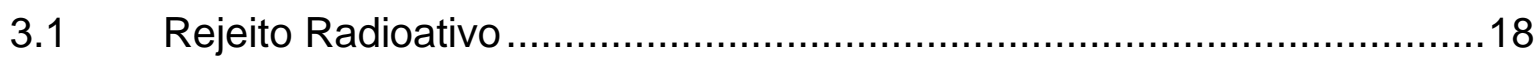

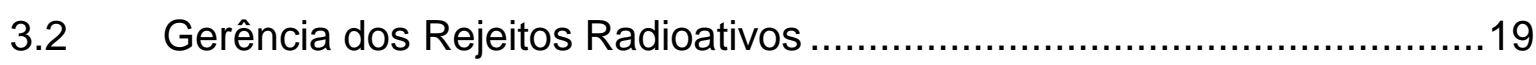

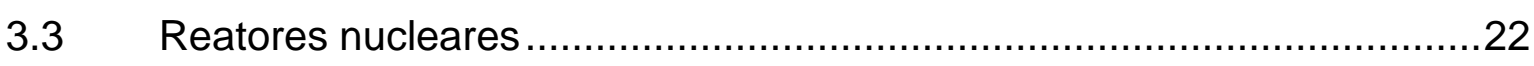

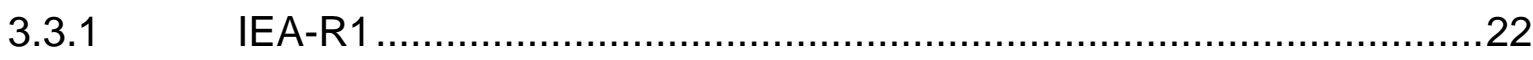

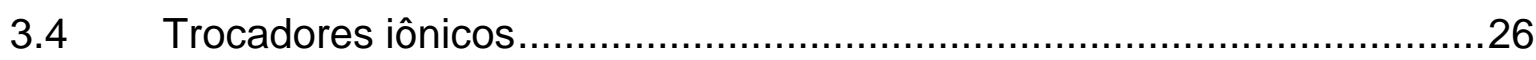

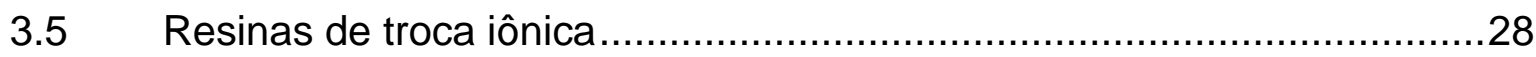

3.6 Processos Oxidativos Avançados (POAs) ........................................... 30

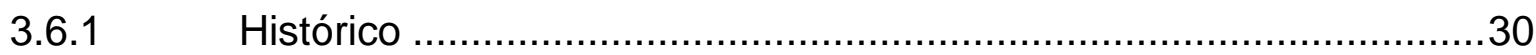

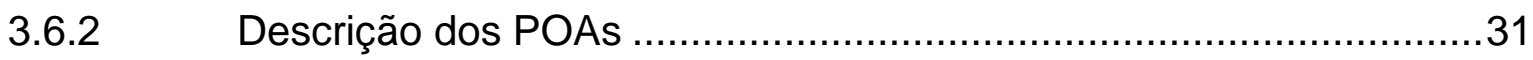

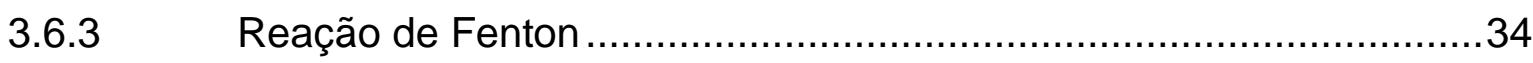

3.6.4 Emprego de Fenton na degradação das resinas...............................36

3.6.5 Condições operacionais da reação de Fenton …................................38

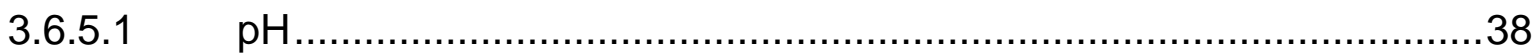

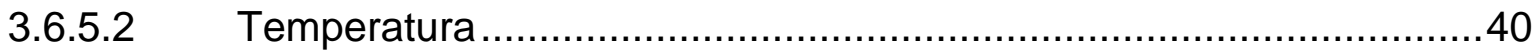

3.6.5.3 Concentração de catalisador ............................................................ 40

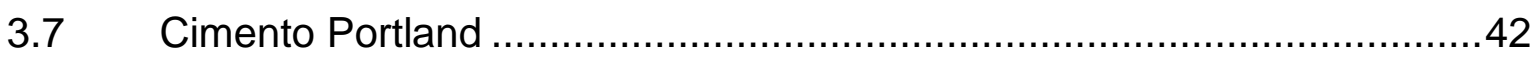

4 METODOLOGIA

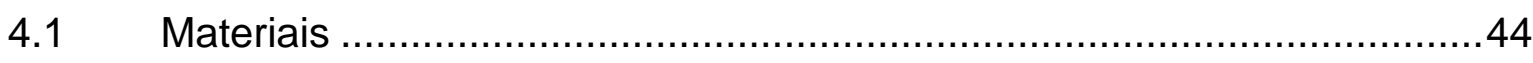

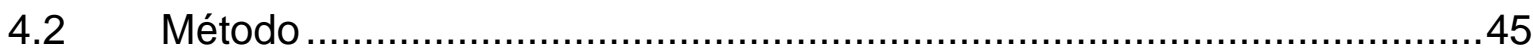

4.2.1 Concentração de peróxido de hidrogênio ..........................................49

4.2.2 Quantidade final de resina e molaridade .......................................49

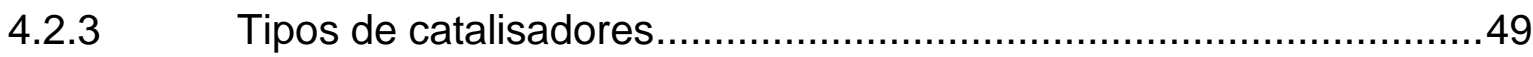

4.2.4 Dióxido de carbono produzido .....................................................

4.2.5 Oxigênio dissolvido (OD) .......................................................... 50

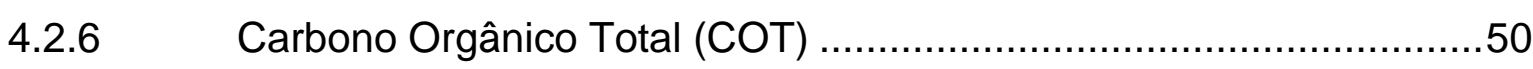

4.2.7 Microscopia de varredura e óptica................................................... 


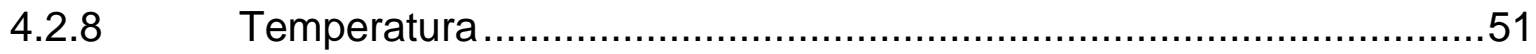

4.2.9 Análise de grupos funcionais por meio de Infravermelho ..................51

4.2.10 Imobilização com cimento Portland ...............................................

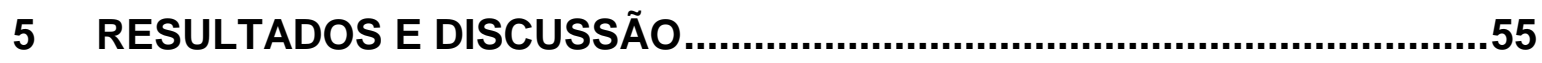

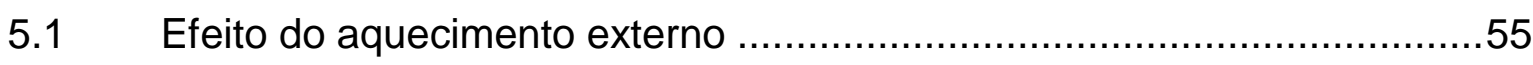

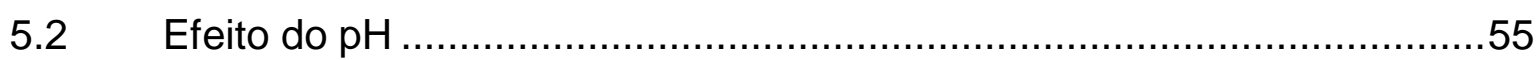

5.3 Efeito da variação na concentração de catalisador ..................................56

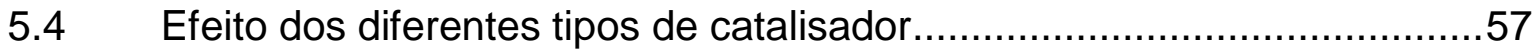

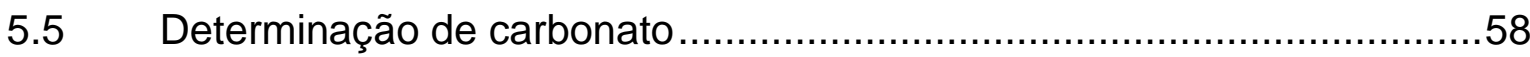

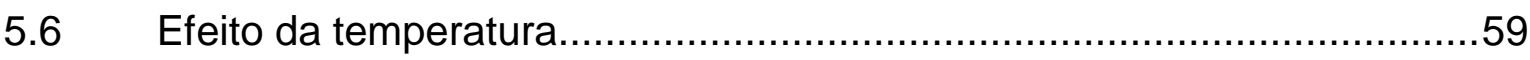

5.7 Efeito da variação da concentração de catalisador na degradação de 10

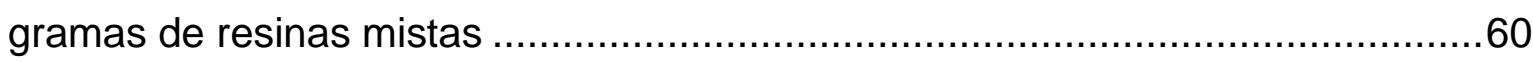

5.8 Determinação de Oxigênio Dissolvido (O.D.)........................................

5.9 Determinação do Carbono orgânico total (COT)........................................63

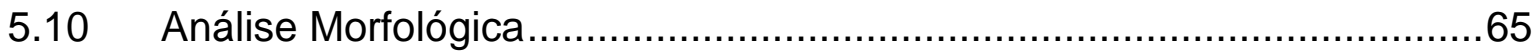

5.11 Análise de grupos funcionais por meio de Infravermelho.........................67

5.12 Resumo das condições experimentais e dos parâmetros de avaliação

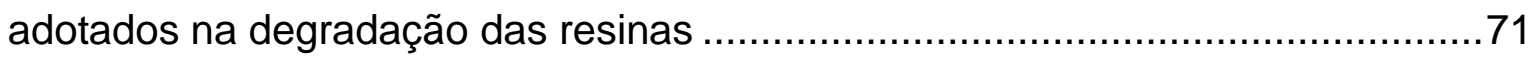

5.13 Imobilização com cimento Portland ....................................................73

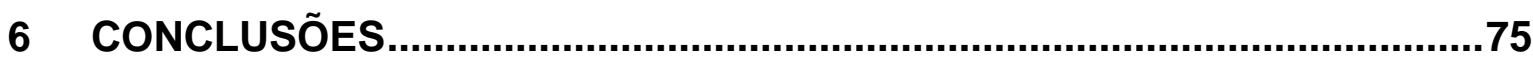

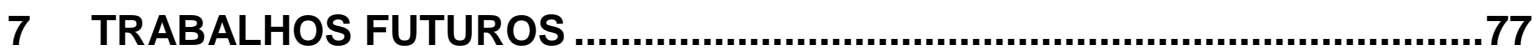

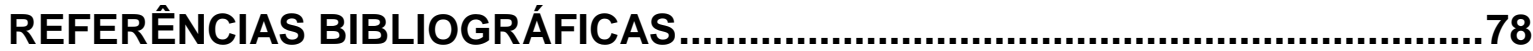




\section{LISTA DE TABELAS}

TABELA 1- Características físico-químicas da água da piscina do reator IEA-R124

TABELA 2 - Potencial redox de alguns oxidantes

TABELA 3 - Constantes de velocidade do radical hidroxila e do ozônio para alguns compostos orgânicos (Calgon Carbon Corporation, 1996 apud Domènech et al., 2001) 32

TABELA 4 - Condições experimentais utilizadas nos experimentos da degradação de um grama de resina 46

TABELA 5 - Condições experimentais na degradação de 10 gramas de resina...48

TABELA 6 - Massas de resina residual obtidas nas reações de oxidação .56

TABELA 7 - Massas de resinas residuais obtidas nas reações de oxidação com 1 grama de resina úmida $(0,56 \mathrm{~g} \mathrm{seco})$ diferentes catalisadores

TABELA 8 - Massas de carbonato obtidas e massa de resinas residuais nas reações de oxidação .58

TABELA 9 - Massas de resinas residuais secas das reações de oxidação de 10 gramas com diferentes temperaturas.

TABELA 10 - Massas de resinas residuais obtidas nas reações de oxidação com os volumes de peróxido de hidrogênio utilizados e temperaturas. 60 TABELA 11 - Relação $\mathrm{H}_{2} \mathrm{O}_{2} / \mathrm{Fe}^{2+}$ para suas respectivas concentrações de catalisador.

TABELA 12 - Análise dos espectros de FTIR de resinas catiônicas e aniônicas sem tratamento de Fenton e de resinas mistas remanescentes após Fenton ......70 TABELA 13 - Tempo de pega final e resistência à compressão axial .73 


\section{LISTA DE FIGURAS}

FIGURA 1 - Esquema de imobilização direta e com tratamento com reagentes de Fenton. .15

FIGURA 2 - Fluxograma da gerência de rejeitos radioativos (Hiromoto, 1999). ...19

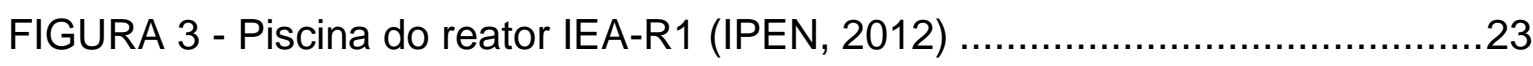
FIGURA 4 - Tratamento e retratamento das águas do reator (ISIKI, 2003) .........25 FIGURA 5 - Estruturas das resinas de troca iônica. (a). resinas catiônicas fortemente ácidas. (b). resinas aniônicas fortemente básicas. .29 FIGURA 6- Instrumentação utilizada na oxidação de um grama de resinas de troca iônica.

FIGURA 7 - Instrumentação utilizada para a degradação de 10 gramas de resina de troca iônica em um reator químico. 1. Peróxido de hidrogênio. 2. Bomba peristáltica. 3. Agitador. 4. Reator de vidro. 5. Solução de catalisador. 6. Multímetro. .48

FIGURA 8 - Analisador de carbono orgânico total TOC-V CPH series .50 FIGURA 9 - Imagem da argamassadeira utilizada para misturar cimento com as soluções Fenton .52

FIGURA 10 - Moldes plásticos com as amostras 53

FIGURA 11- Imagem da agulha de Vicat para determinação do tempo de pega 54 FIGURA 12 - Imagem de prensa hidráulica para determinação da resistência à compressão axial .54

FIGURA 13 - Concentração do oxigênio dissolvido em função do tempo, das reações de oxidação com diferentes concentrações de catalisador. 63 FIGURA 14 - Variação da concentração de carbono orgânico total em função do tempo de reação com diferentes concentrações de catalisador. FIGURA 15 - Massa de resina degradada e variação do COT em função da molaridade do catalisador 65 FIGURA 16 - a: Imagem das resinas sem tratamento. b, c, d, e: Resinas após 30, 45, 120 e 180 minutos de reação ( $100 \mathrm{mM} \mathrm{Fe}_{2} \mathrm{SO}_{4}$ ). Aproximação 200x .66 FIGURA 17- a: Resinas sem tratamento. b, c, d, e: Resinas após 30, 45, 120 e 180 minutos de reação (50 mM Fe2SO4). a: Aproximação 10x. b, c, d, e: 40x...67 FIGURA 18 - Espectro de Infravermelho por Transformada de Fourier da resina de troca catiônica fortemente ácida 
FIGURA 19 - Espectro de Infravermelho por Transformada de Fourier da resina de troca aniônica fortemente básica ...... .68 FIGURA 20 - Espectro de Infravermelho por Transformada de Fourier da resina de troca aniônica mista após tratamento de Fenton 69 


\section{LISTA DE ABREVIATURAS E/OU SIGLAS}
A.F.B
Aniônica Fortemente Básica (resina)
A.f.B
Aniônica fracamente Básica (resina)
D.V.B
Divinil Benzeno
C.F.A
Catiônica Fortemente Ácida (resina)
C.f.A
Catiônica fracamente Ácida (resina)
COT
Carbono Orgânico Total
CNEN
Comissão Nacional de Energia Nuclear
CYTED
Programa Íbero- Americano de Ciência e Tecnologia para o
desenvolvimento
EPRI
Eletric Power Research Institute
FTIR
Espectroscopia de Infravermelho por Transformada de Fourier
GRR
Gerência de Rejeitos Radioativos
IAEA
International Agency of Energy Atomic
IEA - R1
Reator de Pesquisas do IPEN
IPEN
Instituto de Pesquisas Energéticas e Nucleares
MEV
Microscopia Elêtronica de Varredura
$\mathrm{pH}$
Potencial Hidrogeniônico
OD
Oxigênio Dissolvido
POA
Processo Oxidativo Avançado
RAA
Rejeito de Alta Atividade
RBA
Rejeito de Baixa Atividade
RMA
Rejeito de Média Atividade
USEPA
United States Environmental Protection Agency 


\section{INTRODUÇÃO}

A tecnologia nuclear trata a questão ambiental prioritariamente em seus variados usos e aplicações das radiações e da energia e, por isso, o nível de exigência em termos de segurança é maior perante outras atividades humanas poluidoras. Um exemplo disso é o rejeito radioativo que recebe tratamento especial e é totalmente controlado em termos de armazenamento e controle de inventário, o que não ocorre com os resíduos sólidos urbanos gerados diariamente que também podem conter substâncias nocivas ao meio ambiente.

Diversos tipos de rejeitos radioativos são gerados nas diversas aplicações nucleares, desde um simples pedaço de papel até peças de equipamentos. Neste trabalho é estudado um tipo especial de rejeito gerado no sistema de purificação da água de um reator de pesquisa, a resina de troca iônica. Os reatores de pesquisa e os reatores de potência são os dois principais tipos de reatores nucleares. Os de potência visam gerar energia elétrica, já os reatores de pesquisa possuem diversas funções como treinamento e pesquisas em ciências nucleares, teste de materiais, produção de radioisótopos para indústria e medicina, análise por ativação, testes não destrutivos, etc. (IAEA, 2010).

O reator de pesquisa IEA-R1 do Instituto de Pesquisas Energéticas e Nucleares, IPEN, é o maior reator de pesquisa no Brasil, e é do tipo piscina, que utiliza água leve como blindagem, moderador e fluido refrigerante, e grafite como refletor. $\mathrm{O}$ sistema de tratamento da água da piscina do reator é dividido em dois circuitos: um não radioativo e outro radioativo, compostos por filtros, trocadores iônicos e carvão ativo. O circuito radioativo remove, por meio de leitos de carvão ativo e resina de troca iônica, elementos dissolvidos na água quando o reator está em operação, mantendo sempre baixo grau de impurezas. Esses leitos são regenerados algumas vezes e, quando isso não for mais possível, são substituídos, tornando-se rejeitos radioativos (Wolff, 2012).

A resina e o carvão são rejeitos sólidos que devem passar por um processo de adequação, antes de serem encaminhados para o depósito provisório ou repositório. No caso das resinas, a Norma CNEN - NN 6.09: 
"Critérios de aceitação para deposição de rejeitos radioativos de baixo e médio níveis de radiação" (CNEN, 2002), estabelece que as mesmas devam ser incorporadas em matriz, homogeneamente distribuídas e com um mínimo de material segregado, formando um produto monolítico (CNEN, 2002). Usualmente é adotada a imobilização em cimento Portland, por ser muito simples, de baixo custo, ter boas propriedades mecânicas e requer basicamente, um sistema de mistura dos componentes (água, cimento e resina) e uma blindagem, dependendo da atividade ( $\mathrm{Li}$ e Wang, 2006; Hiromoto et al., 1999). A desvantagem da aplicação deste método é a baixa capacidade de imobilização, que aumenta o volume de rejeitos e acaba por elevar o custo do armazenamento. O aumento no volume de rejeitos deve-se ao fato da resina de troca iônica possuir uma característica de expansão e contração, que impossibilita quantidades maiores de 10\% na mistura com o cimento na imobilização direta (Veazey e Ames, 1997, Helfferich, 1995).

Para aumentar a capacidade de carga, novas tecnologias capazes de destruir o rejeito completamente, aumentando sua incorporação nas matrizes de imobilização desejadas têm sido desenvolvidas com o objetivo principal de redução de volume e custo em relação à imobilização direta (Kim et al., 2009).

Vários métodos de redução são descritos na literatura, como pirólise (Juang e Lee, 2002), incineração (Kinoshita, 1991, IAEA, 2002), digestão ácida (Kabayashi, 1980) e os Processos Oxidativos Avançados (POAs), destacando-se o último por não necessitar de temperaturas elevadas $\left(60^{\circ} \mathrm{C}\right.$ a $\left.100^{\circ} \mathrm{C}\right)$ e trabalhar com pressão ambiente (Matilainen e Sillanpää, 2010; Taylor, 2002). De acordo com o "Eletric Power Research Institute" (EPRI), todas as 12 técnicas de redução de volume estudadas, como a incineração, compactação, evaporação, etc. se mostram economicamente mais viáveis que a imobilização de forma direta (Giuffre et al., 1984).

Existem diversos tipos de processos oxidativos avançados, dentre os quais se pode destacar os processos com ozônio e peróxido de hidrogênio e/ou uma combinação destes $\left(\mathrm{O}_{3} / \mathrm{H}_{2} \mathrm{O}_{2}\right.$ ou $\left.\mathrm{O}_{3} / \mathrm{H}_{2} \mathrm{O}_{2} / \mathrm{UV}\right)$, a fotocatálise e 0 reagente de Fenton (mistura de peróxido de hidrogênio e sais ferrosos) (Araujo, 2008). De acordo com Neyens e Baeyens (2003) e Araujo (2008), o reagente de Fenton se destaca por ter custo relativamente baixo e facilidade de operação, 
além da abundância do catalisador utilizado, o ferro, na natureza e a sua presença em diferentes espécies de minerais.

O reagente de Fenton descoberto no século XX (Fenton, 1894) é amplamente utilizado como processo químico para o tratamento e pré-tratamento de águas residuais e na comunidade científica. Nesses processos os radicais hidroxila altamente reativos são gerados, causando destruição completa ou parcial de muitos compostos orgânicos, por exemplo, fenóis e herbicidas (Pacheco e Peralta-Zamora, 2004; Cruz, 2000; Zarohodna et al., 2007; Martínez et al., 2003; Lange et al., 2006; Andreozzi et al., 1999). A oxidação química visa a mineralização dos contaminantes em dióxido de carbono, água e compostos inorgânicos, ou sua transformação em produtos inofensivos ao meio ambiente (Andreozzi et al., 1999). Na FIG.1 é apresentado o tratamento das resinas radioativas por meio direto e com a utilização de um pré-tratamento com reagentes de Fenton. O pré-tratamento pode ser capaz de reduzir a quantidade de tambores que serão necessários para armazenar a resina de troca iônica imobilizada, diminuindo custos no transporte e deposição final. A título de exemplo, tendo como base de cálculo um tambor de resina, com 240 quilos, na imobilização direta seria gerado 6 tambores de rejeitos. Com a utilização de um pré-tratamento, como os reagentes de Fenton, seria possível incorporar essa quantidade de resina em apenas um tambor, como apresentado na Figura 1.

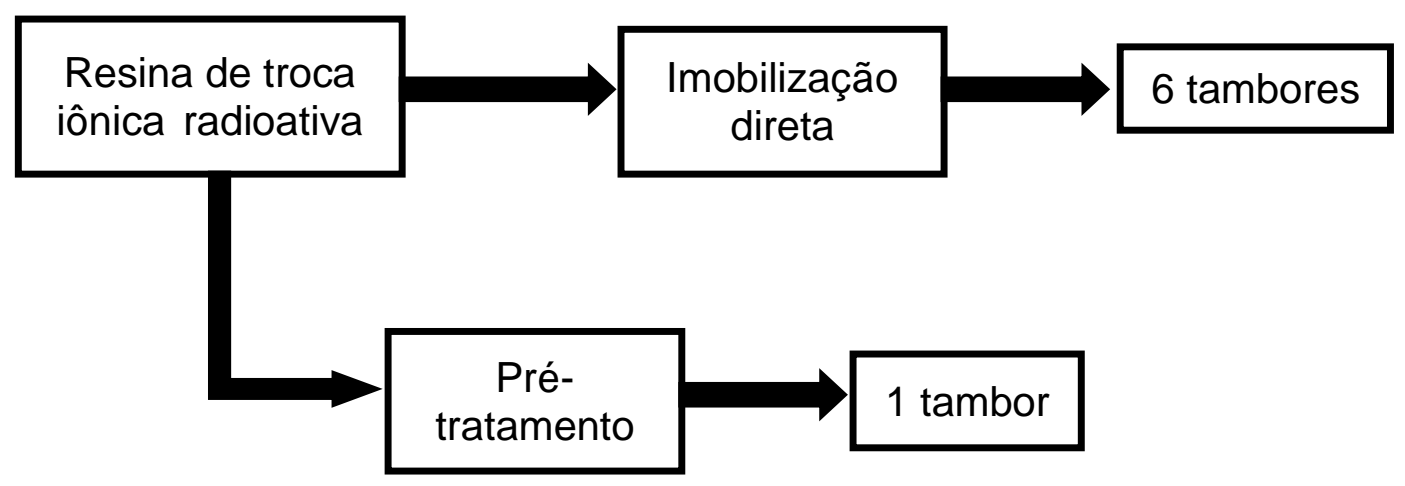

FIGURA 1 - Esquema de imobilização direta e com tratamento com reagentes de Fenton 
Tendo em vista a redução de volume na degradação de compostos orgânicos e a mineralização dos contaminantes, o reagente de Fenton se mostra uma alternativa viável como possível tratamento das resinas de troca iônica provenientes do reator de pesquisas IEA-R1. 


\section{OBJETIVO}

\subsection{Objetivo geral}

> Estudar um método para destruição quantitativa das resinas de troca iônica catiônica e aniônica, empregando o Processo Oxidativo Avançado (POA) com reagentes de Fenton, para aumentar a capacidade de carga do rejeito na imobilização.

\subsection{Objetivos específicos}

Avaliar a quantidade final de massa de resina obtida após o POA com a produção de dióxido de carbono, inicialmente em ensaios exploratórios;

$>$ Determinar a temperatura adequada de operação;

- Determinar a concentração molar de catalisador mais apropriada;

Comparar a massa de resina residual com o Carbono Orgânico Total (COT);

- Verificar a superfície morfológica das resinas pré e pós-reação de Fenton por meio de Microscopia Eletrônica de Varredura (MEV) e microscopia óptica;

Analisar as possíveis diferenças estruturais entre as resinas pré e pós-reação de Fenton por meio de análise por Infravermelho;

Medir o oxigênio dissolvido periodicamente nas reações de Fenton; 


\section{REVISÃO DA LITERATURA}

Neste capítulo apresenta-se a revisão da literatura, abordando tópicos importantes para o entendimento do trabalho, como a descrição dos rejeitos radioativos e da Gerência de Rejeitos Radioativos, dos reatores nucleares, das resinas de troca iônica, e sobre a aplicação dos Processos Oxidativos Avançados (POAs) e os reagentes de Fenton no tratamento de efluentes.

\subsection{Rejeito Radioativo}

De acordo com a IAEA (International Atomic Energy Agency), rejeito radioativo é definido como "qualquer material que contenha ou esteja contaminado com radionuclídeos em concentrações ou valores de atividade maiores que os limites de isenção estabelecidos pela autoridade competente" (IAEA, 2003).

No Brasil, a Comissão Nacional de Energia Nuclear (CNEN) o define como "qualquer material resultante de atividades humanas que contenha radionuclídeos em quantidades superiores aos limites de isenção estabelecidos pela CNEN, para qual a reutilização é imprópria ou não prevista" (CNEN, 2011). De acordo com a Norma CNEN - NE 6.05: "Gerência de Rejeitos Radioativos em Instalações Radiativas", o rejeito radioativo é resultante de atividades nucleares (pesquisa ou industriais), sendo constituído de materiais contaminados com radionuclídeos naturais ou artificiais que emitem radiação ionizante, ou seja, radiação eletromagnética ou até mesmo de partículas que, interagindo com a matéria, ionizam direta ou indiretamente seus átomos ou moléculas (CNEN 6.05).

Os rejeitos radioativos são classificados de diversas maneiras: de acordo com a origem (instalações radiativas e/ou nucleares), o estado físico, os níveis de radioatividade, as quantidades de radionuclídeos de meia-vida longa e curta, a intensidade da radiação, os requisitos de deposição final ou com a toxicidade. Usualmente, a combinação de métodos é a mais indicada, dependendo das etapas da gerência dos rejeitos que necessitam ser colocadas em prática (Ferreira, 2008). 
Os rejeitos são classificados em categorias, de acordo com seu estado físico, natureza da radiação, concentração e taxa de exposição (CNEN, 1985). No Brasil, a CNEN é o órgão que define os critérios a serem utilizados no gerenciamento dos rejeitos.

\subsection{Gerência dos Rejeitos Radioativos}

A gerência dos rejeitos radioativos é responsável pelas atividades relacionadas ao rejeito, desde a administração a operação, com o objetivo de proteger a saúde humana e ambiental, não deixando encargos para as gerações futuras (IAEA, 1995). Não existe um modelo padrão específico de gerência, pois depende de fatores sociais, políticos, tecnológicos, e, também, da diversidade e da quantidade gerada. A redução de volume e o acondicionamento são duas etapas importantes da gerência porque estão relacionadas ao custo de armazenamento e segurança física e radiológica (Marumo, 2006). A FIG. 2 (Hiromoto, 1999) apresenta um fluxograma genérico das etapas da gerência de rejeitos (IAEA, 1983; Amphlett, 1961; IAEA, 1992).

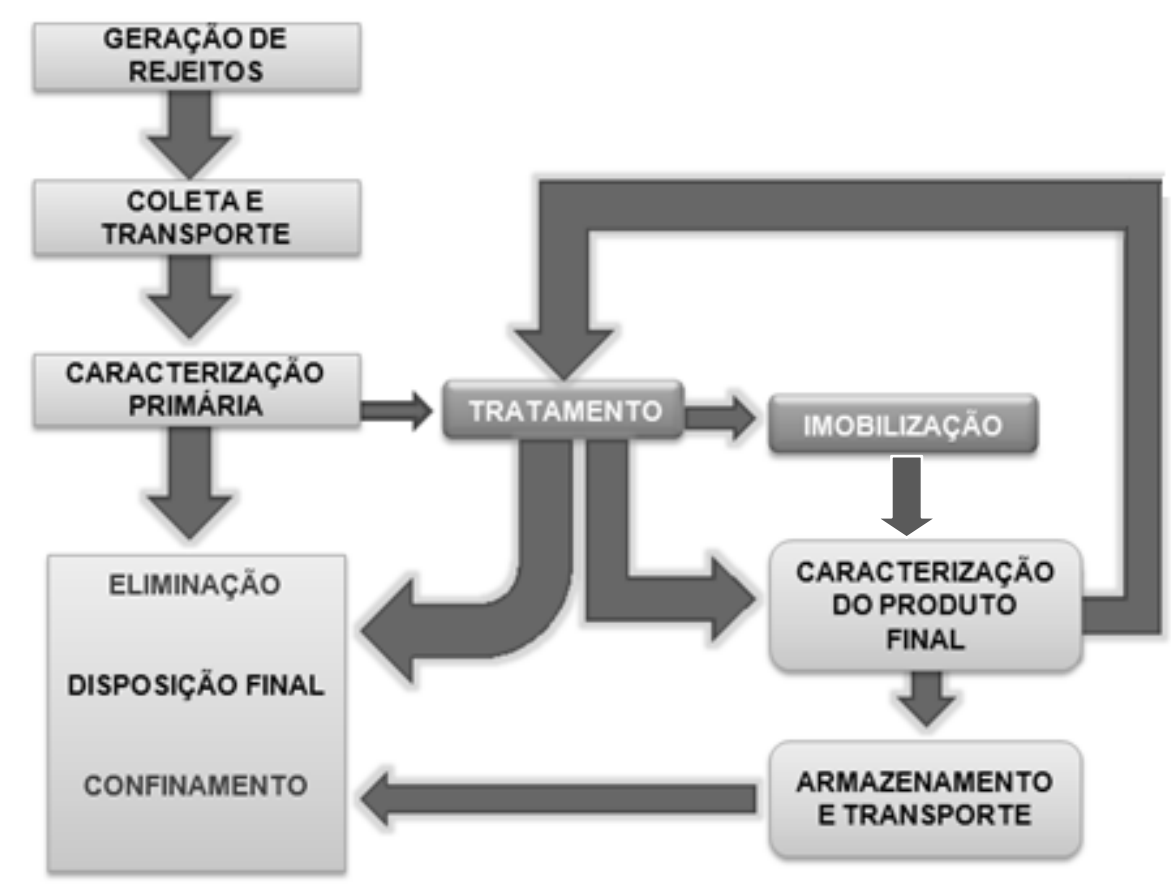

FIGURA 2 - Fluxograma da gerência de rejeitos radioativos (Hiromoto, 1999). 
A primeira etapa da gerência é a "geração de rejeitos", que visa a diminuição dos custos e das doses operacionais durante o manuseio. A redução do volume de rejeitos em sua origem, ou seja, minimização, está diretamente ligada a esta etapa. $\mathrm{Na}$ "coleta e transporte" o rejeito deve estar em embalagem apropriada, com identificação e o transporte adequado para a unidade de tratamento desejada.

A caracterização primária dos rejeitos é realizada por meio de ensaios para a determinação das suas propriedades físicas, químicas e radiológicas. Uma análise pode determinar se o rejeito possui atividade abaixo dos limites de dispensa estabelecidos pelas normas da CNEN, podendo então ser tratado como resíduo convencional.

O tratamento visa reduzir o volume, condicionar fisicamente e quimicamente o rejeito, para compatibilizar com a matriz de imobilização e os materiais da embalagem, além de reduzir os custos das etapas seguintes da gerência.

O rejeito pode estar tanto na forma sólida quanto nas formas líquidas e gasosas. Pode ser sem tratamento, tratado ou condicionado para transporte e deposição (ARPANSA, 2008). O objetivo de tratar e condicionar esses materiais é produzir embalagens de rejeito que podem ser manuseadas, transportadas, armazenadas e descartadas com segurança. A embalagem final deve satisfazer os critérios de aceitação e deposição da instalação.

No caso das resinas de troca iônica, os tratamentos comumente utilizados são: a incineração, decomposição térmica, digestão ácida e oxidação úmida (Zahorodna et al., 2008).

No Brasil não há incineradores disponíveis para o tratamento de rejeitos radioativos, e a técnica é considerada sofisticada e dispendiosa, justificando apenas com a utilização de grandes quantidades de rejeitos (Endo, 1991, Fabiano et al., 1998).

A decomposição térmica, como a combustão, é considerada eficiente no tratamento, redução de volume e descontaminação. Entretanto, requer altas tempeturaturas (acima de $800^{\circ} \mathrm{C}$ ) e ainda pode ocorrer a liberação de radionuclídeos $\left({ }^{137} \mathrm{Cs},{ }^{106} \mathrm{Ru}, \ldots\right)$ para a fase gasosa, sendo necessário filtros de retenção. Além disso, o sistema de tratamento na fase gasosa é necessário para prevenir emissões de substâncias perigosas como o óxido nítrico e sulfúrico. 
Outro fator importante é que antes de entrarem em combustão, as resinas podem formar grandes aglomerados por fusão, causando corrosão no refratário. As resinas podem também quimicamente ou radioliticamente degradar-se, resultando na emissão de espécies perigosas no meio ambiente (Leybros et al., 2009).

A digestão ácida é a combinação dos ácidos sulfúrico e nítrico. De acordo com Kobayashi et al. (1980), os estudos preliminares mostraram desvantagens do processo, como o longo tempo de digestão de alguns produtos da degradação das resinas e quantidade considerável de ácido nítrico necessária.

O armazenamento temporário é feito quando ainda não há um repositório final ou ainda quando o embalado de rejeito necessita de alguma vistoria antes de ser encaminhado para a deposição. O local que é utilizado para o armazenamento depende de diversos fatores, como a concepção da instalação e os riscos radiológicos associados a essa prática. Os requisitos de montagem e a avaliação de segurança das instalações de armazenamento de rejeitos dependem basicamente do perigo radiológico potencial dos resíduos armazenados e das atividades a serem realizadas no local (ARPANSA, 2008).

$O$ transporte pode ser externo, realizado em áreas externas à instalação licenciada, ou interno, realizado em áreas internas à instalação licenciada. Os veículos utilizados para transporte devem possuir meios de fixação adequados para os recipientes para evitar dano aos mesmos e devem ser devidamente monitorados e, caso haja necessidade, descontaminados (CNEN, 1985).

Caso não haja uma instalação apropriada e os critérios de aceitação não sejam definidos, uma avaliação deve ser feita para determinar o tipo apropriado de deposição para o fluxo de rejeitos e os critérios adequados, que exigem o mínimo de espaços vazios na embalagem, e líquido livre e materiais tóxicos abaixo dos limites especificados em norma (ARPANSA, 2008).

Após a etapa de tratamento, os rejeitos que ainda não atendem aos critérios para armazenamento, transporte e deposição final, são imobilizados. Esta etapa tem como objetivo converter o rejeito em uma forma sólida mololítica, impedindo a sua liberação ao meio ambiente. Esta técnica é utilizada em rejeitos sólidos úmidos, como o carvão, concentrados de evaporador, cinzas de incineradores e resinas de troca iônica (Hiromoto, 1999). 
As matrizes de imobilização mais utilizadas são o cimento, o betume e os polímeros (Hung, 1994). A escolha da matriz mais adequada depende de fatores como: compatibilidade química com o rejeito, custo, a tecnologia relacionada, disponibilidade comercial e qualidade do produto final. No caso das resinas de troca iônica, a matriz mais utilizada é o cimento Portland.

\subsection{Reatores nucleares}

Um dos rejeitos gerados nos reatores nucleares, de potência ou de pesquisa, é a resina de troca iônica utilizada no sistema de tratamento de água. Os reatores de potência são na grande maioria reatores com água pressurizada capazes de gerar energia por meio de material radioativo. Os reatores nucleares de pesquisa são de baixa potência e utilizados especialmente em experimentos com fissão nuclear e/ou para produzir radioisótopos, empregados na indústria e medicina.

\subsubsection{IEA-R1}

O IPEN possui o primeiro reator nuclear de pesquisa brasileiro, o IEAR1, localizado em uma instalação multidisciplinar, na qual são desenvolvidas pesquisas nas áreas de ciências nucleares e de engenharia.

Este reator de pesquisa é do tipo piscina, contendo $273 \mathrm{~m}^{3}$ de água desmineralizada. A piscina possui cerca de 9 metros de profundidade por 3,05 metros de largura e 10,65 metros de comprimento. 


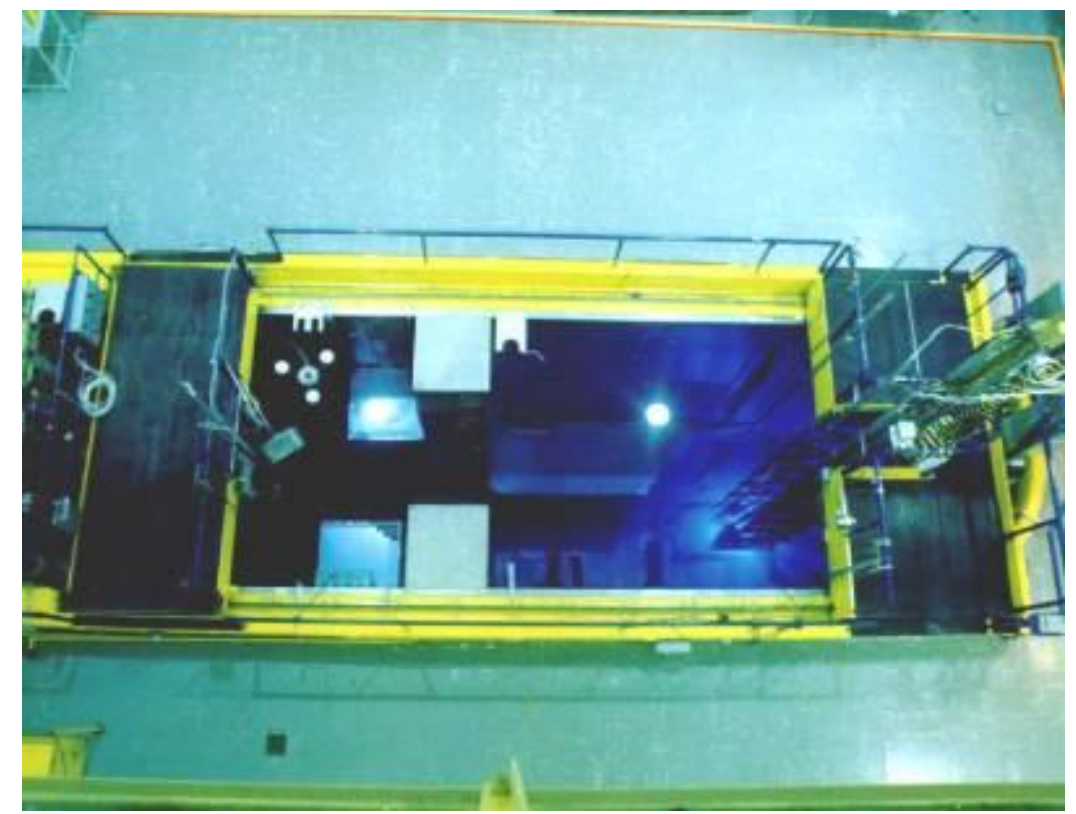

FIGURA 3 - Piscina do reator IEA-R1 (IPEN, 2012)

Como pode ser visto na FIG. 3, a piscina está divida em dois compartimentos, o da direita, utilizado para operação do reator e o da esquerda, utilizado para o armazenamento do combustível queimado e manuseio de amostras. O núcleo do reator está situado a 6,9 metros da superfície da piscina, têm a forma de um paralelepípedo composto por 20 elementos combustíveis padrões, 4 elementos combustíveis de controle, cerca de 25 elementos refletores, 7 posições para irradiação de amostras e tampões encaixados verticalmente em uma placa matriz de alumínio. Esta placa é sustentada por uma treliça conectada a uma plataforma móvel que permite o seu deslocamento ao longo da piscina (IPEN, 2012).

Existem dois circuitos no sistema de tratamento de água do reator, o não radioativo e o radioativo, composto por resinas de troca iônica, carvão ativo e filtros.

O circuito não radioativo é responsável pelo abastecimento da piscina quando o nível estiver abaixo do limite. Recebe água proveniente da rede de abastecimento da Cidade Universitária e é constituído por um filtro tipo "Cuno", para retenção das partículas sólidas em suspensão com dimensões maiores que 25 microns; um tanque "amolecedor", composto por trocadores iônicos para retenção de $\mathrm{Ca}^{++}$e $\mathrm{Mg}^{++}$; um filtro de carvão ativo para retenção de gases dissolvidos na água; e dois trocadores iônicos de leito misto de resinas catiônicas 
e aniônicas, sendo um, de reserva, para ser usado quando o outro necessitar de regeneração (Aguida et al., 1999, Pasqualetto, 1978), que é quando a condutividade da água estiver próxima de 2,0 $\mu \mathrm{S} / \mathrm{cm}$, como observado na TAB. 1 (Cegalla et al. 1997).

TABELA 1- Características físico-químicas da água da piscina do reator IEA-R1

\begin{tabular}{cc}
\hline Parâmetro & Valor \\
\hline Condutividade & $<2,0 \mu \mathrm{S} / \mathrm{cm}$ \\
pH & $5,5 \mathrm{à} 6,5$ \\
Alumínio & $0,02 \mathrm{~g} / \mathrm{L}$ \\
Ferro & $0,001 \mathrm{mg} / \mathrm{L}$ \\
Sódio & $0,4 \mathrm{mg} / \mathrm{L}$ \\
Cálcio + Magnésio & $0,6 \mathrm{mg} / \mathrm{L}$ \\
Cloreto & $<0,2 \mathrm{mg} / \mathrm{L}$ \\
\hline
\end{tabular}

O circuito radioativo é responsável pelo retratamento contínuo da água da piscina. É constituído por duas unidades, com capacidade, cada uma, de retratar $75 \mathrm{~L} / \mathrm{min}$. O circuito mantém o grau de impurezas da água em torno de 2 ppm de substâncias solúveis. Essas impurezas são de diferentes tipos, como (Cegalla et al. 1997):

- Partículas de poeira, depositadas na superfície livre da piscina.

- Elementos radioativos formados por reações nucleares no alumínio estrutural dos elementos combustíveis.

- Contaminações acidentais, por ruptura de cápsulas, contendo materiais que são irradiados no reator.

- Produtos de fissão, devido a falhas ou contaminação nas placas dos elementos combustíveis.

Esses contaminantes podem ter origem na falha do sistema de tratamento ou nos produtos gerados por meio da corrosão dos materiais estruturais (Aguida et al. 1999). O problema dos contaminantes é que esses podem ser ativados por reações do tipo $(n, y)$ com nêutrons lentos, resultando na elevação dos níveis de radiação na água, e por causa das correntes hidráulicas, 
ocorre o aumento dos níveis de radiação na superfície livre da piscina (Pasqualetto, 1976), prejudicando o funcionamento do reator.

O tratamento e retratamento das águas do reator é apresentado na FIG. 4.

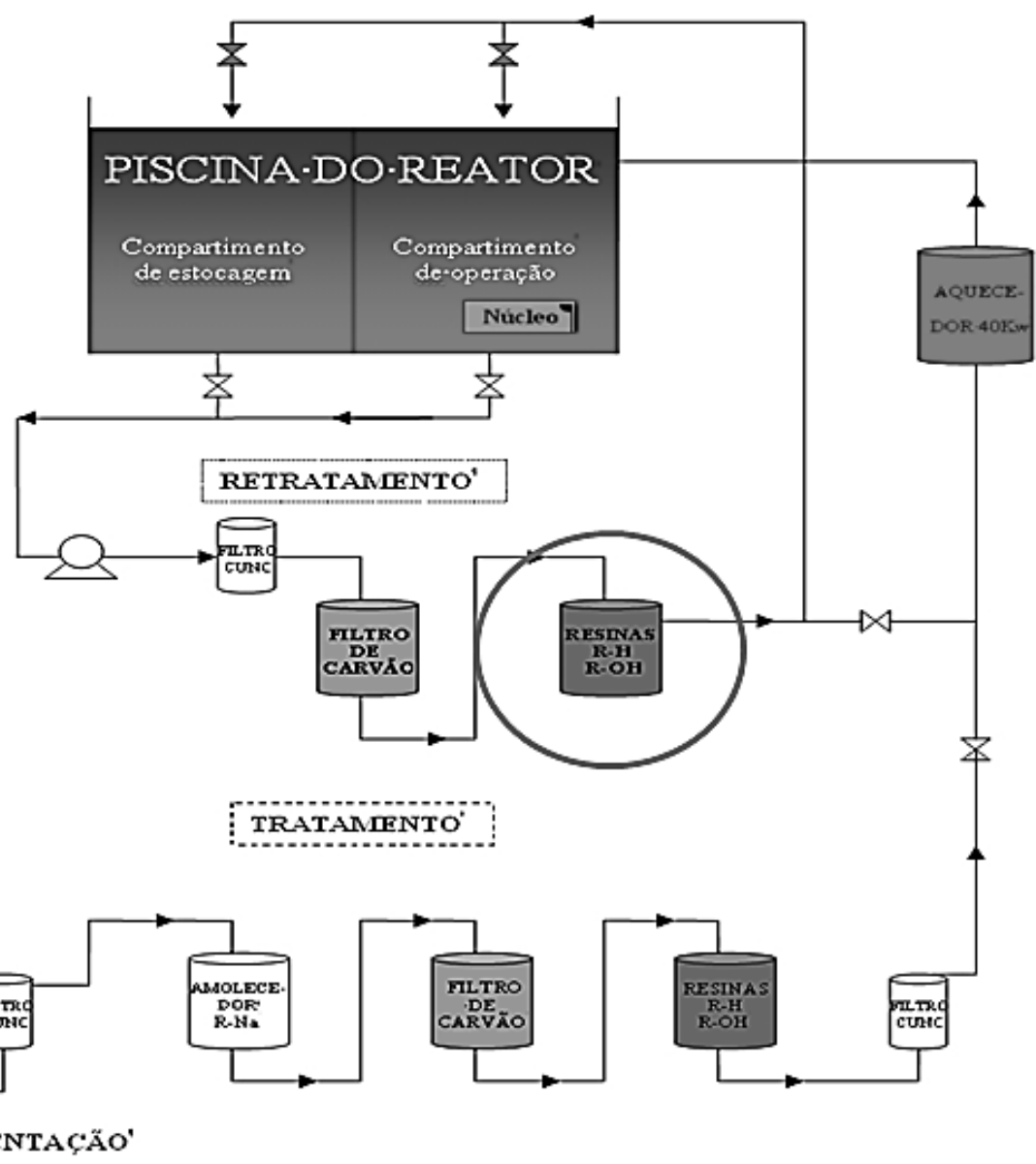

FIGURA 4 - Tratamento e retratamento das águas do reator (ISIKI, 2003).

As resinas utilizadas neste sistema do reator IEA-R1 são do tipo catiônica fortemente ácida, na forma $\mathrm{R}-\mathrm{H}$ e aniônica fortemente básica, na forma R-OH (Cegalla et al., 1997).

O carvão ativo e as resinas de troca iônica do circuito primário tornamse radioativos, pois removem elementos dissolvidos na água quando o reator está em operação. A atividade da água após sua passagem pelo núcleo do reator é resultante da ativação da própria água e de gases nela dissolvidos; da ativação de impurezas dissolvidas na água, provenientes da rede de abastecimento ou da 
corrosão de materiais estruturais; de reações nucleares de recuo nos materiais que se encontram no núcleo do reator e que são submetidos a um fluxo de nêutrons rápidos; do desprendimento de radionuclídeos formados nos materiais constituintes do núcleo; e de produtos de fissão provenientes dos elementos combustíveis por meio de difusão (Pasqualetto, 1976).

Num reator, as resinas de troca iônica têm as seguintes funções principais (Hung, 1994):

- Desmineralização da água;

- Atuar na remoção dos contaminantes radioativos e seus produtos de corrosão ativados;

- Remoção do $\mathrm{O}_{2}$ do refrigerante $\left(\mathrm{H}_{2} \mathrm{O}\right)$ no sistema primário;

- O inibidor de corrosão e envenenador de nêutrons, além de outros aditivos, é controlado pela resina.

Desta forma, após a sua vida-útil, a resina de troca iônica é considerada rejeito radioativo e, por isso, necessita ser armazenada de modo a não oferecer riscos ao homem e ao meio ambiente.

\subsection{Trocadores iônicos}

Troca iônica é definida como um processo ou mecanismo de transferência de íons, geralmente entre duas fases. O processo consiste em uma reação química entre íons em fase líquida e íons em fase sólida (Reynolds, 1982). Para isso o trocador deve ter uma estrutura aberta, orgânica ou inorgânica que permita a passagem de íons (Raitt, 1970). As resinas aniônicas realizam a troca de ânions (íons com carga negativa) e as catiônicas a troca de cátions (íons com carga positiva).

O processo de troca iônica começou a ser utilizado primeiramente na desmineralização da água. Atualmente existem diversas aplicações desse processo em grandes escalas industriais e técnicas. Na tecnologia nuclear as mais comuns são a extração de urânio de soluções ácidas; separação de isótopos radioativos provenientes de fissão nuclear; e a recuperação de materiais dos rejeitos (Raitt, 1970). 
De acordo com Habashi (1993) apud Riani (2008), os primeiros metais utilizados para recuperação pelo processo de troca iônica foram o cobre e a prata em efluentes da indústria do latão e resíduos de indústrias de filmes fotográficos, respectivamente. Entretanto, o urânio foi o primeiro metal a ser recuperado nesse processo. Ainda de acordo com Habashi (1993) apud Riani (2008), no tratamento de efluentes o processo de troca iônica é utilizado para remover íons indesejáveis, sendo substituídos por uma quantidade equivalente de espécies iônicas que apresentam potencial menor de perigo, presentes em uma matriz sólida insolúvel.

Esses materiais trocadores de íons são substâncias poliméricas insolúveis que permitem facilmente a troca dos íons fracamente ligados a suas estruturas por outros presentes em solução. Essas trocas são reversíveis e não alteram fisicamente o material de troca iônica (Singare, 2012).

Os trocadores podem ser inorgânicos, orgânicos, sintéticos ou naturais. As resinas sintéticas possuem redes orgânicas tridimensionais com grupos carregados ou potencialmente carregados. Essas resinas revolucionaram a química moderna e a indústria fornecendo materiais como o nylon, polietileno, poliuretano, PVC, terylene e todas as fibras feitas pelo homem que utilizadas todos os dias. As resinas naturais são sólidos orgânicos amorfos ou semissólidos de origem animal ou vegetal (Raitt, 1970).

Para um trocador iônico $\mathrm{M}^{-} \mathrm{A}^{+}$, na qual os cátions $\mathrm{A}^{+}$são os íons trocados em solução aquosa pelos cátions $\mathrm{B}^{+}$, a troca iônica pode ser representada pela equação 3.1 (Tenório e Espinosa, 2001):

$$
\mathrm{M}^{-} \mathrm{A}^{+}+\mathrm{B}^{+} \leftrightarrows \mathrm{M}^{-} \mathrm{B}^{+}+\mathrm{A}^{+}
$$

Em condições de equilíbrio, um determinado volume de solução em contato com uma quantidade de resina é agitado até que o equilíbrio seja atingido. O "carregamento" de íons na resina é caracterizado pelo coeficiente de distribuição $K_{d}$, definido por (Habashi, 1993):

$$
K_{d}=\frac{C_{i-r e s i n a}}{C_{i-\operatorname{solução}}}
$$




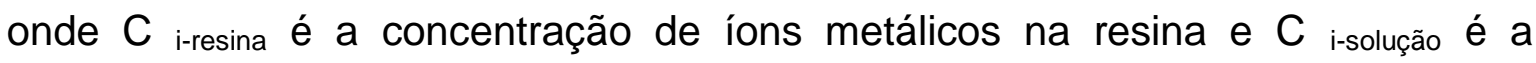
concentração de íons metálicos na fase aquosa. $\mathrm{O}$ valor de $\mathrm{K}_{\mathrm{d}}$ indica a afinidade da resina pelos íons metálicos (Habashi, 1993).

\subsection{Resinas de troca iônica}

Os grupos de troca, as características físico-químicas e a constituição da matriz formam os diferentes tipos de resina de troca iônica. Uma das matrizes mais utilizadas é a baseada em poliestireno, produzida por meio da polimerização de estireno (Riani, 2008). Este polímero linear na presença de divinil-benzeno (D.V.B), forma uma estrutura cruzada, conferindo o grau de copolimerização, cross-linking, da estrutura da resina (Habashi, 1993), além dos núcleos de benzeno nos monômeros utilizados se ligarem a grupamentos ácidos ou básicos também por meio da copolimerização (Silva Filho, 2009).

A fabricação das resinas de troca iônica utilizando a polimerização é feita por suspensão. Ocorre a adição de gotas de monômero em água e no fim do processo se transformam em grânulos esféricos e rígidos.

Nas resinas existe um número limitado de sítios ativos que, quando ocupados, saturam a resina. Sendo o processo um equilíbrio químico, é possível a recuperação de sua capacidade (Mierzwa e Hespanhol, 2005).

Entre os grupamentos ácidos, o ácido sulfônico é o mais comum e está presente na resina catiônica fortemente ácida (C.F.A). O menos comum é o ácido carboxílico e está presente na resina catiônica fracamente ácida (C.f.A). Já os grupamentos básicos podem ser classificados como aniônica fortemente básica (A.F.B), com a presença de aminas quaternárias, ou como aniônicas fracamente básicas (A.f.B), com a presença de aminas terciárias. Nas resinas catiônicas dissocia-se $\mathrm{Na}^{+}$ou $\mathrm{H}^{+}$, nas aniônicas dissocia-se frequentemente a hidroxila $\mathrm{OH}^{-}$. Os demais elementos não reagem e permanecem nas cadeias de estireno e divinilbenzeno (Silva Filho, 2009).

A presença de diferentes grupos resulta em diferentes características nas resinas, como os grupos carbonila e amina secundária que tornam a resina mais hidrofílica do que as resinas de poliestireno devido à possível formação de ligações de hidrogênio desses grupos com moléculas de água (Habashi, 1993). Já o aumento de D.V.B produz resinas menos elásticas. Usualmente, utilizam-se 
resinas com teor de aproximadamente $8 \%$, isso por que apesar de valores maiores serem mais resistentes a condições de oxidação, altos valores diminuem a mobilidade dos íons dentro do leito da resina (Habashi, 1993).

As resinas podem ser macro ou microporosas (tipo gel). As primeiras são produzidas na ausência de D.V.B, como o heptano, ácidos saturados, $\mathrm{C}_{4}-\mathrm{C}_{10}$ ou poliestireno com baixa massa molecular, formando canais dentro da resina., produzindo resinas com alta porosidade. As resinas microporosas ou tipo gel são produzidas sem esses compostos (Wheaton e Lefevre, 2000).

As resinas aniônicas de base forte são obtidas por meio da reação de estireno-DVB com aminas terciárias. Já as catiônicas de ácido forte são produzidas por sulfonação do polímero com ácido sulfúrico. O grupo funcional é o ácido sulfônico, $-\mathrm{SO}_{3} \mathrm{H}$, estas resinas trabalham em qualquer $\mathrm{pH}$, separam todas os sais e requerem de uma quantidade elevada de regenerante (Dardel et al., 2001).

A resina estudada neste trabalho é do tipo mista, constituída pelas resinas catiônica IR120P e aniônica IRA 410. A estrutura destas resinas é apresentada na FIG. 5 (Pohl e Prusisz, 2004).

(a)

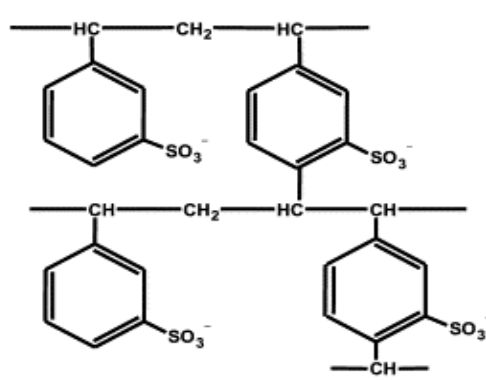

(b)

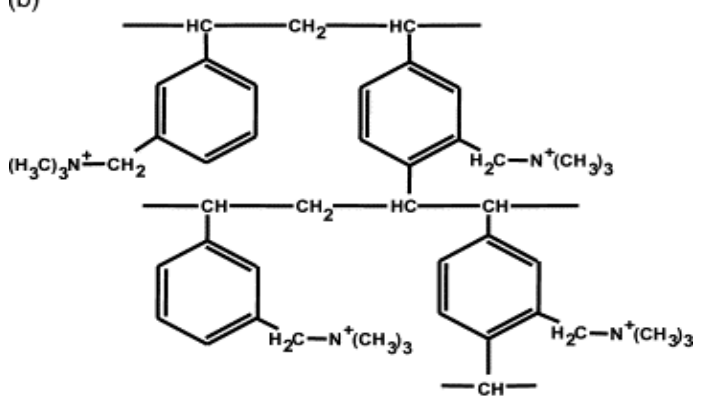

FIGURA 5 - Estruturas das resinas de troca iônica. (a). resinas catiônicas fortemente ácidas. (b). resinas aniônicas fortemente básicas. 
A resina IR120P é catiônica fortemente ácida e a resina IRA 410 aniônica fortemente básica, ou seja, a primeira possui como grupo funcional principal o ácido sulfônico, já as aniônicas possuem aminas quaternárias.

\subsection{Processos Oxidativos Avançados (POAs)}

\subsubsection{Histórico}

É antiga a utilização de fortes oxidantes para tratamento e desinfecção de água. De acordo com Gálvez et al.(2001), De Meritens em 1886 utilizou ozônio como desinfetante pela primeira vez em um trabalho científico. Depois disso, houve vários estudos sobre o assunto POA, mostrando a sua eficiência e as desvantagens do processo. Atualmente os pesquisadores possuem uma visão mais conservadora e realista desta tecnologia, que quando desenvolvida corretamente resulta em uma aplicação eficiente e viável.

Em 1998, a United States Environmental Protection Agency (USEPA), reconhecendo a importância desses processos, publicou o Handbook of Advanced Photochemical Oxidation Processes, contribuindo para o desenvolvimento dessa área da tecnologia (United States Environmental Protection Agency, 1998). O Brasil também reconheceu a importância dessas tecnologias e faz parte, desde o início, do Programa Ibero-Americano de Ciência e Tecnologia para o desenvolvimento (CYTED), criado em 1984, que possui representantes na Argentina, Bolívia, Brasil, Colômbia, Costa Rica, Cuba, Chile, Equador, El Salvador, Espanha, Guatemala, Honduras, México, Nicarágua, Panamá, Paraguai, Peru, Portugal, República Dominicana, Uruguai e Venezuela (Blesa, 2001; CNPq, 2013).

Existem trabalhos com POA em fase gasosa, solos, efluentes líquidos e na inativação de microorganismos patogênicos. Canela (1999) utilizou a destruição fotocatalítica de compostos causadores de odor em efluentes e Alberici (1996) conduziu experimentos visando a destruição de compostos orgânicos voláteis por fotocatálise heterogênea, ambos em fase gasosa. Nos solos, Guiselli (2001) remediou solos contaminados com pesticidas organoclorados utilizando o reagente de Fenton e Higarashi (1999) utilizou POA para remediação de solos 
brasileiros contaminados com pesticidas. Há também estudos de efluentes líquidos com luz solar, como em Ziolli (1999), que utilizou fotodegradação da fração de petróleo solúvel em águas de mar sob ação da luz solar e Nogueira (1995) que usou fotodestruição de compostos tóxicos utilizando $\mathrm{TiO}_{2}$ e luz solar. Também foi utilizado fonte luminosa artificial com o objetivo de mineralizar compostos orgânicos (Alberici, 1992, Teixeira, 1997 e 2002) ou na inativação de microorganismos patogênicos (Donaire, 2001).

\subsubsection{Descrição dos POAs}

POAs são processos que se caracterizam em transformar uma ampla diversidade de compostos orgânicos em dióxido de carbono, água e ânions inorgânicos, por meio de reações oxidantes, principalmente com a utilização do radical hidroxila (Matthews, 1994; Klavarioti et al., 2009).

Esses radicais são altamente oxidantes, com um potencial de oxidação de 2,8 V, abaixo apenas do flúor que possui 3,03 V, como apresentado na TAB. 2 (Domènech et al., 2001).

TABELA 2 - Potencial redox de alguns oxidantes

\begin{tabular}{ll}
\hline Espécie & Potencial redox $(\mathrm{V})$ \\
\hline Flúor & 3,03 \\
Radical hidroxila & 2,80 \\
Oxigênio & 2,42 \\
Ozônio & 2,07 \\
Peróxido de hidrogênio & 1,78 \\
Permanganato & 1,68 \\
Dióxido de cloro & 1,57 \\
Cloro & 1,36 \\
lodo & 0,54 \\
\hline
\end{tabular}

$\mathrm{Na}$ TAB. 3, pode-se observar a diferença significativa entre as constantes de velocidade de reação de diferentes compostos com o radical hidroxila e com o ozônio. Para serem eficientes os POAs devem gerar altas 
concentrações do radical hidroxila em estado estacionário (Domènech et al., 2001).

TABELA 3 - Constantes de velocidade do radical hidroxila e do ozônio para alguns compostos orgânicos (Calgon Carbon Corporation, 1996 apud Domènech et al., 2001)

\begin{tabular}{ccc}
\hline Composto & $\mathrm{HO}^{*}\left(\mathrm{~L} \mathrm{~mol}^{-1} \mathrm{~s}^{-1}\right)$ & $\mathrm{O}_{3}\left(\mathrm{~L} \mathrm{~mol}^{-1} \mathrm{~s}^{-1}\right)$ \\
\hline Alcenos clorados & $10^{9}-10^{11}$ & $10^{-1}-10^{3}$ \\
Fenóis & $10^{9}-10^{10}$ & $10^{3}$ \\
Aromáticos & $10^{8}-10^{10}$ & $1-10^{2}$ \\
Cetonas & $10^{9}-10^{10}$ & 1 \\
Alcoóis & $10^{8}-10^{9}$ & $10^{-2}-1$ \\
Alcanos & $10^{6}-10^{9}$ & $10^{-2}$ \\
Benzeno & $7,8 \times 10^{9}$ & 2 \\
\hline
\end{tabular}

Os POAs são processos limpos e não seletivos capazes de degradar compostos orgânicos nas fases líquidas, gasosas ou adsorvidos em uma matriz sólida. São conhecidos por serem efetivos na mineralização de componentes tanto danosos quanto tóxicos, uma vez que degradam as moléculas orgânicas poluentes, e não apenas as deslocam para outra fase (Salgado, 2009). Outra vantagem é que este processo não adiciona toxicidade no tratamento, pois o radical oxidante só existe durante o processo, se reduzindo em hidróxido ou produzindo água na reação com $\mathrm{H}^{+}$(Lima, 1998). Segundo Guimarães apud Rocha (1982), a ação do poluente depende de fatores como sua concentração na água, susceptibilidade de cada indivíduo, sua ação na fauna e flora aquáticas e na toxicidade específica para o ser humano.

De acordo com Domènech et al. (2004), os POAs apresentam vantagens como:

- A possibilidade de mineralizar completamente o contaminante. Ao contrário de diversas tecnologias convencionais que, por não utilizar espécies fortemente oxidantes, não conseguem degradar completamente o contaminante; 
- Não gerar resíduos que possam necessitar de processo de tratamento e deposição;

- Tratar resíduos que possuem contaminantes em baixa concentração, na ordem de $\mu \mathrm{g} / \mathrm{Kg}$;

- Mudança de fase do contaminante e transformação química;

- Eficiência no tratamento de compostos refratários;

- Baixas concentrações de subprodutos de reação quando esses são gerados;

- Melhoria das suas propriedades organolépticas no tratamento de água.

- Permitirem a transformação de produtos refratários em produtos tratáveis por métodos mais econômicos, como o biológico;

- Eliminarem efeitos de desinfetantes e oxidantes residuais como o cloro;

- Serem econômicos em comparação a outros métodos convencionais (incineração, por exemplo).

Os radicais hidroxila podem ser gerados por meio do ozônio $\left(\mathrm{O}_{3}\right)$ e peróxido de hidrogênio $\left(\mathrm{H}_{2} \mathrm{O}_{2}\right)$, semicondutores, como dióxido de titânio $\left(\mathrm{TiO}_{2}\right)$ e óxido de zinco (ZnO) e irradiação ultravioleta (UV) (Mansilla et al., 1997).

Moraes (2005), descreveu que os principais mecanismos de oxidação pelo radical hidroxila são a abstração de prótons, transferência de elétrons e adição radicalar, representados por $\mathrm{RH}, \mathrm{RX}$ e $\mathrm{PhX}$, respectivamente (Eq. 3.3 a 3.5).

$\mathrm{OH}^{\cdot}+\mathrm{RH} \rightarrow \mathrm{H}_{2} \mathrm{O}+\mathrm{R}^{\cdot}$

(Equação 3.3)

$\mathrm{OH}^{\circ}+\mathrm{RX} \rightarrow \mathrm{RX}+\mathrm{OH}^{\circ}$

$\mathrm{OH}^{\circ}+\mathrm{PhX} \rightarrow \mathrm{HOPhX}$

(Equação 3.5) 
Os catalisadores sólidos são classificados como heterogêneos e homogêneos. Os principais POAs disponíveis na literatura (Stakinasis, 2008) são:

- Peróxido de hidrogênio/ Luz UV

- Peróxido de hidrogênio/ozônio

- Dióxido de titânio/Luz UV

- Ozônio/Luz UV

- Ozônio/UV/Peróxido de hidrogênio

- Ozônio/Dióxido de titânio/Peróxido de hidrogênio

- Ozônio/ Dióxido de titânio

- Reações de Fenton $\left(\mathrm{Fe}^{2+} / \mathrm{H}_{2} \mathrm{O}_{2}, \mathrm{H}_{2} \mathrm{O}_{2} / \mathrm{Fe}^{2+} / \mathrm{UV}\right)$

- Sonólise

- Sonólise com ozônio

- Oxidação catalítica

- Oxidação úmida supercrítica

Esses métodos combinam agentes oxidantes (e.g. $\mathrm{H}_{2} \mathrm{O}_{2}, \mathrm{O}_{3}$ ) com catalisadores (e.g. ultravioleta, luz visível). As tecnologias mais utilizadas, como observado na grande quantidade de informações disponíveis na literatura, são os processos que produzem radicais hidroxila, como o dióxido de titânio/ Luz UV, peróxido de hidrogênio/ Luz UV e as reações de Fenton (Stakinasis, 2008). O último se destaca por ter custo relativamente baixo e facilidade de operação, além da abundância de ferro na natureza e a sua presença em diferentes espécies de minerais (Araujo, 2008, Neyens e Baeyens, 2003).

\subsubsection{Reação de Fenton}

O processo Fenton envolve a reação de peróxido de hidrogênio $\left(\mathrm{H}_{2} \mathrm{O}_{2}\right)$ com um sal ferroso, utilizado como catalisador, para formar radicais hidroxila livres (equação 3.6) (Andreozzi et al., 1999). Com o potencial de 2,8 V, esses radicais são altamente oxidantes e irão reagir amplamente com moléculas orgânicas por meio de reações sucessivas de oxidação (Gogate, 2004, Neyens e Baeyens, 2008). A reação de Fenton é autocatalítica (produtos catalisam a reação), ou seja, pelo menos um dos produtos atua como catalisador (Sandres e 
Ambrosio, 2013). Mantendo-se baixa a concentração de peróxido na reação e o $\mathrm{pH}$ levemente ácido, mantêm-se as concentrações dos reagentes $\left(\mathrm{H}_{2} \mathrm{O}_{2}\right.$ e $\left.\mathrm{OH}^{-}\right)$ baixas e reduz a quantidade de peróxido não desejável (Taylor, 2002). Segundo Place (1990) apud Jian et al.(1996), a imobilização das resinas de troca iônica tratadas com o reagente de Fenton podem diminuir em 50\% os custos de deposição final e transporte comparada a solidificação direta. Na ausência de um substrato, pode-se ocorrer a oxidação de outro íon Fe(II) por meio do radical hidroxila formado, como na equação 3.7.

A formação de íons férricos pode decompor $\mathrm{H}_{2} \mathrm{O}_{2}$ cataliticamente a $\mathrm{H}_{2} \mathrm{O}$ e $\mathrm{O}_{2}$ (equações 3.7 a 3.11), formando também íons ferrosos e radicais.

Na equação 3.12, verifica-se que o peróxido de hidrogênio pode atuar como sequestrador de radical hidroxila, formando o radical hidroperoxila $\left(\mathrm{HO}_{2}{ }^{\circ}\right)$, que apresenta um potencial de redução menor que $0 \mathrm{OH}^{\circ}$, prejudicando 0 processo de degradação. Isto ocorre na presença de excesso de peróxido, pois a concentração de $\mathrm{Fe}^{2+}$ no meio é baixa em relação à de $\mathrm{Fe}^{3+}$, já que a reação entre $\mathrm{Fe}^{3+}$ e $\mathrm{H}_{2} \mathrm{O}_{2}$ (equação 3.8) é muito mais lenta que a decomposição de $\mathrm{H}_{2} \mathrm{O}_{2}$ na presença de $\mathrm{Fe}^{2+}$ (equação 3.6) (Nogueira et al., 2007).

De acordo com Haber e Weiss (1934) apud Nogueira et al. (2007), Rigg et al. (1954), Walling e Goosen (1973) e Buxton e Greenstock (1988), as reações envolvidas na oxidação com Fenton são apresentadas nas equações 3.6 a equação 3.12:

$$
\begin{aligned}
& \mathrm{H}_{2} \mathrm{O}_{2}+\mathrm{Fe}^{2+} \rightarrow \mathrm{Fe}^{3+}+\mathrm{OH}^{-}+\mathrm{OH}^{\cdot} \text { (radical) } \quad \mathrm{k}_{1}=76 \mathrm{M}^{-1} \mathrm{~s}^{-1} \quad \text { (Equação 3.6) } \\
& \mathrm{Fe}^{2+}+\mathrm{OH}^{\cdot} \rightarrow \mathrm{Fe}^{3+}+\mathrm{OH} \quad \mathrm{k}_{2}=3,2 \times 10^{8} \mathrm{M}^{-1} \mathrm{~s}^{-1} \\
& \mathrm{Fe}^{2+} \text { e } \mathrm{Fe}^{3+} \text { existem como aquo-complexos. } \\
& \mathrm{Fe}^{3+}+\mathrm{H}_{2} \mathrm{O}_{2} \rightleftharpoons \mathrm{FeOOH}^{2+}+\mathrm{H}^{+} \quad \mathrm{K}_{3}=0,001-0,01 \mathrm{M}^{-1} \mathrm{~s}^{-1} \quad \text { (Equação 3.8) } \\
& \mathrm{FeOOH}^{2+} \rightarrow \mathrm{Fe}^{2+}+\mathrm{HO}_{2}^{\cdot} \\
& \text { (Equação 3.9) } \\
& \mathrm{Fe}^{2+}+\mathrm{HO}_{2}^{\cdot} \rightarrow \mathrm{Fe}^{3+}+\mathrm{HO}_{2}^{\cdot} \quad \mathrm{K}_{5}=1,3 \times 10^{6} \mathrm{M}^{-1} 1 \mathrm{~s}^{-1}
\end{aligned}
$$




$$
\begin{array}{ll}
\mathrm{Fe}^{3+}+\mathrm{HO}_{2}^{\cdot} \rightarrow \mathrm{Fe}^{2+}+\mathrm{O}_{2}+\mathrm{H}^{+} & \mathrm{K}_{6}=1,2 \times 10^{6} \mathrm{M}^{-1} 1 \mathrm{~s}^{-1} \\
\mathrm{H}_{2} \mathrm{O}_{2}+\mathrm{OH}^{\cdot} \rightarrow \mathrm{HO}_{2}^{\cdot}+\mathrm{H}_{2} \mathrm{O} & \mathrm{K}_{7}=2,7 \times 10^{7} \mathrm{M}^{-1} 1 \mathrm{~s}^{-1}
\end{array}
$$

O reagente de Fenton tem sido utilizado no tratamento de diversos tipos de efluentes, como clorofenóis (Kwon et al., 1999), oxidação de resíduo de lixiviação de aterro (Kang e Hwang, 2000), sulfactantes (Lin et al., 1999) e também na degradação de corantes, no qual se mostrou mais vantajoso que o hipoclorito, ozônio e processo eletroquímico (Szpyrkowick et al., 2001). Pode-se também utilizá-lo para aumentar a biodegradabilidade dos contaminantes, para posteriormente tratá-lo biologicamente (Kitis et al., 1999; Zhu et al., 2001). Empregar métodos oxidativos para destruição das resinas pode ser uma alternativa viável para melhoria do tratamento. Kouznetsov e Kniazev, (2001), em um estudo sobre tratamento microbiológico de resinas de troca iônica, obtiveram resultados satisfatórios de biodestruição tanto com bactérias oxidantes de manganês quanto com microrganismos heterotróficos após tratamento com reagente de Fenton.

De acordo com Jian et al. (1996), as equações 3.13 a 3.16, representam a degradação das resinas na reação de Fenton. As equações 3.13 e 3.14 representam as reações de dissolução dos grupos funcionais, enquanto as equações 3.15 e 3.16 apresentam as reações dos agentes das ligações cruzadas $\left(\mathrm{C}_{10} \mathrm{H}_{10}\right)$ e a unidade do estireno $\left(\mathrm{C}_{8} \mathrm{H}_{8}\right)$, respectivamente.

$$
\begin{aligned}
& \mathrm{C}_{8} \mathrm{H}_{8} \mathrm{SO}_{3}+20 \mathrm{H}_{2} \mathrm{O}_{2} \rightarrow 8 \mathrm{CO}_{2}+23 \mathrm{H}_{2} \mathrm{O}+\mathrm{H}_{2} \mathrm{SO}_{4} \\
& \mathrm{C}_{12} \mathrm{H}_{19} \mathrm{NO}+31 \mathrm{H}_{2} \mathrm{O}_{2} \rightarrow 12 \mathrm{CO}_{2}+\mathrm{NH}_{4} \mathrm{OH}+38 \mathrm{H}_{2} \mathrm{O} \\
& \mathrm{C}_{10} \mathrm{H}_{10}+25 \mathrm{H}_{2} \mathrm{O}_{2} \rightarrow 10 \mathrm{CO}_{2}+30 \mathrm{H}_{2} \mathrm{O} \\
& \mathrm{C}_{8} \mathrm{H}_{8}+\mathrm{H}_{2} \mathrm{O}_{2} \rightarrow 8 \mathrm{CO}_{2}+24 \mathrm{H}_{2} \mathrm{O}
\end{aligned}
$$

\subsubsection{Emprego de Fenton na degradação das resinas}

Devido a importância na degradação das resinas de troca iônica, para aumento na capacidade de carga na imobilização, o tratamento e a viabilidade da reação de Fenton são descritos. 
Um estudo sobre o comportamento na decomposição das resinas catiônicas fortemente ácidas, aniônicas fortemente básicas e mistas foi realizado por Jian et al. (1996), utilizando diferentes catalisadores de forma unitária $\mathrm{Fe}^{2+}$, $\mathrm{Cu}^{2+}$ e mista $\mathrm{Ni}^{2+} / \mathrm{Cu}^{2+}, \mathrm{Mg}^{2+} / \mathrm{Cu}^{2+}$ e $\mathrm{Fe}^{2+} / \mathrm{Cu}^{2+}$ com peróxido de hidrogênio. Foram utilizadas de 15 a 25 gramas de resinas úmidas nos experimentos. As temperaturas variaram de 83 a $93 \stackrel{\circ}{\circ}$ e de 90 a $99 \stackrel{\circ}{\circ}$ e houve aproximadamente $90 \%$ de dissolução das resinas. Os resíduos de decomposição para imobilização sofreram ajustes de $\mathrm{pH}$ e foram evaporados até o valor máximo de sais de $40 \%$ para cimentação. Os autores observaram uma maior dificuldade em degradar resinas aniônicas perante resinas catiônicas e mistas. Concluiram que a redução de volume do processo de oxidação com $\mathrm{H}_{2} \mathrm{O}_{2}$ foi de até $40 \%$, comparado com o volume da resina diretamente cimentada, que tem um aumento de volume de 80\% (Zhang, 1995 apud Jian et al., 1996)

Taylor (2002) tratou $100 \mathrm{~mL}$ de um simulado de rejeito, contendo $20 \mathrm{~g}$ de resina de troca iônica. As resinas utilizadas foram as catiônicas fortemente ácidas Amberjet ${ }^{\circledR} 1500$ (Rohm \& Haas) e as aniônicas fortemente básicas (Amberjet $^{\circledR}$ 4400). Foram empregados $180 \mathrm{~mL}$ de $\mathrm{H}_{2} \mathrm{O}_{2} \quad 50 \%$ para oxidar completamente 20 gramas de resina mista.

Zahorodna et al. (2007) utilizou resina catiônica Amberjet® $10.51500 \mathrm{H}$ (Rohm \& Haas). Foi utilizado como catalisador o sulfato ferroso heptahidratado em um intervalo de 2 a $20 \mathrm{mM}$. O método utilizado para quantificar a mineralização da resina foi avaliar a massa de $\mathrm{CaCO}_{3}$. A maior massa de $\mathrm{CaCO}_{3}$ encontrada foi de 0,429 gramas.

Nogueira et al. (2007) revisou os fundamentos dos processos Fenton e foto-Fenton e discutiu se os principais aspectos na degradação de contaminantes orgânicos em água. Ainda de acordo com Nogueira et al. (2007), vários fatores influenciam a velocidade de degradação, como: pH; estrutura química do contaminante; carga orgânica presente e as concentrações de ferro e de peróxido de hidrogênio. A eficiência de degradação máxima foi na faixa de pH de 2,5 a 3,0.

Zahorodna et al. (2008) utilizou a mesma metodologia da reação de Fenton do trabalho anterior desses autores e concluiu que os ácidos oxálicos e fórmicos produzidos são parâmetros qualitativos da degradação de alifáticos e anéis aromáticos, respectivamente. 
Araujo (2008) utilizou o processo heterogêneo de Fenton utilizando hematita como catalisador para descolorir soluções de corante reativo. Foram avaliados $\mathrm{pH}$, cor, peróxido de hidrogênio residual, entre outros. O processo Fenton Heterogêneo se mostrou eficiente na degradação da cor do corante reativo Vermelho (Drimaren $\mathrm{X}-6 \mathrm{BN}$ ). $\mathrm{O}$ pH ácido abaixo de 3,5 foi o mais favorável no processo Fenton heterogêneo. E de acordo com a autora, o Fenton heterogêneo é mais lento em relação ao Fenton tradicional (homogêneo) utilizando o $\mathrm{FeSO}_{4} .7 \mathrm{H}_{2} \mathrm{O}$, com a duração de 120 e 6 minutos, respectivamente, para atingir o mesmo objetivo.

\subsubsection{Condições operacionais da reação de Fenton}

As condições operacionais da reação Fenton determinam a efetividade na decomposição da resina. Os principais são descritos nos próximos tópicos.

\subsubsection{1 pH}

Os processos oxidativos avançados em geral necessitam do $\mathrm{pH}$ correto para serem eficientes, por isso a sua importância no tratamento de efluentes. $O$ potencial de oxidação dos radicais hidroxila decresce com o aumento do pH. Em

meio ácido o potencial é $\mathrm{E}_{\mathrm{H}}{ }^{0}=2,80 \mathrm{~V}$ e em meio básico têm-se $\mathrm{E}_{\mathrm{H}}{ }^{14}=1,95 \mathrm{~V}$ (KWON et al., 1999).

De acordo com Neyens e Baeyens (2003), o meio ácido é essencial para a reação de Fenton principal (equação 3.4), já que os ións $\mathrm{H}^{+}$deslocam o equilíbrio da reação para a geração de $\mathrm{HO}^{-}$e de radical hidroxila $\left(\mathrm{HO}^{\bullet}\right)$.

$\mathrm{Na}$ literatura existem divergências sobre qual seria o $\mathrm{pH}$ ótimo para a degradação eficiente utilizando POAs. Chen et al. (2001) e Zhang et al. (2005) indicaram que o $\mathrm{pH}$ ótimo seria próximo a 3. Neamtu et al. (2002) sugeriram a adoção de uma faixa de $\mathrm{pH}$ entre 3 e 4.

Essas divergências existem, pois complexos são gerados em diferentes $\mathrm{pH}$. De acordo com Utset et al. (2000), o pH maior que 3 indica a existência de $\mathrm{Fe}^{2+}\left(\mathrm{H}_{2} \mathrm{O}\right)^{2+}$ responsável pelo ataque a moléculas orgânicas. $\mathrm{O} \mathrm{pH}$ maior que 4 diminui as espécies de ferro livre na solução já que formam complexos de ferro e devido a precipitação de hidróxidos de ferro, diminuindo a velocidade de decomposição do peróxido de hidrogênio (Lin e Lo, 1997). O pH menor que 2 faz com que seja produzido $\left(\mathrm{Fe}^{2+}\left(\mathrm{H}_{2} \mathrm{O}\right)\right)^{2+}$, que irá gerar uma menor 
quantidade de radicais hidroxila pela reação mais lenta com o peróxido de hidrogênio, diminuindo assim a eficiência na oxidação das resinas (De Llat e Gallard, 2000).

O peróxido de hidrogênio é instável, principalmente em $\mathrm{pH}$ alcalino, decompondo-se (equação 3.15) (Cruz, 2000):

$$
\mathrm{H}_{2} \mathrm{O}_{2}+\mathrm{OH}^{-} \rightarrow 2 \mathrm{H}_{2} \mathrm{O}+\mathrm{O}_{2}
$$

Jian et al. (1996) mantiveram a reação em um valor de pH próximo de 5 e obtiveram degradações maiores que 85\%. Srinivas, Sugilal e Wattal (2003), não utilizaram controle de $\mathrm{pH}$, mas não obtiveram dissolução completa das resinas mistas.

Na degradação de outras substâncias, o pH também é um parâmetro importante a ser avaliado. Lucas e Perez (2006) e Oliveira et al. (2007) utizaram pH 3 em processos Fenton e foto-Fenton na degradação de corantes. Esplugas et al. (2002) e Catrinescu et al. (2003) utilizaram o pH na faixa de 3 a 3,5 e 3, respectivamente, na degradação de fenol. Além disso, Catrinescu et al. observaram grandes diferenças na eficiência da degradação desse composto no intervalo de $\mathrm{pH}$ de 2,5 a 7 e que também diminuíam em reações mais demoradas. Ainda de acordo com esses autores, o valor ótimo de $\mathrm{pH}$ é em torno de 3, porque corresponde a concentração máxima de $\mathrm{Fe}^{+2}$ e a menor taxa de decomposição de $\mathrm{H}_{2} \mathrm{O}_{2}$, sendo que o aumento de $\mathrm{pH}$ precipita hidróxidos férricos insolúveis e decompõe $0 \mathrm{H}_{2} \mathrm{O}_{2}$, predominantemente.

Andreozzi et al. (1999) e Pignatello (1992) apontam que o melhor valor de $\mathrm{pH}$ se situa na faixa de 2,7 a 2,8, já que neste $\mathrm{pH}$ a redução de $\mathrm{Fe}^{+3}$ para $\mathrm{Fe}^{+2}$ (tipo-Fenton) ocorre em uma taxa apreciável, auxiliando na degradação dos compostos orgânicos.

De acordo com Goslan et al. (2006) e Alves (2004), a faixa ótima de pH é de 3 a 7 e de 3 a 6, respectivamente. Essa informação é importante, pois no caso de uma aplicação de POA na degradação das resinas de troca iônica, o ajuste de $\mathrm{pH}$ não seria necessário, utilizando menor quantidade de reagentes, dimuindo custos (Matilainen e Sillanpää., 2010). 


\subsubsection{Temperatura}

A temperatura também é uma variável importante a ser avaliada na reação de Fenton. Sabe-se que a decomposição térmica acelerada do peróxido de hidrogênio ocorre em temperaturas acima de 60ㄷ (FISPQ, 2012), o que justificaria trabalhar com a reação de Fenton em temperaturas inferiores a essa, já que utilizaria um menor volume de reagente, reduzindo custos principalmente na aplicação em grandes quantidades de rejeito.

De acordo com Neyens e Baeyens (2003), temperaturas acima de $40^{\circ} \mathrm{C}$ já resultariam em declínio na concentração de $\mathrm{H}_{2} \mathrm{O}_{2}$ e com temperaturas abaixo desta, aumenta-se o tempo de reação.

Taylor (2002) observou que a reação é muito lenta até a temperatura exceder $70^{\circ} \mathrm{C}$ e aumenta quase linearmente a partir dos 90ㅇ. Jian et al. (1996), utilizaram a faixa de temperatura de 97 a $99^{\circ} \mathrm{C}$. A decomposição direta do peróxido de hidrogênio e justificada, já que de acordo com os autores, a decomposição direta do peróxido de hidrogênio é comparativamente violenta em temperaturas menores que estas, entretanto temperaturas excessivas causam problemas como formação de espuma e difusão dos radionuclídeos para a fase gasosa.

Srinivas et al. (2003) utilizaram a faixa de temperatura de 50 a $60^{\circ} \mathrm{C}$ para degradar resinas catiônicas e aniônicas separadamente. Quando utilizada temperatura entre 90 a $95 \stackrel{\circ}{C}$ foi necessário utilizar excesso de 70 a $200 \%$ de peróxido de hidrogênio para efetivamente degradar as resinas.

A faixa de temperatura a ser adotada depende do material a ser tratado. Além disso, de acordo com Alvez (2004), a maioria das aplicações comerciais com reagente de Fenton utiliza de temperaturas de 20 a $40^{\circ} \mathrm{C}$. Entretanto, nota-se que temperaturas maiores são utilizadas na oxidação de resinas de troca iônica e outros compostos orgânicos pela maior dificuldade em degradá-las.

\subsubsection{Concentração de catalisador}

A correta concentração do catalisador é essencial para a degradação do material desejado, já que o excesso e a falta desse influenciam diretamente na eficiência da reação. 
Zahorodna et al. (2008) utilizou $\mathrm{FeSO}_{4} \cdot 7 \mathrm{H}_{2} \mathrm{O}$ na concentração de 2 a $20 \mathrm{mM}$. Foi observado pelos autores que quando utilizadas concentrações menores ou iguais a $15 \mathrm{mM}$, a reação de Fenton ocorria exclusivamente no ataque à superfície das resinas. $O$ tempo de dissolução das resinas também foi avaliado pelos autores e, neese caso, observaram que o tempo necessário para dissolução das resinas diminuiu rapidamente com o aumento de 2 até $14 \mathrm{mM}$ de solução de catalisador. Não houve mudança significativa no tempo de reação quando submetidas de 14 a 20 mM de solução de catalisador, apesar do aumento da concentração de $\mathrm{Fe}^{+3}$.

Jian et al. (1996) observou que o catalisador influencia significativamente na reação de decomposição. Os catalisadores utilizados foram - $\mathrm{Cu}\left(\mathrm{NO}_{3}\right)_{2}$ e a mistura de $\mathrm{Cu}\left(\mathrm{NO}_{3}\right)_{2}$ com $\mathrm{FeSO}_{4}$ nas concentrações de 2,5 mM e $5 \mathrm{mM}$ (2,5 mM para cada catalisador). Para os autores, o $\mathrm{Fe}^{2+}$ é o catalisador mais efetivo na degradação da resina de troca iônica catiônica, entretanto o $\mathrm{Cu}^{2+}$ é o mais efetivo na degradação de resina aniônica e a mistura $\mathrm{Fe}^{2+} / \mathrm{Cu}^{2+}$ é preferível nas resinas mistas. Além disso, os autores utilizaram sistema de alimentação contínuo de catalisador, já que assim, evita-se a produção de compostos quelantes, produzidos na reação do catalisador com ácidos aromáticos e aminas orgânicas.

Gunale et al. (2009) utilizou $\mathrm{CuSO}_{4}$ como catalisador na degradação de resinas de troca iônica catiônicas em um processo híbrido de reação de Fenton seguida de oxidação úmida. Foram avaliadas três diferentes concentrações: 0,01 $\mathrm{kmol} \mathrm{m}^{3-}(10 \mathrm{mM}), 0,02 \mathrm{kmol} \mathrm{m}^{3-}(20 \mathrm{mM})$ e $0,04 \mathrm{kmol} \mathrm{m}^{3-}(40 \mathrm{mM})$. De acordo com os autores, a concentração de $40 \mathrm{mM}$ pode causar decomposição violenta de $\mathrm{H}_{2} \mathrm{O}_{2}$, o que resultaria condições mais perigosas de operação. Ainda de acordo com Gunale et al., apesar do $\mathrm{H}_{2} \mathrm{O}_{2}$ resultar em compostos não tóxicos ou perigosos $\left(\mathrm{H}_{2} \mathrm{O}+\mathrm{CO}_{2}\right)$, do ponto de vista da engenharia existem dificuldades de segurança associadas à reação e ao manuseio desse material. Além disso, o maior valor de catalisador avaliado, 0,04 $\mathrm{kmol} \mathrm{m}^{3-}(40 \mathrm{mM})$, ocasionou valores maiores de COD e COT. Por esses motivos, os autores consideram a concentração de $0,02 \mathrm{kmol} \mathrm{m}^{-3}(20 \mathrm{mM})$ como a mais adequada na degradação das resinas.

A relação $\mathrm{H}_{2} \mathrm{O}_{2}$ /catalisador foi descrita por Araujo (2008) e por Taylor (2002). Para Araujo (2008), deve-se salientar que a faixa de dosagem dos 
reagentes utilizados na reação de Fenton varia de acordo com o efluente a ser tratado. Taylor (2002) utilizou 2 gramas de $\mathrm{Cu}\left(\mathrm{NO}_{3}\right)_{2}$, ou seja, uma concentração de $106 \mathrm{mM}$, para cada simulado e 111 gramas de $\mathrm{H}_{2} \mathrm{O}_{2}$, resultando em uma razão molar de aproximadamente 163:1 de $\mathrm{H}_{2} \mathrm{O}_{2} / \mathrm{Fe}^{2+}$.

Zahorodna et al. (2007) variou o volume e a concentração de peróxido de hidrogênio, além de variar de 2 a $20 \mathrm{mM}$ a concentração do catalisador. Nos experimentos foram utilizados $45 \mathrm{~mL}$ de $\mathrm{H}_{2} \mathrm{O}_{2}$ em 45 minutos de reação. A relação $\mathrm{H}_{2} \mathrm{O}_{2} / \mathrm{Fe}^{2+}$ nesse estudo foi de 148:1.

\subsection{Cimento Portland}

Diversos países utilizam a cimentação na imobilização de rejeito radioativo. A Alemanha tem duas plantas para cimentação de rejeito desde 1978 . A Grã-bretanha, Itália, Suécia, Hungria, Ucrânia, Eslováquia, China, Espanha, França e outros, são alguns dos países que utilizam esse processo na gerência dos rejeitos radioativos (NUKEM, 2007; BENAVIDES e SCHMIDT, 1992).

O cimento Portland é a denominação técnica oficial para o material usualmente conhecido na construção civil como cimento (Associação Brasileira de Cimento Portland, 2002). Essa palavra vem do latim "Caementum" que identifica um material com propriedades hidráulicas, um ligante, que misturado com água reage quimicamente, unindo fragmentos minerais (VARELA e VIEIRA, 2005). É um dos materiais mais importantes da engenharia civil e que se expandiu para outros campos de aplicação, como na solidificação de resíduos industriais e rejeitos radioativos (CAPONERO e TENÓRIO, 1999; LI e WANG, 2006). Mostrase, assim, como um material fundamental cujas características e propriedades devem ser bem conhecidas a fim de se aproveitá-la da melhor forma possível. Apresenta-se na forma de pó fino, que possui propriedades aglutinantes. Sob a ação da água reage quimicamente unindo fragmentos minerais (VARELA e VIEIRA, 2005). Forma, inicialmente, uma massa plástica (pasta de cimento), bastante moldável, que endurece com o tempo, resultando numa massa compacta e de alta resistência.

O cimento é um produto químico composto, em sua maior parte, por silicatos e aluminatos de cálcio, praticamente isentos de cal livre. Em contato com a água, os silicatos e aluminatos complexos hidratam-se resultando no endurecimento da massa (VARELA e VIEIRA, 2005). 
A imobilização de rejeitos radioativos com cimento Portland é o método mais empregado para converter o rejeito em uma forma sólida monolítica a fim de se criar uma barreira contra a liberação dos radionuclídeos presentes para o meio ambiente. $\mathrm{O}$ produto da mistura entre cimento e o rejeito deve ser homogêneo e possuir estabilidade mecânica e físico-química e resistência química, entre outras características, para garantir a segurança nas etapas posteriores da gerência de rejeitos (HIROMOTO et al.,1999).

As principais vantagens do cimento são a disponibilidade e baixo custo; durabilidade; pode atuar como uma barreira de difusão de íons; pode incorporar muitos íons em uma solução sólida; mantêm alto $\mathrm{pH}$, que decresce a solubilidade dos radionuclídeos; provêm blindagem que não é degradada pela radiação; permeabilidade e difusão controladas (SHARP et al., 2003). Além dessas características, o cimento é muito atrativo por causa da resistência mecânica e durabilidade das composições (IAEA, 1993). Por outro lado, como desvantagens devem ser consideradas a geração de calor de hidratação durante a mistura; possibilidade de expansão ou contração; aumento de volume e da massa do rejeito; e baixa capacidade de carga para alguns tipos de rejeitos.

De acordo com Veazey e Ames (1997), a formulação recomendada final que atende todas os padrões de desempenho é determinada pela relação cimento/água/resina como 63/27/10\%. Sabendo-se desses valores, pode-se notar que a quantidade de resina que pode ser imobilizada de forma direta é pequena, trazendo custos significativos na sua imobilização. Apesar da melhoria nas tecnologias de solidificação com o cimento (LI e WANG, 2006), existe essa limitação, que é decorrência da propriedade de contração e expansão das resinas, que resulta, no caso de quantidades superiores a 10\%, na destruição completa da matriz.

A redução de volume e o acondicionamento por estarem relacionados a custos como o de armazenamento, segurança física e radiológica, são duas etapas de extrema importância (MARUMO, 2006). 


\section{METODOLOGIA}

\subsection{Materiais}

Os materiais e equipamentos empregados foram:

Materiais:

Resina de troca catiônica IR120P

Resina de troca aniônica IRA410

Sulfato ferroso hepta hidratado P.A., marca Merck

Cloreto de cobalto P.A., marca Merck

Hidróxido de cálcio P.A., marca Merck

Hidróxido de sódio lentilhas puríssimo, marca Nuclear

Peróxido de hidrogênio 25\% P.A., marca Cosmoquímica

Peróxido de hidrogênio 50\% P.A., marca Sigma-Aldrich

Nitrogênio líquido

Béqueres de 50, $100 \mathrm{ml}$, marca Pirex

Proveta e bureta, marca Pirex

Balões de fundo redondo de $500 \mathrm{~mL}$, marca Indusglass

Erlenmeyers de $100 \mathrm{ml}$, marca Pirex

Erlenmeyers de 2000 ml, marca Vidrolabor

Lavador de gases, marca Quimiglass

Papel filtro quantitativo tipo JP42, filtração lenta JProlab

Tetraborato de sódio, marca Merck

Vermelho de metila, Sigma Aldrich

Fenolftaleína, Merck

Cloreto de sódio, Merck

Alaranjado de metila, Merck

Ácido clorídrico P.A 0,1M

Permanganato de potássio, marca Imporcil

Oxalato de sódio, marca Ecibra 
Equipamentos:

Bomba peristáltica, modelo Pump P-1, marca Pharmacia Biotech

Agitador magnético, modelo 753A, marca Fisatom

Multímetro digital, modelo $5660 \mathrm{C}$, marca Icel

Agitador, modelo MA039, marca Marconi

Medidor de oxigênio dissolvido, modelo SX751, marca Akso

Espectrofotômetro, modelo Ultraspec 3000, marca Pharmacia Biotech

Balança analítica, modelo AG204, marca Mettler-Toledo.

Estufa, modelo 315SE, marca Fanem

Microscópio eletrônico de varredura, modelo XL30, marca Philips

Analisador de carbono orgânico total (COT), modelo VCS, marca

Shimadzu

Reator de vidro FGG SP, com capacidade de 25 litros.

\subsection{Método}

Os estudos de degradação das resinas foram conduzidos exploratoriamente com $1 \mathrm{~g}$ de resina e, posteriormente, com $10 \mathrm{~g}$, ambas úmidas.

As reações de oxidação com $1 \mathrm{~g}$ de resina foram conduzidas em um balão de destilação de fundo redondo com três bocas paralelas, acoplado a duas bombas peristálticas, um dewar de nitrogênio e um erlenmeyer contendo solução de hidróxido de cálcio saturado, conforme a instrumentação apresentada na FIG. 6. A solução de hidróxido de cálcio foi colocada na saída do balão para quantificar o gás carbônico resultante da reação por meio da precipitação do carbonato de cálcio. Daí a necessidade da condução da reação em atmosfera de nitrogênio, para eliminação do gás carbônico atmosférico. A resina foi, primeiramente, posta em contato com a solução de catalisador e mantida sob agitação por $15 \mathrm{~min}$. Em seguida, o peróxido de hidrogênio foi adicionado lentamente, a uma vazão de $0,88 \mathrm{~mL} / \mathrm{min}$., de forma a evitar uma reação muito rápida. $\mathrm{O}$ total adicionado foi de $80 \mathrm{~mL}$. O tempo de reação foi de $90 \mathrm{~min}$. Nesta etapa foram avaliados o tipo e a concentração do catalisador, a necessidade de aquecimento e os fluxos dos reagentes. Os catalisadores estudados foram o $\mathrm{FeSO}_{4} \cdot 7 \mathrm{H}_{2} \mathrm{O}, \mathrm{Cu}\left(\mathrm{NO}_{3}\right)_{2} \cdot 5 \mathrm{H}_{2} \mathrm{O}$ e $\mathrm{CoCl}_{2}$, respectivamente nas concentrações de 15 a $80 \mathrm{mM}$, de $40 \mathrm{mM}$ e $100 \mathrm{mM}$. As concentrações de peróxido de hidrogênio utilizadas foram 25 e $30 \%$. Foram 
testadas as resinas catiônica, aniônica e mista (proporção 1:1). Na TAB. 4 são apresentadas as condições experimentais empregadas.

TABELA 4 - Condições experimentais utilizadas nos experimentos da degradação de um grama de resina

\begin{tabular}{|c|c|c|c|c|}
\hline Resina & $\begin{array}{l}\text { Conc. do } \\
\mathrm{H}_{2} \mathrm{O}_{2}(\%)\end{array}$ & $\mathrm{H}_{2} \mathrm{O}_{2}(\mathrm{~mL})$ & Catalisador & $\begin{array}{c}\text { Concentração } \\
\text { de catalisador } \\
(\mathrm{mM})\end{array}$ \\
\hline Aniônica* & 30 & 45 & \multirow{11}{*}{$\begin{array}{l}\text { Sulfato } \\
\text { ferroso }\end{array}$} & 15 \\
\hline Catiônica* & 30 & 45 & & 15 \\
\hline Aniônica & 30 & 45 & & 15 \\
\hline Catiônica & 30 & 45 & & 15 \\
\hline Mista & 30 & 45 & & 15 \\
\hline Mista* & 30 & 45 & & 20 \\
\hline Mista* & 25 & 45 & & 30 \\
\hline Mista* & 25 & 45 & & 80 \\
\hline Mista & 25 & 80 & & 50 \\
\hline Mista & 25 & 80 & & 70 \\
\hline Mista & 25 & 80 & & 80 \\
\hline Mista & 25 & 80 & $\begin{array}{c}\text { Sulfato } \\
\text { ferroso e } \\
\text { nitrato de } \\
\text { cobre }\end{array}$ & 40 cada \\
\hline Mista & 25 & 80 & $\begin{array}{l}\text { Cloreto de } \\
\text { cobalto }\end{array}$ & 100 \\
\hline
\end{tabular}

* Experimentos com aquecimento externo em $70^{\circ} \mathrm{C}$. 


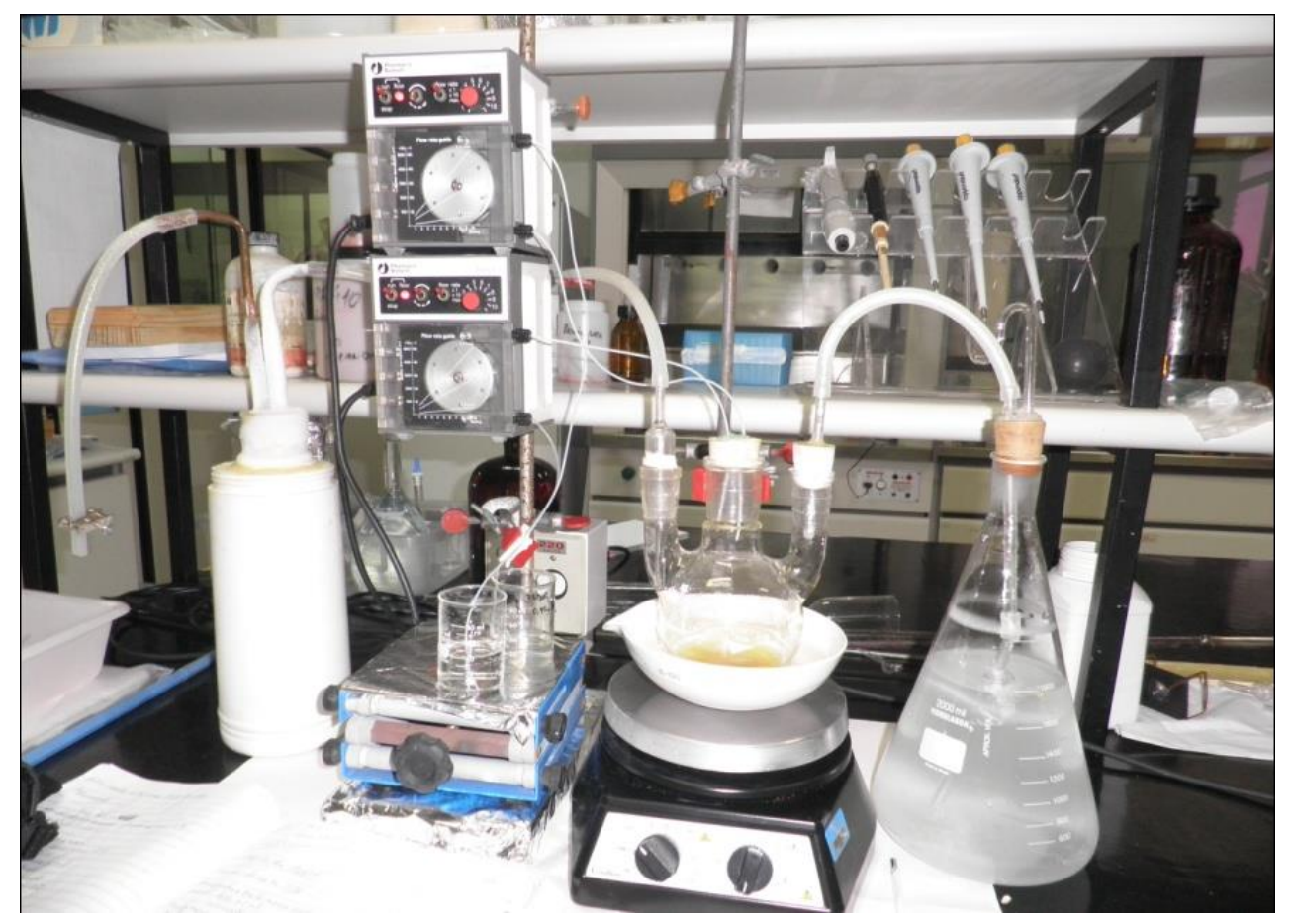

FIGURA 6 - Instrumentação utilizada na oxidação de um grama de resinas de troca iônica

Os primeiros experimentos com oxidação de 10 gramas de resina foram conduzidos como na FIG. 6, mas depois de estabelecidos novos parâmetros, as reações foram conduzidas em um reator de vidro com tampa removível e com quatro aberturas, sendo a central utilizada para a haste do agitador. Nas outras aberturas foram acoplados dois funis de separação, um dewar de nitrogênio e um erlenmeyer contendo solução de hidróxido de cálcio, conforme apresentado na FIG. 7. Os funis foram posteriormente substituídos pelas bombas peristálticas. A resina foi posta em contato com a solução de catalisador e mantida sob agitação por $15 \mathrm{~min}$. Em seguida, o peróxido de hidrogênio foi adicionado lentamente, a uma vazão de 2,3 $\mathrm{mL} / \mathrm{min}$., de forma a evitar uma reação muito rápida. A concentração de peróxido de hidrogênio foi de $25 \%$, o volume variou entre 20 a $100 \mathrm{~mL}$ e de 350 a $800 \mathrm{~mL}$ no reator, dependendo do fluxo necessário para manutenção da temperatura desejada. Não houve aquecimento externo, apenas foi utilizado o controle de temperatura da própria reação. $O$ tempo de reação foi de $180 \mathrm{~min}$. O catalisador utilizado foi o sulfato ferroso, nas concentrações de $25 \mathrm{mM}$ a $150 \mathrm{mM}$. Somente a resina mista foi estudada. Na TAB. 5 estão resumidas as condições experimentais empregadas. A eficiência da degradação nesta etapa foi avaliada por quantidade 
final de resina e molaridade dos catalisadores, diferentes catalisadores, dióxido de carbono produzido, oxigênio dissolvido (OD), carbono orgânico total (COT), variação de temperatura, análise morfológica. Parte da solução remanescente da reação de Fenton foi imobilizada com cimento Portland para avaliação do tempo de pega, água livre após 24 horas e resistência à compressão axial.

TABELA 5 - Condições experimentais na degradação de 10 gramas de resina

\begin{tabular}{ccc}
\hline $\begin{array}{c}\text { Concentração do peróxido } \\
(\%)\end{array}$ & $\begin{array}{c}\text { Volume do } \mathrm{H}_{\mathbf{2}} \mathbf{O}_{\mathbf{2}} \\
(\mathbf{m L})\end{array}$ & $\begin{array}{c}\text { Concentração do } \\
\text { catalisador (mM) }\end{array}$ \\
\hline 25 & 460 & 25 \\
25 & 320 a 350 & 50 \\
25 & 320 a 380 & 100 \\
25 & 325 a 350 & 150 \\
\hline
\end{tabular}

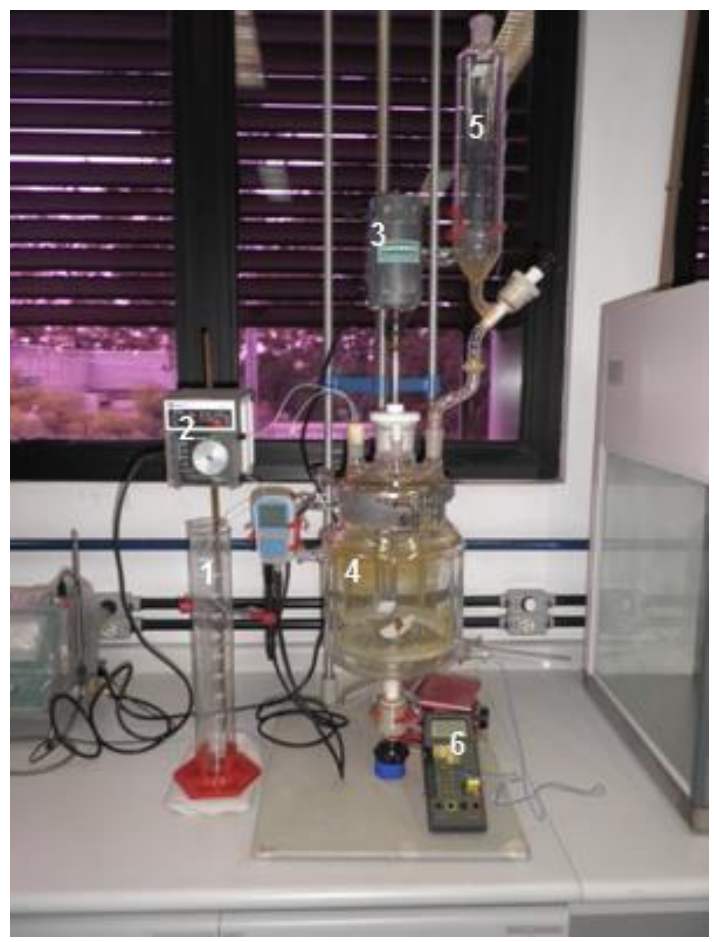

FIGURA 7 - Instrumentação utilizada para a degradação de 10 gramas de resina de troca iônica em um reator químico. 1. Peróxido de hidrogênio. 2. Bomba peristáltica. 3. Agitador. 4. Reator de vidro. 5. Solução de catalisador. 6.

Multímetro. 


\subsubsection{Concentração de peróxido de hidrogênio}

A concentração real das soluções de peróxido de hidrogênio empregadas foi determinada por permanganometria. Esse procedimento é necessário, pois este reagente decompõe-se facilmente, sendo necessária a determinação de sua concentração periodicamente. Na permanganometria, utiliza-se a concentração de uma solução de peróxido de hidrogênio 3\% por meio da volumetria de óxido-redução com permanganato de potássio.

\subsubsection{Quantidade final de resina e molaridade}

A quantidade final de resina foi obtida por separação com peneira de malha de $0,045 \mathrm{~mm}$, secagem por 12 horas em uma estufa a $70^{\circ} \mathrm{C}$ e posterior pesagem.

\subsubsection{Tipos de catalisadores}

Foram utilizados como catalisadores $0 \mathrm{Fe}^{2+}$, a mistura dos catalisadores $\mathrm{Fe}^{2+} / \mathrm{Cu}^{2+}$, e $\circ \mathrm{Co}^{+2}$ presente no rejeito. Os experimentos foram realizados com um grama de resina mista ( $50 \%$ catiônica e 50\% aniônica) e sem aquecimento externo.

\subsubsection{Dióxido de carbono produzido}

O gás carbônico liberado da reação de oxidação da resina foi retido de duas formas, primeiro, pela precipitação na forma carbonato de cálcio numa solução de hidróxido de cálcio saturada, e, posteriormente, na forma de carbonato de sódio com solução de hidróxido de sódio 4M. O carbonato de cálcio formado no primeiro método foi quantificado por gravimetria e, o carbonato de sódio, por titrimetria com ácido clorídrico e alaranjado de metila como indicador. As massas, em gramas, teóricas de carbonato de cálcio que deveriam ser formadas na degradação completa de meio grama de resina são de 3,1, 3,51 e 3,33 para as resinas catiônicas, aniônicas e mistas, respectivamente. As massas, em gramas, téoricas, no caso do carbonato de sódio são de 3,28, 3,72 e 3,53 para as catiônicas, aniônicas e mistas, respectivamente. 


\subsubsection{Oxigênio dissolvido (OD)}

Este parâmetro foi medido na degradação de 10 gramas de resinas mistas no reator químico, com o objetivo de se avaliar o grau de oxidação das resinas. O oxigênio dissolvido foi medido com a utilização de um eletrodo, que por meio de uma membrana permeável permite a entrada de oxigênio por difusão. $O$ catodo existente no aparelho reduz o oxigênio da amostra e forma no anodo o produto da oxidação. A corrente elétrica medida é proporcional à quantidade de oxigênio existente na amostra analisada (manual SX751).

\subsubsection{Carbono Orgânico Total (COT)}

O COT foi utilizado para medir a eficiência na degradação nos tempos de reação de 15, 30, 45, 60, 120 e 180 minutos. O COT foi determinado na mistura reacional com auxílio de um analisador Shimadzu. Este analisador emprega a oxidação térmica na presença de ácido, onde a partir do carbono inorgânico e carbono total, são determinadas as medidas do carbono orgânico total (SHIMADZU, 2012).

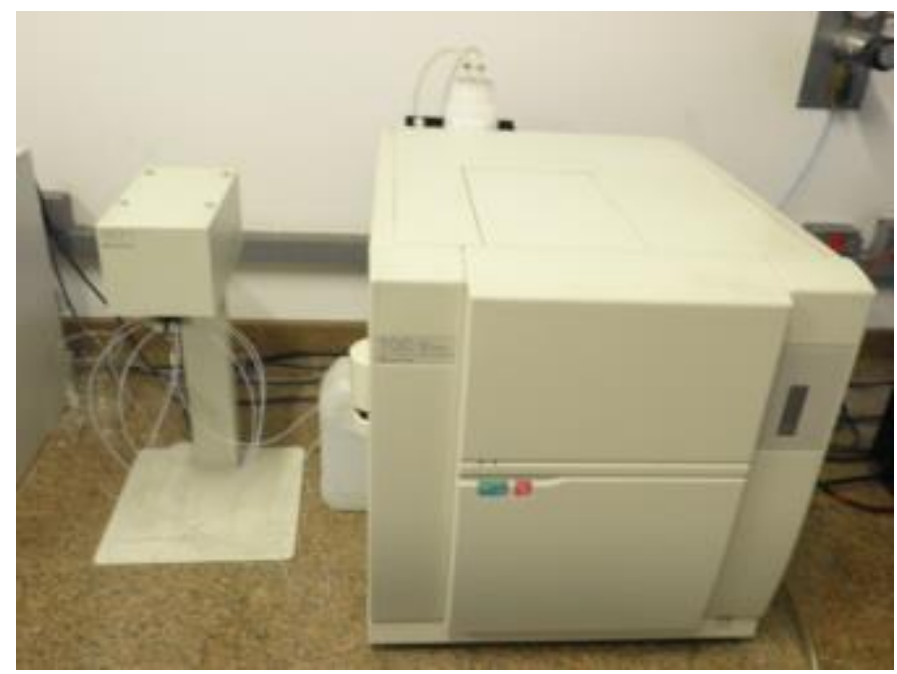

FIGURA 8 - Analisador de carbono orgânico total TOC-V CPH series

\subsubsection{Microscopia de varredura e óptica}

As amostras de resina foram fixadas em suporte metálico e após deposição de ouro foram analisadas em um microscópio eletrônico de varredura (MEV), com analisador de energia por raios $\mathrm{X}$ dispersivos (EDAX), com 0 
aumento de 200x. Esta metodologia foi realizada a fim de avaliar morfologicamente a superfície das resinas parcialmente degradadas (resina residual).

Outras amostras de resina foram fixadas em lâminas e analisadas em um microscópio óptico com aproximações de 40x.

\subsubsection{Temperatura}

A temperatura das reações foi controlada por meio de um termopar fixado no fundo do balão ou reator, acoplado a um multímetro digital.

\subsubsection{Análise de grupos funcionais por meio de Infravermelho}

Os espectros de infravermelho foram obtidos utilizando um espectrômetro FTIR (Fourier Transform Infrared) da marca Bomem, modelo MBSeries. Os resultados foram analisados por meio do software Knowitall Informatics System 9.5 (Bio-Rad Laboratories, 2012) e por comparação com valores tabelados de absorções características dos grupos e também com resultados de análises apresentados em artigos (Silverstein et al., 2006; Salgado, 2004; Cheng e Chung, 2009; Zagorodni et al., 2002). A resolução dos espectros foi de $4 \mathrm{~cm}^{-1} \mathrm{e}$ a faixa de frequência observada foi de 400 à $4000 \mathrm{~cm}^{-1}$.

\subsubsection{Imobilização com cimento Portland}

Toda a solução final pós-reação de Fenton foi armazenada. Parte foi utilizada para verificar se seria necessário o ajuste de $\mathrm{pH}$, já que a solução final é ácida.

As reações de oxidação das resinas geraram soluções aquosas, que num caso real seriam radioativas e não poderiam ser descartadas como resíduo químico comum. Por esse motivo, foram realizados experimentos de solidificação dessas soluções com cimento Portland CPII 32 nas proporções solução/cimento iguais a 0,28, 0,30 e 0,35 (massa/massa). Foram avaliadas soluções com e sem ajuste de $\mathrm{pH}$. Os pHs utilizados foram 2, 7 e 10. 


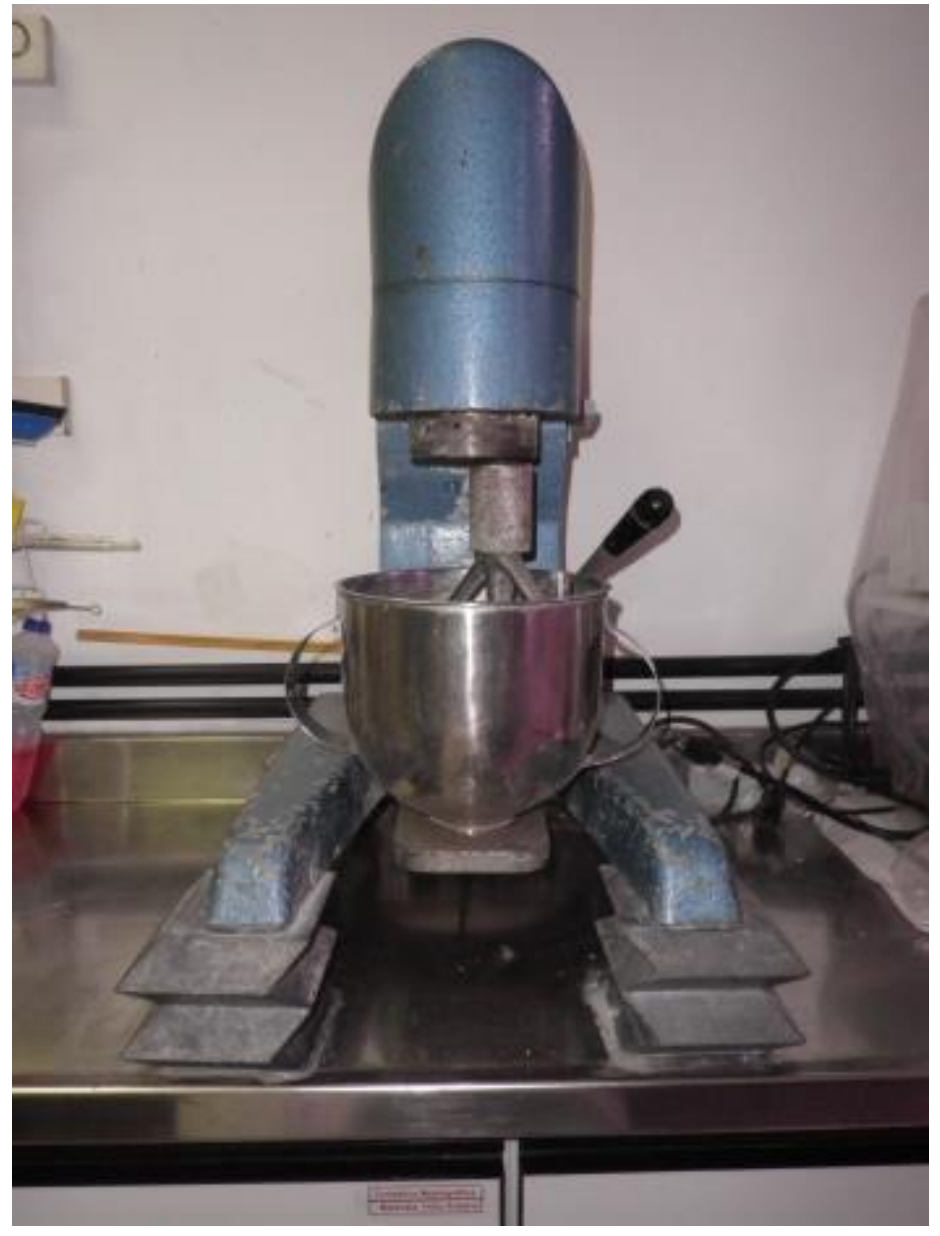

FIGURA 9 - Argamassadeira utilizada para misturar cimento com as soluções Fenton

Os corpos de prova foram confeccionados em moldes plásticos descartáveis, com $5 \mathrm{~cm}$ de diâmetro e $10 \mathrm{~cm}$ de altura. A pasta de cimento foi previamente misturada em uma argamassadeira (FIG.9), transferida para os moldes plásticos e mantida em cura selada por 28 dias a $22^{\circ} \mathrm{C}$, como mostrado na FIG. 10. 


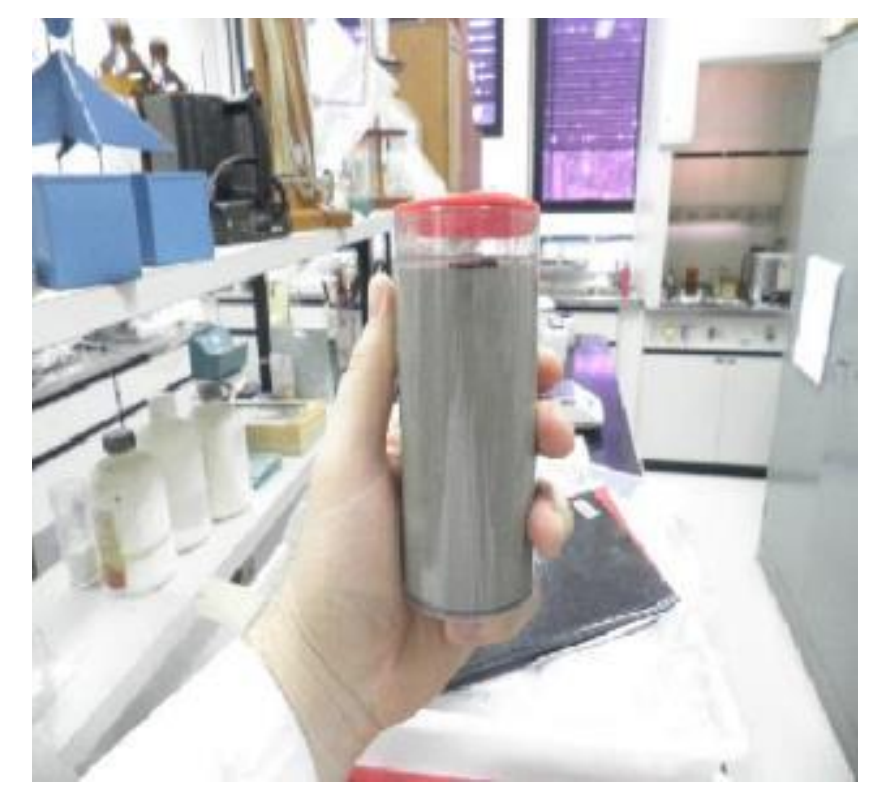

FIGURA 10 - Moldes plásticos com as amostras

Os parâmetros avaliados foram o líquido livre após 24 horas, o tempo de pega (tempo de solidificação) da mistura e a resistência à compressão axial. $O$ tempo de pega foi determinado por meio da agulha de Vicat (FIG. 11), no momento em que essa agulha não penetrava mais na amostra. Foi utilizado o teste de Grubbs (Jesus, 2010) nos valores de resistência à compressão axial para detectar os outliers, que foram eliminados. Na Figura 12 é apresentada a prensa utilizada para determinar a resistência mêcanica.

O restante da solução final foi levado concentrado em um béquer, sobre chapa aquecedora, até atingir um volume com $40 \%$ de teor de sólidos. Esse concentrado foi imobilizado com cimento Portland Comum e tempo de cura de 3 dias. Após esse período, os corpos de prova foram rompidos na prensa hidráulica para avaliação da resistência mêcanica. 


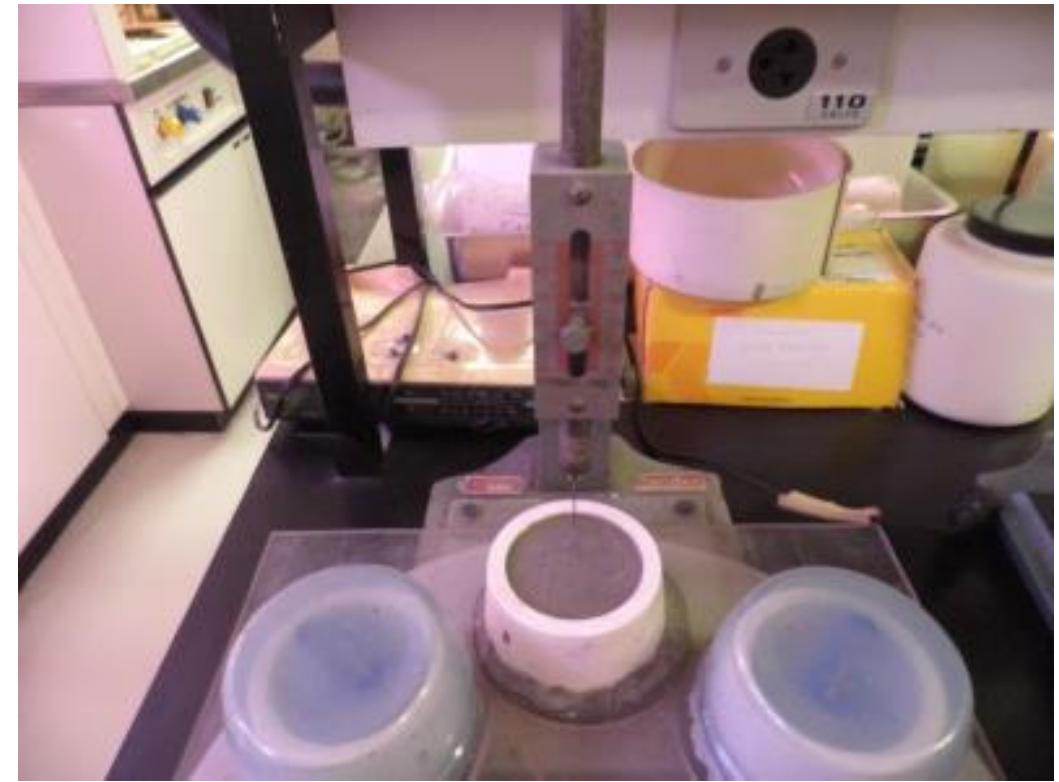

FIGURA 11- Imagem da agulha de Vicat para determinação do tempo de pega.

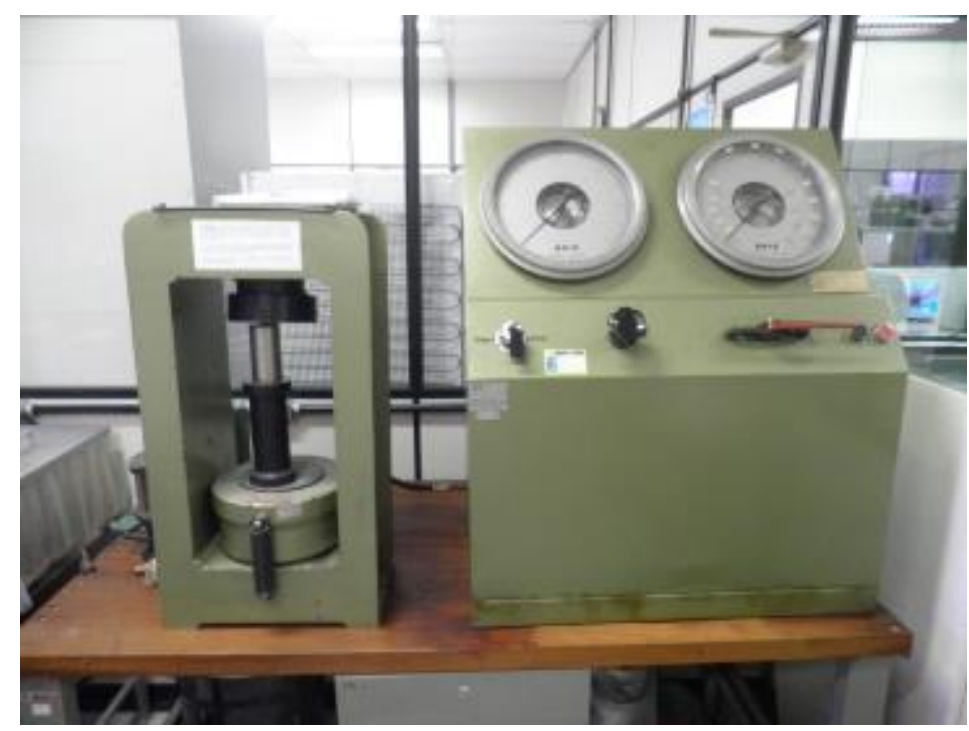

FIGURA 12 - Imagem de prensa hidráulica para determinação da resistência à compressão axial. 


\section{RESULTADOS E DISCUSSÃO}

\subsection{Efeito do aquecimento externo}

Os primeiros experimentos foram em caráter exploratório utilizando $1 \mathrm{~g}$ de resina úmida catiônica, aniônica e mista. A concentração da solução de $\mathrm{FeSO}_{4} .7 \mathrm{H}_{2} \mathrm{O}$ utilizada foi de $20 \mathrm{mM}$ nos primeiros experimentos.

Houve degradação de aproximadamente $99 \%$ das resinas catiônicas e aniônicas conforme avaliado pela massa de resina residual, quando submetidas à oxidação com aquecimento. No caso das reações conduzidas sem aquecimento, a degradação foi menos eficiente nas resinas aniônicas e mistas, aproximadamente $70 \%$ e $16 \%$, respectivamente. Já a resina catiônica sem aquecimento apresentou uma degradação de cerca de $98 \%$. De acordo com Jian et al.(1996), este comportamento poderia ser explicado pela maior dificuldade em degradar resinas aniônicas e mistas comparada às resinas catiônicas. Os motivos apresentados pelos autores são: (1) $O$ átomo $S$ das resinas catiônicas libera elétrons, enquanto os radicais hidroxila atraem elétrons. Isto faz com que estes se aproximem e reajam facilmente. $\mathrm{O}$ grupo $\mathrm{SO}_{3} \mathrm{H}$ se separa do benzeno formando ácido sulfúrico, decompondo o benzeno e tornando o líquido resultante livre de compostos aromáticos nas resinas catiônicas. $\mathrm{O}$ radical $\mathrm{N}^{+}$da resina aniônica atrai elétrons e possui radical benzil estável, tornando-o difícil reagir com radicais hidroxila. (2) Na decomposição da resina aniônica são produzidas espécies quelantes para os íons metálicos, que prejudicam a eficiência dos catalisadores, alterando seu comportamento redox e, por conseguinte sua reatividade. (3) As aminas quaternárias se decompõem com dificuldade devido a sua lenta oxidação. (4) A degradação das resinas é acompanhada de copolimerização, tornando os sólidos obtidos flutuantes, dificultando sua decomposição.

\subsection{Efeito do pH}

$\mathrm{O}$ pH inicial e o final da solução resultante da degradação da resina foi aproximadamente 4 e 2 , respectivamente. Como há relatos na literatura de que a eficiência da reação é maior em uma faixa de pH de 3-4 (REFs), foi conduzido um 
experimento com resina aniônica, mantendo esse parâmetro perto de 3. O resultado foi de aproximadamente $72 \%$ de degradação, ou seja, semelhante a um experimento sem controle de $\mathrm{pH}$ e, portanto, não justificando o controle desse parâmetro nos experimentos seguintes.

\subsection{Efeito da variação na concentração de catalisador}

Posteriormente, foram realizados experimentos variando a concentração do $\mathrm{FeSO}_{4} .7 \mathrm{H}_{2} \mathrm{O}$ com e sem aquecimento externo. Os resultados obtidos nesses experimentos exploratórios são mostrados na TAB. 6.

TABELA 6 - Massas de resina residual obtidas nas reações de oxidação

\begin{tabular}{cccccc}
\hline Resina & $\begin{array}{c}\text { Massa } \\
\text { inicial } \\
\text { seca }\end{array}$ & $\begin{array}{c}\text { Concentração } \\
\text { FesO }_{4 \cdot 7} \mathbf{O} \mathbf{O} \\
(\mathbf{m M})\end{array}$ & $\begin{array}{c}\text { Número de } \\
\text { experimentos }\end{array}$ & $\begin{array}{c}\text { Degradação } \\
(\%)\end{array}$ & $\begin{array}{c}\text { Massa } \\
\text { resina } \\
\text { residual } \\
(\mathbf{g})^{\star *}\end{array}$ \\
\hline Mista* $^{*}$ & 0,56 & 20 & 3 & 68 & $0,17 \pm 0,03$ \\
& & 30 & 3 & 85 & $0,08 \pm 0,03$ \\
& & 80 & 3 & 97 & $0,02 \pm 0,01$ \\
\hline Mista & 0,56 & 50 & 8 & 98 & $0,01 \pm 0,01$ \\
& & 70 & 4 & 97 & $0,02 \pm 0,01$ \\
& & 80 & 4 & 98 & $0,01 \pm 0,01$ \\
\hline
\end{tabular}

Tempo: 90 min

Temperatura: 50 a $70^{\circ} \mathrm{C}$

* Experimentos com aquecimento externo em $70^{\circ} \mathrm{C}$.

** $\bar{X} \pm \mathrm{S}$ (média \pm desvio-padrão) das massas de resina residual medidas por meio de uma balança semianalítica.

As reações de oxidação de resina mista submetida ao aquecimento foram realizadas por meio de dois ensaios com 20 mM, dois ensaios com 35 mM e três ensaios com $80 \mathrm{mM}$ de $\mathrm{FeSO}_{4} \cdot 7 \mathrm{H}_{2} \mathrm{O}$. As reações de oxidação sem aquecimento foram realizadas por meio de seis ensaios com $50 \mathrm{mM}$, seis ensaios com 70 mM e três ensaios com 80 mM. Foram realizados ensaios exploratórios com o objetivo de se obter a menor quantidade de resina residual variando a molaridade de catalisador. Os percentuais de degradação obtidos nas reações conduzidas com aquecimento e molaridades $20 \mathrm{mM}, 35 \mathrm{mM}$ e $80 \mathrm{mM}$ foram de aproximadamente $68 \%, 85 \%$ e $97 \%$, respectivamente. As reações sem 
aquecimento com concentrações de 50, 70 e $80 \mathrm{mM}$ resultaram em degradações superiores a $97 \%$. Observou-se, portanto uma maior eficiência empregando-se concentrações maiores do catalisador. A molaridade $50 \mathrm{mM}$ foi considerada a mais eficiente por utilizar menos catalisador que as outras realizadas e degradar a mesma porcentagem.

Nota-se na TAB. 6 valores de desvio padrão próximos, ou até mesmo, iguais aos valores da média. Isso ocorre principalmente pois algumas massas de resina residual final foram próximas ao valor mínimo de medição (balança semianalítica).

\subsection{Efeito dos diferentes tipos de catalisador}

Além do $\mathrm{Fe}^{2+}$, os catalisadores $\mathrm{Cu}^{2+} \mathrm{e} \circ \mathrm{Co}^{2+}$ também foram avaliados na reação de Fenton. A mistura $\mathrm{Fe}^{2+} / \mathrm{Cu}^{2+}$, que de acordo com Jian et al.,(1996), é a mais eficiente na degradação de resinas mistas, e o $\mathrm{Co}^{2+}$ por já estar presente no rejeito radioativo. As concentrações de catalisador utilizadas e as massas de resina residuais são apresentadas na TAB. 7 .

TABELA 7 - Massas de resinas residuais obtidas nas reações de oxidação com 1 grama de resina úmida $(0,56 \mathrm{~g} \mathrm{seco})$ diferentes catalisadores

\begin{tabular}{ccccc}
\hline Catalisador & $\begin{array}{c}\text { Concentração } \\
(\mathbf{m M})\end{array}$ & $\begin{array}{c}\text { № de } \\
\text { experimentos }\end{array}$ & $\begin{array}{c}\text { Degradação } \\
(\%)\end{array}$ & $\begin{array}{c}\text { Massa de } \\
\text { resina } \\
\text { residual (g) } \\
* *\end{array}$ \\
\hline Sulfato ferroso & 80 & 8 & 98 & $0,01 \pm 0,01$ \\
\hline $\begin{array}{c}\text { Sulfato ferroso } \\
\text { e nitrato de } \\
\text { cobre }\end{array}$ & $40^{*}$ & 1 & 92 & 0,04 \\
\hline $\begin{array}{c}\text { Cloreto de } \\
\text { cobalto }\end{array}$ & 100 & 1 & - & Não reagiu \\
\hline
\end{tabular}

Tempo: 90 minutos

Temperatura: 50 a $70^{\circ} \mathrm{C}$

* A solução de catalisadores utilizada neste experimento foi composta de $40 \mathrm{mM}$ para o $\mathrm{FeSO}_{4} .7 \mathrm{H}_{2} \mathrm{O}$ e $40 \mathrm{mM}$ para o $\mathrm{Cu}\left(\mathrm{NO}_{3}\right)_{2}$.

** $\bar{X} \pm \mathrm{S}$ (média \pm desvio-padrão) das massas de resina residual medidas por meio de uma balança semianalítica. 
Observa-se que a mistura de $\mathrm{Fe}^{2+} / \mathrm{Cu}^{2+}$ foi tão eficiente quanto o $\mathrm{Fe}^{2+}$ na degradação da resina, atingindo $92 \%$. Este resultado é semelhante ao estudo de Jian et al. (1996), no qual, houve mais de $85 \%$ de degradação num estudo utilizando 25 gramas de resinas de troca iônica mistas 2:1 (catiônica: aniônica) com $\mathrm{Fe}^{2+} / \mathrm{Cu}^{2+}$ e aquecimento.

\subsection{Determinação de carbonato}

As massas de carbonato de sódio são resultantes da reação do dióxido de carbono, liberado na reação, com a solução de hidróxido de cálcio. O dióxido de carbono foi monitorado para avaliar de balanço de massa do processo. As massas obtidas estão apresentadas na TAB. 8.

TABELA 8 - Massas de carbonato obtidas e massa de resinas residuais nas reações de oxidação

\begin{tabular}{cccc}
\hline Experimentos & $\begin{array}{c}\text { Massa de } \\
\text { resina inicial } \\
(\mathbf{g})\end{array}$ & $\begin{array}{c}\text { Massa de resina } \\
\text { residual }(\mathbf{g})\end{array}$ & $\begin{array}{c}\text { Massa de } \\
\text { carbonato }(\mathbf{g})^{\star \star}\end{array}$ \\
\hline Catiônica & 0,56 & $<0,01$ & $1,03 \pm 0,11$ \\
Aniônica & 0,56 & $0,12 \pm<0,01$ & $0,87 \pm<0,01$ \\
Mista & 0,56 & $0,02 \pm<0,01$ & $0,98 \pm 0,04$ \\
Mista * & 0,56 & $0,03 \pm<0,01$ & $0,85 \pm 0,02$ \\
\hline
\end{tabular}

Tempo: 90 minutos

Temperatura: 50 a $70^{\circ} \mathrm{C}$

Concentração de $\mathrm{FeSO}_{4} .7 \mathrm{H}_{2} \mathrm{O}: 20$ a $80 \mathrm{mM}$

* dióxido de carbono foi capturado com hidróxido de sódio.

** $\bar{X} \pm S$ (média \pm desvio-padrão para $n=5$ ) das massas de resina residual e de carbonato medidas por meio de uma balança semianalítica.

Verifica-se na TAB. 8 que as massas de carbonato quantificadas foram similares, não havendo correlação com a massa de resina residual. Esses valores são muito inferiores à massa teórica esperada, cerca de $3 \mathrm{~g}$, calculada de acordo com equações de químicas. Esses baixos valores, cerca de $30 \%$ do valor teórico, foram provavelmente ocasionados pela ineficiência na dissolução do gás 
na solução de hidróxido de sódio. No entanto, essas massas foram superiores às verificadas por Zahorodna et al. (2008), o qual obteve cerca de 14 \% do teórico. Este método, portanto, mostrou-se ineficiente para retenção de dióxido de carbono.

\subsection{Efeito da temperatura}

Para estudar o efeito da temperatura na degradação das resinas, foram realizados experimentos em um reator químico utilizando dez gramas de amostras úmidas com a molaridade de $50 \mathrm{mM}$ de sulfato ferroso. $\mathrm{O}$ volume utilizado de $\mathrm{H}_{2} \mathrm{O}_{2}$ foi de $700 \mathrm{~mL}$. Os resultados obtidos nestes experimentos estão apresentados na TAB. 9.

TABELA 9 - Massas de resinas residuais secas das reações de oxidação de 10 gramas com diferentes temperaturas.

\begin{tabular}{cccc}
\hline $\begin{array}{c}\text { Temperatura } \\
\left({ }^{\circ} \mathbf{C}\right)^{\star}\end{array}$ & $\begin{array}{c}\text { Número de } \\
\text { experimentos }\end{array}$ & Degradação (\%) & $\begin{array}{c}\text { Massa de resina } \\
\text { residual(g) }\end{array}$ \\
\hline $48,1 \pm 4,1$ & 3 & 92 & $0,47 \pm 0,04$ \\
$58,5 \pm 0,9$ & 3 & 99 & $0,02 \pm 0,01$ \\
$70,8 \pm 2,6$ & 3 & 98,5 & $0,08 \pm 0,01$ \\
\hline
\end{tabular}

Tempo: 180 minutos

Concentração de $\mathrm{FeSO}_{4} .7 \mathrm{H}_{2} \mathrm{O}: 50 \mathrm{mM}$

Volume de $\mathrm{H}_{2} \mathrm{O}_{2} 25 \%$ : $350 \mathrm{~mL}$

* $\bar{X} \pm \mathrm{S}$ (média \pm desvio-padrão) das temperaturas e das massas de resinas residuais medidas por meio de uma balança semianalítica.

As reações de oxidação de dez gramas de resinas úmidas mistas com $50 \mathrm{mM}$ de catalisador foram conduzidas em três faixas de temperaturas, 50, 60 e $70{ }^{\circ} \mathrm{C}$. Pode-se observar na TAB. 9, que as menores massas de resina residual foram observadas nas temperaturas aproximadas de 60 e $70^{\circ} \mathrm{C}$, equivalendo a 99 e 98,5\% de degradação, respectivamente. Apesar destes resultados indicarem esta faixa ideal de trabalho, deve-se considerar que $\mathrm{O}_{2} \mathrm{O}_{2}$ sofre decomposição térmica acelerada acima de $60^{\circ} \mathrm{C}$ (FISPQ, 2012), o que aumentaria seu consumo na reação. Neste conjunto de experimentos, o consumo de peróxido de hidrogênio não foi avaliado, pois foi fixado em $700 \mathrm{~mL}$. 
A faixa de temperatura adequada foi fixada no intervalo 50 a $60^{\circ} \mathrm{C}$, para evitar a decomposição térmica do $\mathrm{H}_{2} \mathrm{O}_{2}$ em água e oxigênio.

As soluções com concentração de $50 \mathrm{mM}$ de $\mathrm{FeSO}_{4} \cdot 7 \mathrm{H}_{2} \mathrm{O}$ mostraramse eficientes no controle das temperaturas desejadas.

\subsection{Efeito da variação da concentração de catalisador na degradação de $\mathbf{1 0}$ gramas de resinas mistas}

No entanto, para tentar compreender melhor o processo da degradação, foram conduzidos experimentos com diferentes concentrações de $\mathrm{FeSO}_{4} .7 \mathrm{H}_{2} \mathrm{O}$. Na TAB. 10 são apresentados os resultados obtidos utilizando soluções nas concentrações 25, 50, 100 e 150 mM do catalisador.

TABELA 10 - Massas de resinas residuais obtidas nas reações de oxidação com os volumes de peróxido de hidrogênio utilizados e temperaturas.

\begin{tabular}{|c|c|c|c|c|}
\hline $\begin{array}{c}\text { Concentração } \\
\text { de } \\
\mathrm{FeSO}_{4} 7 \mathrm{H}_{2} \mathrm{O} \\
(\mathrm{mM})\end{array}$ & $\begin{array}{l}\text { Temperatura } \\
\left({ }^{\circ} \mathrm{C}\right)^{\star}\end{array}$ & $\begin{array}{c}\text { Volume de } \\
\mathrm{H}_{2} \mathrm{O}_{2} 25 \% \\
(m L)^{\star}\end{array}$ & $\begin{array}{c}\text { Número de } \\
\text { experimentos }\end{array}$ & $\begin{array}{c}\text { Massa de } \\
\text { resina } \\
\text { residual }(\mathrm{g})^{\star}\end{array}$ \\
\hline 25 & $41,1 \pm 1,0$ & $480 \pm 20$ & 3 & $1,56 \pm 0,03$ \\
\hline 50 & $60,4 \pm 6,5$ & $323 \pm 6$ & 8 & $0,01 \pm<0,01$ \\
\hline 100 & $53,8 \pm 0,7$ & $345 \pm 26$ & 6 & $0,11 \pm 0,07$ \\
\hline 150 & $54,4 \pm 0,5$ & $337 \pm 13$ & 3 & $0,65 \pm 0,07$ \\
\hline
\end{tabular}

Tempo: 180 minutos.

${ }^{*} \bar{X} \pm \mathrm{S}$ (média \pm desvio-padrão) das temperaturas, volumes de $\mathrm{H}_{2} \mathrm{O}_{2} 25 \%$ e das massas de resina residual.

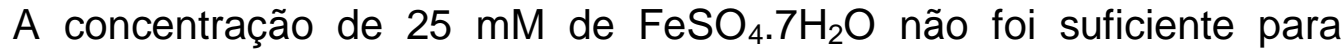
manter a temperatura desejada, resultando numa degradação de 67,6\%. Comparando-se as outras soluções, a de $150 \mathrm{mM}$ foi menos eficiente indicando, portanto, que 0 excesso na concentração de $\mathrm{FeSO}_{4} .7 \mathrm{H}_{2} \mathrm{O}$ pode ter interferido no processo. As soluções de 50 e $100 \mathrm{mM}$ foram as mais eficazes degradando praticamente $100 \%$ das resinas. No entanto, considerando a massa de sulfato ferroso utilizada, pode-se afirmar que concentração do catalisador mais eficiente é 
a $50 \mathrm{mM}$. Resultado semelhante foi obtido por Taylor (2002), no qual empregou $180 \mathrm{~mL}$ de $\mathrm{H}_{2} \mathrm{O}_{2} 50 \%$ para oxidar completamente 20 gramas de resina mista.

A relação $\mathrm{H}_{2} \mathrm{O}_{2} / \mathrm{Fe}^{2+}$ foi avaliada nas reações de Fenton. As relações para cada concentração de catalisador utilizada são mostradas na TAB. 11.

TABELA 11 - Relação $\mathrm{H}_{2} \mathrm{O}_{2} / \mathrm{Fe}^{2+}$ para suas respectivas concentrações de catalisador.

\begin{tabular}{cc}
\hline Concentração do catalisador $(\mathrm{mM})$ & Relação $\mathrm{H}_{2} \mathrm{O}_{2} / \mathrm{Fe}^{2+}$ \\
\hline 25 & $335: 1$ \\
50 & $111: 1$ \\
100 & $60: 1$ \\
150 & $39: 1$ \\
\hline
\end{tabular}

As diferentes relações observadas na TAB. 11 podem ser explicadas devido às temperaturas utilizadas nos ensaios. Nos experimentos com $25 \mathrm{mM}$ de $\mathrm{FeSO}_{4} 7 \mathrm{H}_{2} \mathrm{O}$ foi utilizado um volume maior de $\mathrm{H}_{2} \mathrm{O}_{2}$, já que a baixa concentração do catalisador foi insuficiente no aumento da temperatura. Isso resultou em uma relação maior de $\mathrm{H}_{2} \mathrm{O}_{2} / \mathrm{Fe}^{+2}$ na proporção de 335:1. Nos ensaios com 50 e 100 $\mathrm{mM}$ de $\mathrm{FeSO}_{4} .7 \mathrm{H}_{2} \mathrm{O}$, que foram os mais eficientes na degradação das resinas, as relações foram de 111:1 e 60:1. As relações mássicas utilizadas neste trabalho foram menores que as encontradas na literatura, por exemplo, 163:1 Taylor (2002) e 148:1 Zahorodna et al. (2007), mas não é possível afirmar que foram mais eficientes pois empregaram concentrações mais baixas de catalisador.

\subsection{Determinação de Oxigênio Dissolvido (O.D.)}

As reações de degradação não foram eficazes nas concentrações de 25 e $150 \mathrm{mM}$ de $\mathrm{FeSO}_{4} \cdot 7 \mathrm{H}_{2} \mathrm{O}$, pois as relações estequiométricas não foram adequadas. Estas relações inadequadas foram causadas pelo excesso de $\mathrm{H}_{2} \mathrm{O}_{2}$ ou concentração de catalisador. Pode ser observado na FIG. 13 que a reação com $25 \mathrm{mM}$ de $\mathrm{FeSO}_{4} .7 \mathrm{H}_{2} \mathrm{O}$, apresentou a partir dos 15 minutos uma elevada concentração de O.D. comparada as concentrações de 50 e 100 mM de 
$\mathrm{FeSO}_{4} .7 \mathrm{H}_{2} \mathrm{O}$, atingindo seu valor máximo nos 60 minutos. Isto pode ter acontecido devido ao excesso de peróxido de hidrogênio em relação a concentração de sulfato ferroso, demonstrando que existe um forte elemento cinético que rege o perfil oxigênio/tempo do sistema reacional estudado. De acordo com Juanes et al. (2011), o aumento de OD pode significar excesso de peróxido de hidrogênio sendo adicionado no sistema, demonstrando ineficiência do processo. Ainda, de acordo com Araujo, (2008), o excesso de oxidante pode ter sequestrado os radicais hidroxil gerados, formando o radical $\mathrm{HO}_{2}{ }^{\circ}$. Estes radicais atuam oxidando $\mathrm{Fe}^{2+}$ em $\mathrm{Fe}^{3+}$ e reduzindo $\mathrm{Fe}^{3+}$ em $\mathrm{Fe}^{2+}$ como mostrado nas equações. (3.10) e (3.11), no qual resulta na formação mais alta em relação a demais concentrações de catalisador. Com a concentração de $150 \mathrm{mM}$ de $\mathrm{FeSO}_{4} \cdot 7 \mathrm{H}_{2} \mathrm{O}$, a concentração do oxigênio dissolvido também foi elevada como observado na FIG. 13. O aumento de $\mathrm{Fe}^{2+}$ resulta na maior formação de $\mathrm{Fe}^{3+}$ e do radical hidroperoxil como observado nas Eq.(3.7) e (3.10). O radical hidroperoxil é o responsável pelo aumento na concentração de $\mathrm{O}_{2}$ como observado na Eq. 3.11).

Este perfil é típico de reações autocatalíticas, na qual as quantidades e concentrações dos reagentes levam ao aumento ou à diminuição do período de indução (que é o tempo necessário para geração dos produtos que catalisam a relação em quantidade apreciável para que a mesma se inicie) (Sandres e Ambrosio, 2013; Lam et al., 2011; Gold et al., 1987 apud Bou-Diab e Fierz, 2002). 


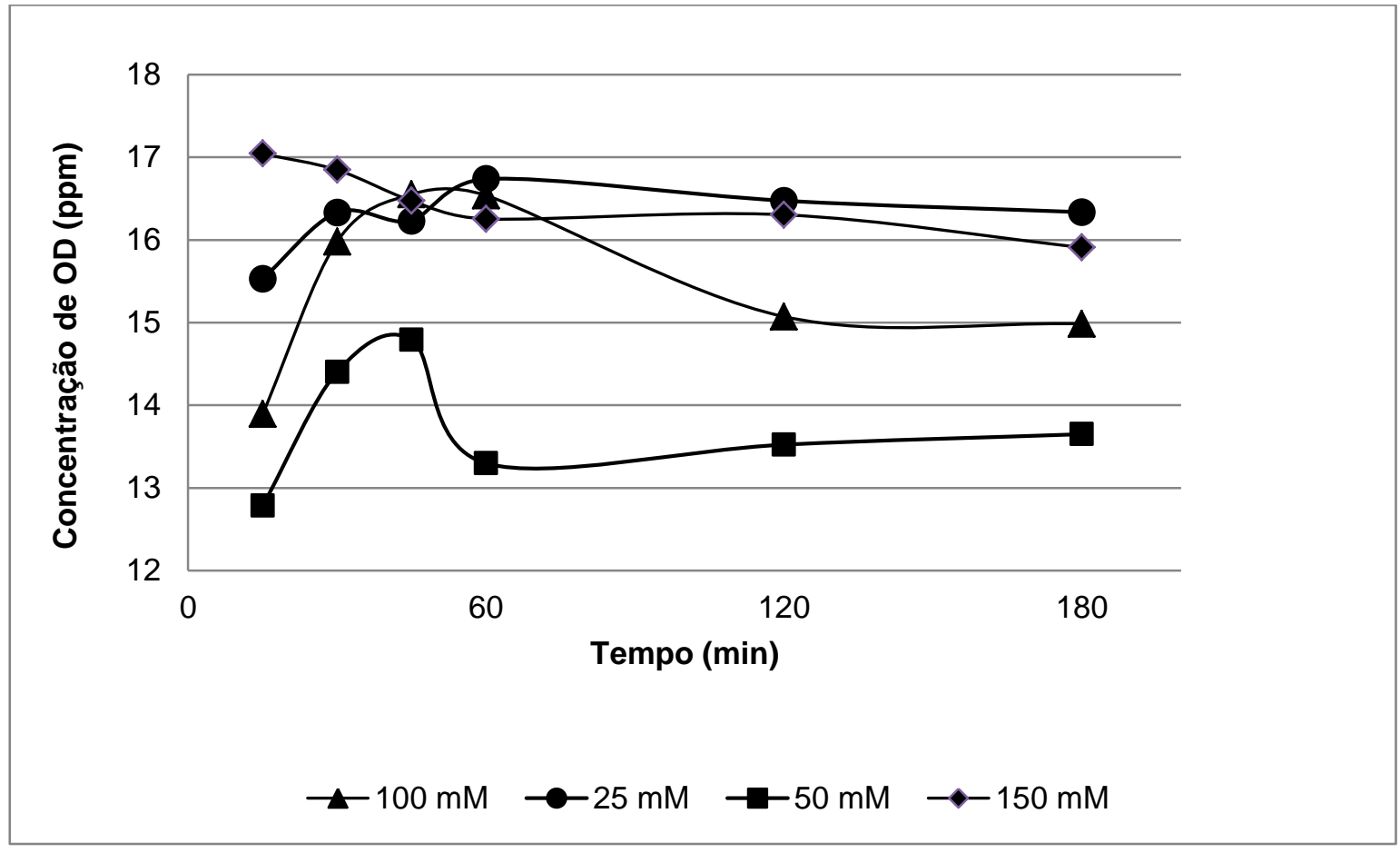

FIGURA 13 - Concentração do oxigênio dissolvido em função do tempo, das reações de oxidação com diferentes concentrações de catalisador.

\subsection{Determinação do Carbono orgânico total (COT)}

A eficiência do COT como parâmetro de controle da reação foi avaliada. Os resultados obtidos na determinação do carbono orgânico total são mostrados na FIG. 14. 


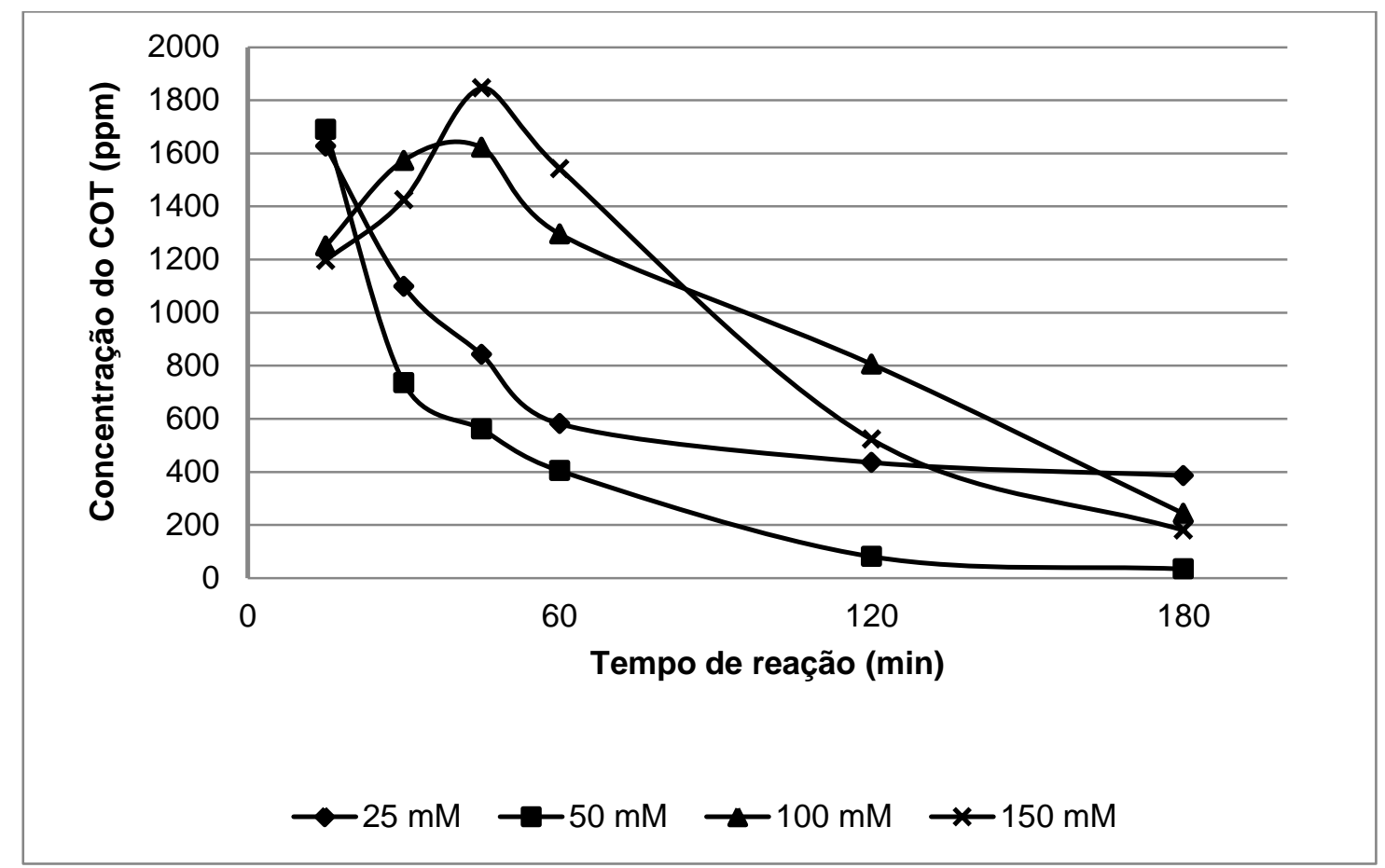

FIGURA 14 - Variação da concentração de carbono orgânico total em função do tempo de reação com diferentes concentrações de catalisador.

É possível observar na FIG. 14, que o menor valor final de carbono orgânico total obtido foi na degradação com $50 \mathrm{mM}$ de catalisador. O COT mostrou-se influenciado pela concentração de catalisador, interferindo no começo do processo de degradação. O comportamento do COT em função do tempo com quantidades menores de catalisador mostrou uma queda progressiva. Nas quantidades maiores, aproximadamente após 45 minutos de reação, o carbono orgânico total apresentou seu valor máximo.

De acordo com Araujo (2008), o excesso de íons $\mathrm{Fe}^{2+}$ pode servir como "sequestrante" de radicais $\mathrm{OH}$, conforme a equação (3.7), reduzindo a disponibilidade destes radicais na oxidação das resinas de troca iônica. Além disso, de acordo com as equações 3.7 e 3.6, a velocidade de reação do radical oxidante $\mathrm{OH}^{\cdot}$ com o íon $\mathrm{Fe}^{2+}$ é de $3,2 \times 10^{8} \mathrm{~L} \mathrm{~mol}^{-1} \mathrm{~s}^{-1}$, é muito maior que a própria reação de Fenton que é de $76 \mathrm{~L}$. $\mathrm{mol}^{-1} \mathrm{~s}^{-1}$ (Walling e Goosen, 1973).

De acordo com Taylor (2002), a resina de troca iônica é primeiramente solubilizada em sulfonatos de poliestireno linear e aminas,aumentando a concentração de COT na solução, que se oxidam de uma série de intermediários a dióxido de carbono e sulfatos de amônio, diminuindo a concentração de COT. 
A porcentagem de oxidação do COT da solução foi comparada com a porcentagem da massa da resina de troca iônica degradada na reação resultante de Fenton (FIG 15). Em geral, os resultados foram semelhantes, indicando que o COT é um parâmetro eficiente para determinar as taxas de degradação das resinas.

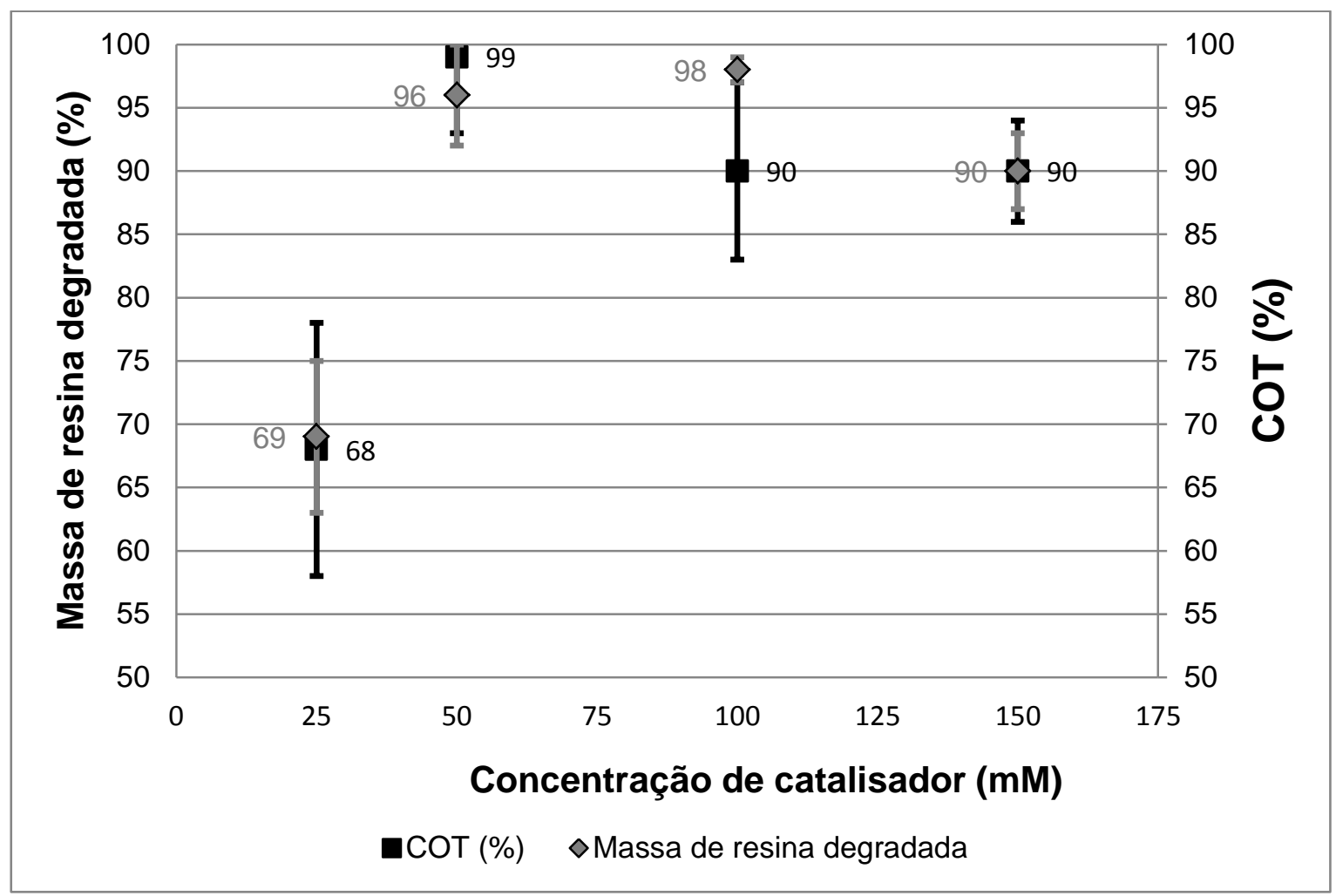

FIGURA 15 - Massa de resina degradada e variação do COT em função da molaridade do catalisador

\subsection{Análise Morfológica}

A FIG. 16 apresenta as imagens obtidas por meio de um microscópio eletrônico de varredura de amostras de resinas submetidas ao ataque com aproximadamente $350 \mathrm{~mL}$ de peróxido de hidrogênio em função do tempo de reação. Nessas imagens é possível observar que as resinas não são atacadas somente da superfície externa para interna e, sim, como um todo, já que apresentam trincas logo no início da reação, indicando que a solução de ataque consegue penetrar nos canais internos e provocar uma expansão. A imagem "e" 
mostra apenas parte da resina que não degradou ( $1 \%$ da massa inicial), pois 0 restante foi totalmente dissolvido.

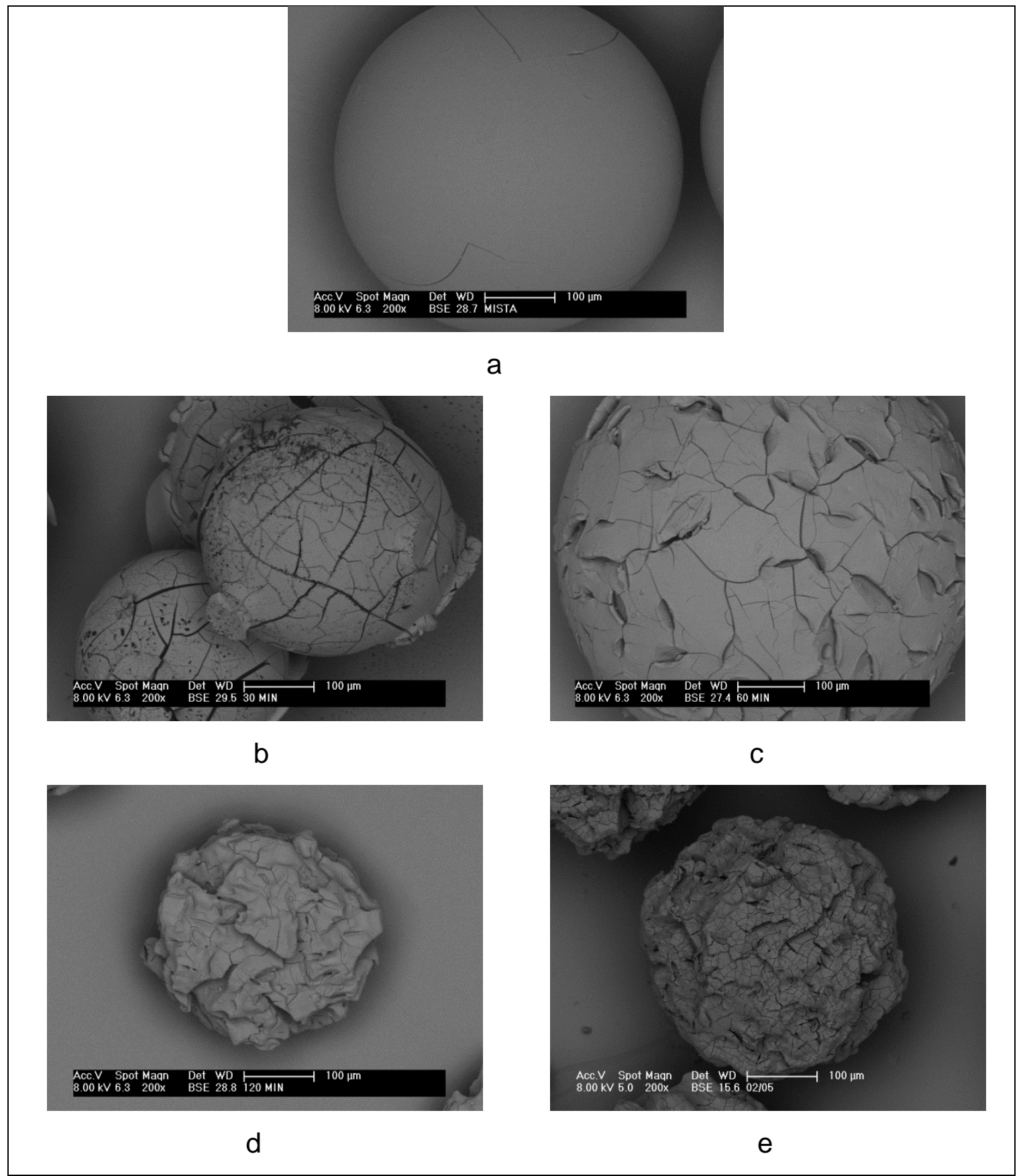

FIGURA 16 - a: Imagem das resinas sem tratamento. b, c, d, e: Resinas após 30, 45, 120 e 180 minutos de reação (100 mM Fe $\mathrm{SO}_{4}$ ). Aproximação 200x

A microscopia ótica foi utilizada para avaliar a estrutura geral da resina (FIG. 17). Não foram observadas diferenças significativas até 45 minutos "c". A partir daí, nota-se um aumento de trincas/quebras na superfície das resinas, diminuindo o volume final. 


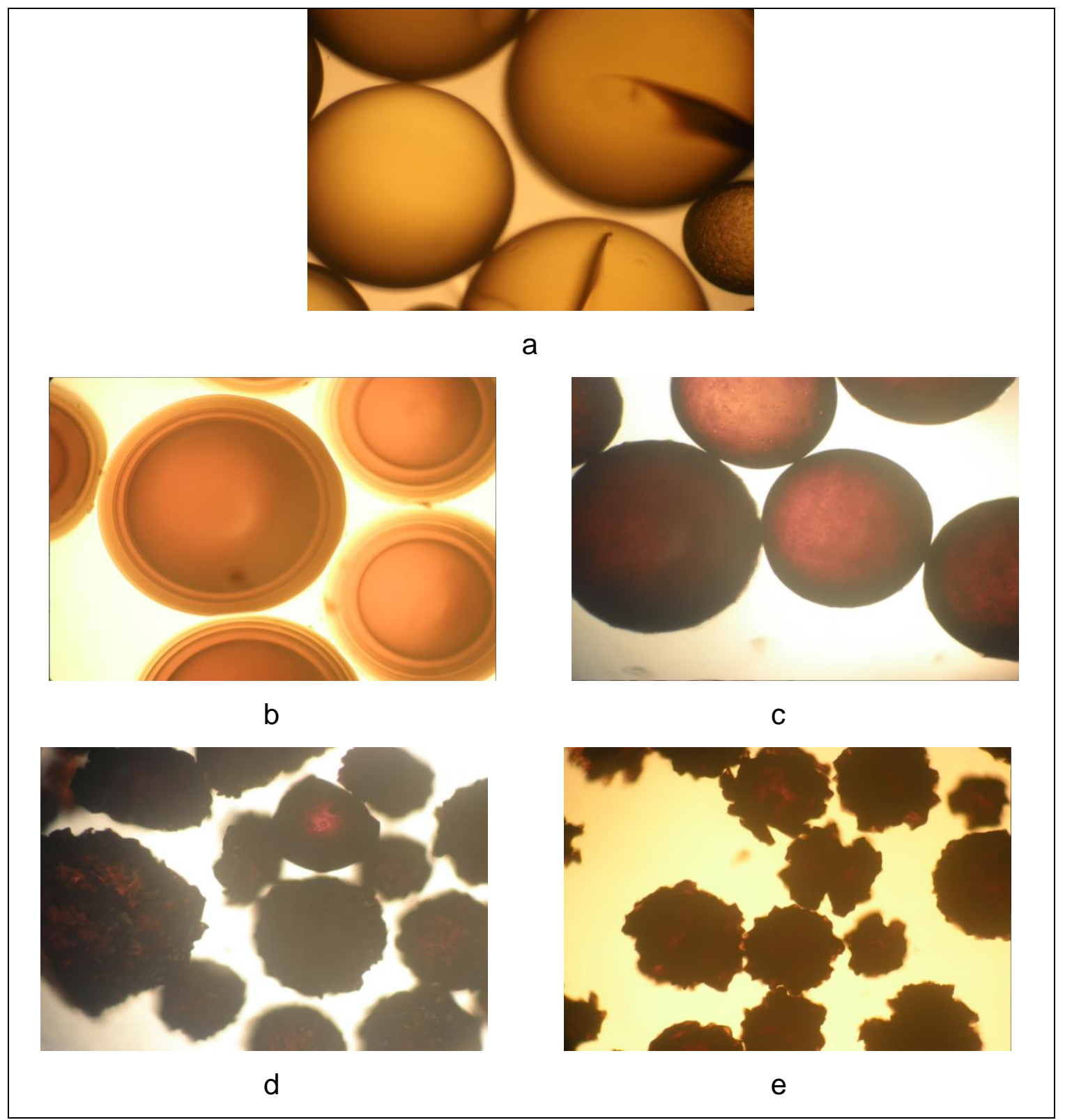

FIGURA 17- a: Resinas sem tratamento. b, c, d, e: Resinas após 30, 45, 120 e 180 minutos de reação (50 mM Fe2SO4). a: Aproximação 10x. b, c, d, e: 40x.

\subsection{Análise de grupos funcionais por meio de Infravermelho}

As resinas catiônicas e aniônicas sem tratamento e a resina mista póstratamento com Fenton foram analisadas por meio de Espectroscopia de Infravermelho por Transformada de Fourier (FTIR). Os espectros são apresentados nas FIG. 18, 19 e 20. 


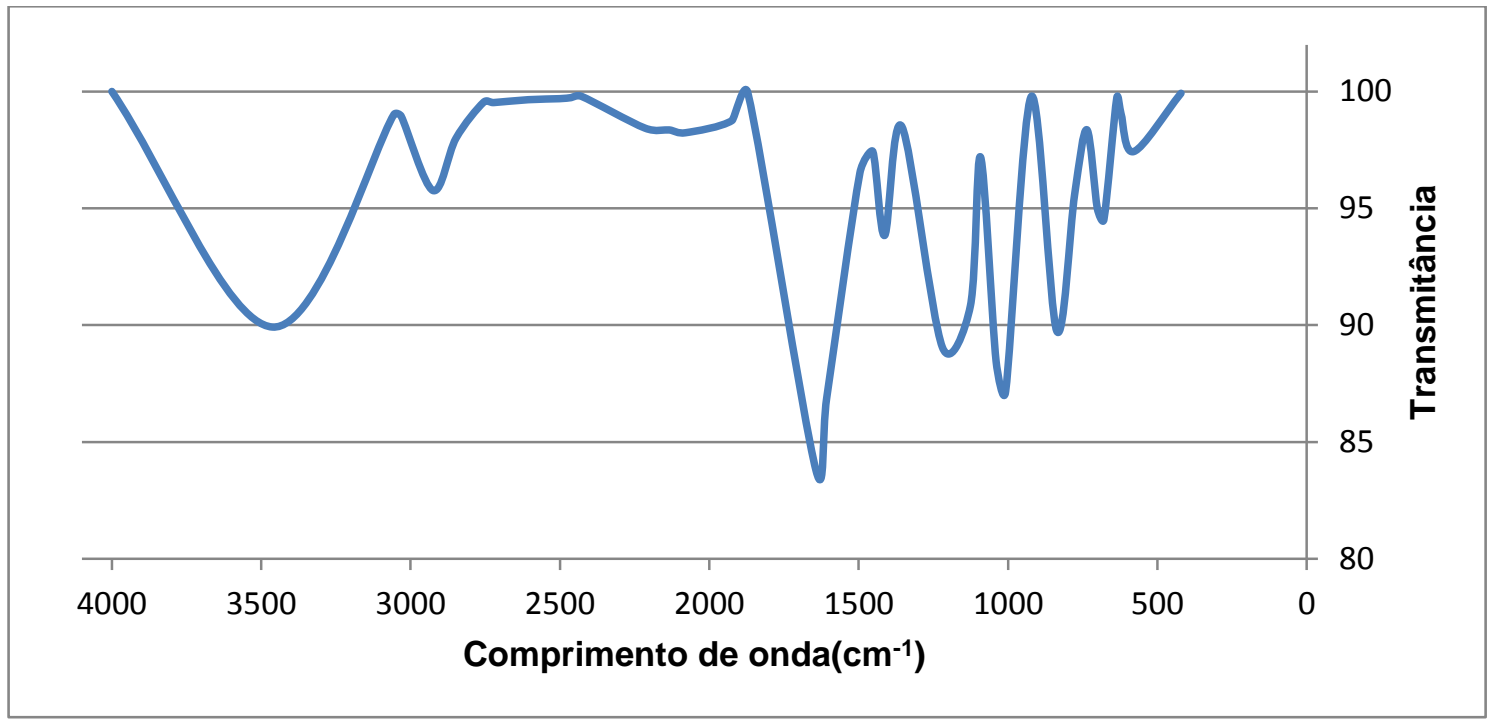

FIGURA 18 - Espectro de Infravermelho por Transformada de Fourier da resina de troca catiônica fortemente ácida

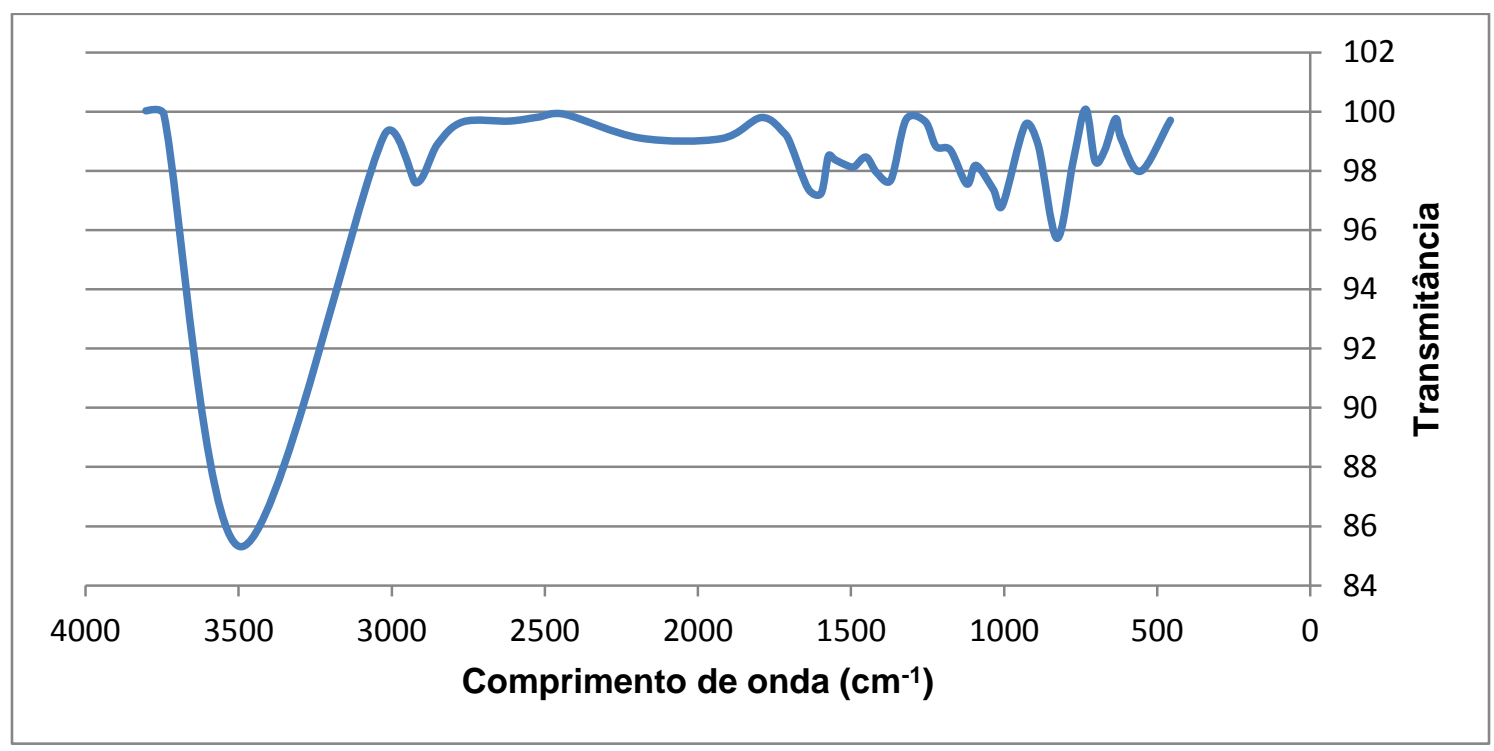

FIGURA 19 - Espectro de Infravermelho por Transformada de Fourier da resina de troca aniônica fortemente básica 


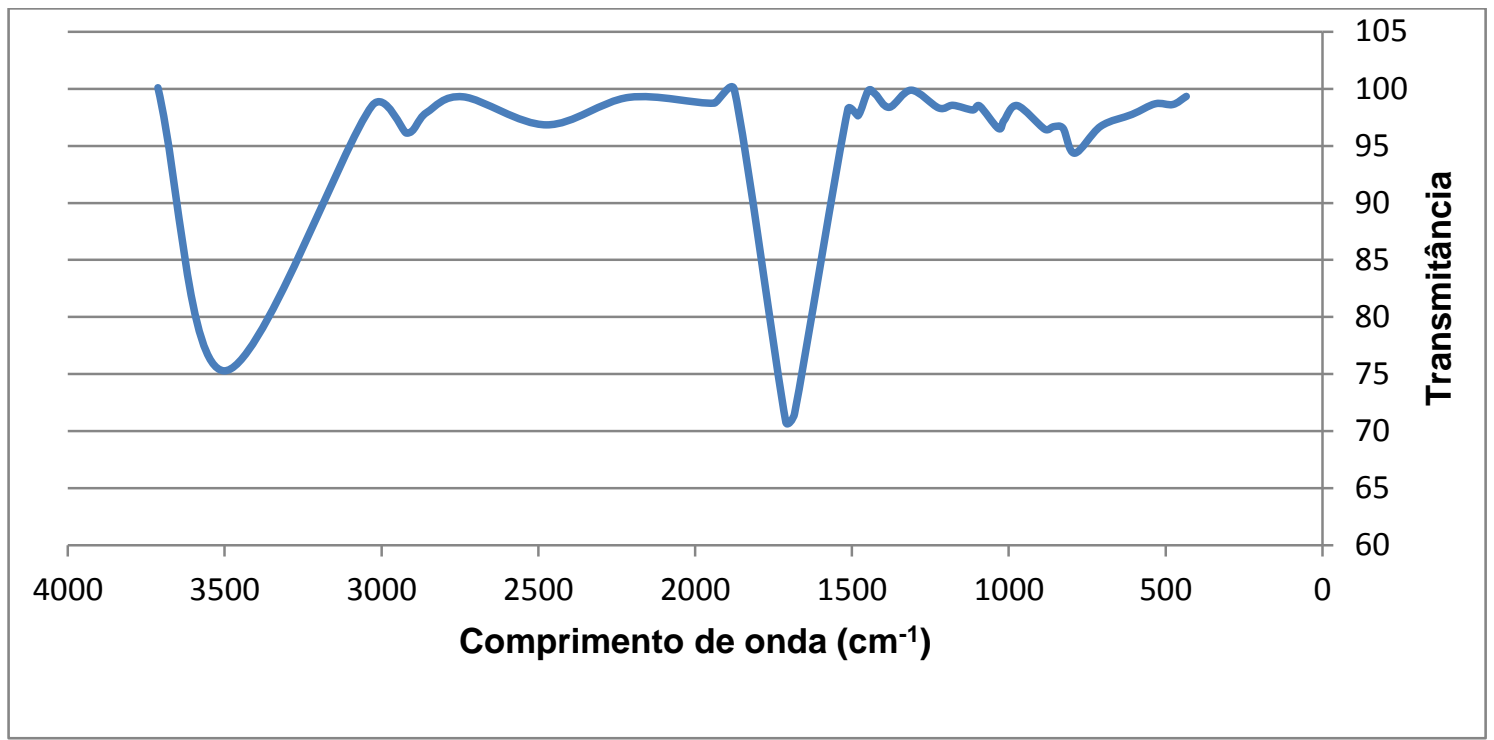

FIGURA 20 - Espectro de Infravermelho por Transformada de Fourier da resina de troca aniônica mista após tratamento de Fenton

A análise dos espectros foi realizada e a identificação dos grupos e das ligações são mostrados na TAB. 12. 
TABELA 12 - Análise dos espectros de FTIR de resinas catiônicas e aniônicas sem tratamento de Fenton e de resinas mistas remanescentes após Fenton

\begin{tabular}{|c|c|c|c|}
\hline $\begin{array}{l}\text { Catiônica s/ } \\
\text { tratamento }\end{array}$ & $\begin{array}{l}\text { Aniônica s/ } \\
\text { tratamento }\end{array}$ & $\begin{array}{l}\text { Mista c/ } \\
\text { tratamento }\end{array}$ & Atribuição \\
\hline $3463 \mathrm{~F}$ & $3494 \mathrm{~F}$ & $3503 \mathrm{~F}$ & O-H água \\
\hline $2848 \mathrm{~m}$ & $2850 \mathrm{~m}$ & - & Alongamento $\mathrm{C}-\mathrm{H}$ de alcanos \\
\hline - & - & $1683 \mathrm{~F}$ & İon carboxilato \\
\hline $1637 \mathrm{~F}$ & $1637 \mathrm{~F}$ & - & $\begin{array}{l}\text { Alongamento de anéis de benzeno } \\
\text { de hidratação da água }\end{array}$ \\
\hline - & $1598 \mathrm{~F}$ & - & Ligação N-H \\
\hline - & $1370 \mathrm{~m}$ & - & $\mathrm{N}-\mathrm{CH}_{3}$ da amina quaternária \\
\hline $\begin{array}{l}1220 \mathrm{~F}, 1126 \mathrm{~F}, \\
1040 \mathrm{~F} \mathrm{e} 679 \mathrm{~F}\end{array}$ & - & - & Ácido sulfônico \\
\hline - & $1176 \mathrm{~m}$ & - & $\begin{array}{l}\text { C-N das aminas quaternárias } \\
\text { alifáticas }\end{array}$ \\
\hline $\begin{array}{l}1126 \mathrm{Fa} \\
1040 \mathrm{~F} \\
1007 \mathrm{~F}\end{array}$ & - & - & $\mathrm{SO}_{3}$ Alongamentos simétricos \\
\hline- & $\begin{array}{l}1122 \mathrm{~F} \\
1092 \mathrm{~F}\end{array}$ & - & $\begin{array}{l}\text { Aminas alifáticas (normalmente } \\
\text { aparecem como dubletes) }\end{array}$ \\
\hline $889 \mathrm{f}$ & - & - & $\begin{array}{c}\text { Alongamento simples da banda S- } \\
\mathrm{OH} \text {; fora da definição do plano - } \\
\mathrm{COOH}\end{array}$ \\
\hline $837 \mathrm{Fa}$ & $828 \mathrm{Fa}$ & & $\begin{array}{l}\text { Ligação C-H do benzeno para- } \\
\text { disubstituído }\end{array}$ \\
\hline $\begin{array}{c}835 \mathrm{Fa} \\
776 \mathrm{f}\end{array}$ & - & - & $\begin{array}{c}\text { Fora do plano de deformação do } \\
\text { ph-H em anéis de benzeno } \\
\text { disubstituídos }\end{array}$ \\
\hline - & $774 \mathrm{f}$ & - & $\begin{array}{l}\text { ph-H em anéis de benzeno } \\
\text { disubstituídos }\end{array}$ \\
\hline
\end{tabular}

"F" = forte," m" = média," f" = fraca e "a" = alta 
Foi possível identificar os principais componentes das resinas catiônicas e aniônicas, como os compostos orgânicos de enxofre encontrados na forma de ácido sulfônico nos picos $1220 \mathrm{~cm}^{-1}, 1126 \mathrm{~cm}^{-1}, 1040 \mathrm{~cm}^{-1}$ e $679 \mathrm{~cm}^{-1}$, todos com forte intensidade. Já as aminas (presentes nas resinas aniônicas) foram identificadas na ligação $\mathrm{N}-\mathrm{CH}_{3}$ da amina quaternária em $1370 \mathrm{~cm}^{-1}$, em $1176 \mathrm{~cm}^{-1}$ e na ligação $\mathrm{C}-\mathrm{N}$, também das aminas quaternárias, e na ligação $\mathrm{N}-\mathrm{H}$ no pico $1598 \mathrm{~cm}^{-1}$ com forte intensidade. $\mathrm{Na}$ identificação da resina mista remanescente (após reação de Fenton) foi observado, além do pico característico do O-H em $3503 \mathrm{~cm}^{-1}$, a forte presença do íon carboxilato em $1683 \mathrm{~cm}^{-1}$, que se deve à presença dos ácidos oxálicos e fórmicos formados na reação de Fenton. De acordo com Zahorodna et al. (2008), esses ácidos produzidos são parâmetros qualitativos na degradação de alifáticos e anéis aromáticos, respectivamente.

\subsection{Resumo das condições experimentais e dos parâmetros de avaliação adotados na degradação das resinas}

As condições experimentais e parâmetros de avaliação adotados nas reações de degradação das resinas de troca iônica são apresentadas na Tabela 14. 
Tabela 14 - Condições experimentais de todos os experimentos conduzidos na degradação de 1 e 10 gramas de resinas úmidas

\begin{tabular}{|c|c|c|c|c|c|c|c|c|c|c|}
\hline Resina & $\begin{array}{l}\text { Massa de } \\
\text { resina } \\
\text { inicial } \\
\text { úmida }(\mathrm{g})\end{array}$ & $\begin{array}{l}\text { Aquecimento } \\
\text { externo }\end{array}$ & $\begin{array}{c}\text { Temperatura } \\
\left({ }^{\circ} \mathrm{C}\right)\end{array}$ & $\begin{array}{c}\text { Tipo de } \\
\text { catalisador }\end{array}$ & $\begin{array}{l}\text { Concentração de } \\
\text { catalisador }(\mathrm{mM})\end{array}$ & $\begin{array}{l}\text { Carbonato } \\
\text { de sódio* }\end{array}$ & OD* & COT* $^{*}$ & $\begin{array}{c}\% \text { de } \\
\text { degradação }\end{array}$ & $\begin{array}{c}\text { Massa de } \\
\text { resina } \\
\text { residual }\end{array}$ \\
\hline Catiônica & 1 & Sim & 50 a 70 & $\mathrm{Fe}^{2+}$ & 20 & Não & - & - & 99 & $<0,01$ \\
\hline Catiônica & 1 & Não & 50 a 70 & $\mathrm{Fe}^{2+}$ & 20 & - & - & - & 98 & $0,01 \pm<0,01$ \\
\hline Aniônica & 1 & Sim & 50 a 70 & $\mathrm{Fe}^{2+}$ & 20 & - & - & - & 99 & $<0,01$ \\
\hline Aniônica & 1 & Não & 50 a 70 & $\mathrm{Fe}^{2+}$ & 20 & Não & - & - & 70 & $0,17 \pm 0,13$ \\
\hline Mista & 1 & Não & 50 a 70 & $\mathrm{Fe}^{2+}$ & 20 & - & - & - & 16 & $0,46 \pm 0,13$ \\
\hline Mista & 1 & Não & 50 a 70 & $\mathrm{Fe}^{2+} / \mathrm{Cu}^{2+}$ & 40 cada & - & - & - & 92 & 0,04 \\
\hline Mista & 1 & Não & 50 a 70 & $\mathrm{Co}^{2+}$ & 100 & - & - & - & Não reagiu & 0,04 \\
\hline Mista & 1 & Sim & 50 a 70 & $\mathrm{Fe}^{2+}$ & 20 & - & - & - & 68 & $0,17 \pm 0,03$ \\
\hline Mista & 1 & Sim & 50 a 70 & $\mathrm{Fe}^{2+}$ & 35 & - & - & - & 85 & $0,08 \pm 0,03$ \\
\hline Mista & 1 & Sim & 50 a 70 & $\mathrm{Fe}^{2+}$ & 80 & Não & - & - & 97 & $0,02 \pm 0,01$ \\
\hline Mista** & 1 & Não & 50 a 70 & $\mathrm{Fe}^{2+}$ & 50 & - & - & - & 98 & $0,01 \pm 0,01$ \\
\hline Mista & 1 & Não & 50 a 70 & $\mathrm{Fe}^{2+}$ & 70 & Não & - & - & 97 & $0,02 \pm 0,01$ \\
\hline Mista & 1 & Não & 50 a 70 & $\mathrm{Fe}^{2+}$ & 80 & - & - & - & 98 & $0,01 \pm 0,01$ \\
\hline Mista & 10 & Não & 50 & $\mathrm{Fe}^{2+}$ & 50 & - & - & - & 92 & $0,47 \pm 0,04$ \\
\hline Mista & 10 & Não & 60 & $\mathrm{Fe}^{2+}$ & 50 & - & - & - & 99 & $0,02 \pm 0,01$ \\
\hline Mista & 10 & Não & 70 & $\mathrm{Fe}^{2+}$ & 50 & - & - & - & 98,5 & $0,08 \pm 0,01$ \\
\hline Mista & 10 & Não & 40 & $\mathrm{Fe}^{2+}$ & 25 & - & Sim & Sim & 67,6 & $1,56 \pm 0,03$ \\
\hline Mista ${ }^{\star *}$ & 10 & Não & 60 & $\mathrm{Fe}^{2+}$ & 50 & - & Sim & Sim & 99 & $0,01 \pm<0,01$ \\
\hline Mista & 10 & Não & 54 & $\mathrm{Fe}^{2+}$ & 100 & - & Sim & Sim & 98 & $0,11 \pm 0,07$ \\
\hline Mista & 10 & Não & 54 & $\mathrm{Fe}^{2+}$ & 150 & - & Sim & Sim & 88 & $0,65 \pm 0,07$ \\
\hline
\end{tabular}




\subsection{Imobilização com cimento Portland}

Corpos de prova com diferentes relações solução/cimento (s/c) foram confeccionados com o objetivo de determinar a melhor relação entre estes. As proporções utilizadas foram de 0,28, 0,30 e 0,35 s/c. Os corpos de prova com s/c de 0,30 e 0,35 apresentaram líquido livre superior a 0,5\% do volume total, depois de 24 horas, acima do limite estabelecido pela Norma NN 6.09 - "Critérios de Aceitação para Deposição de Rejeitos Radioativos de Baixo e Médio Níveis de Radiação" (CNEN, 2002). Por este motivo, foi utilizada a relação s/c de 0,28 para os corpos de prova com diferentes $\mathrm{pH}$. Todas as misturas apresentaram boa trabalhabilidade durante a moldagem e não foi observada segregação antes da pega final.

Na TAB. 13 são apresentados o tempo de pega final e a resistência à compressão axial para os diferentes $\mathrm{pH}$.

TABELA 13 - Tempo de pega final e resistência à compressão axial

\begin{tabular}{ccc}
\hline $\mathbf{p H}$ & Tempo de pega (horas) & $\begin{array}{c}\text { Resistência à compressão axial* } \\
(\mathbf{M p a})^{\star \star}\end{array}$ \\
\hline Ácido & 8 & $16 \pm 1$ \\
Neutro & 5 & $8 \pm 2$ \\
Básico & 6 & $8 \pm 1$
\end{tabular}

*Valor mínimo de resistência mecânica em norma: 10 MPa (CNEN, 2002).

${ }^{\star \star} \bar{X} \pm \mathrm{S}$ (média \pm desvio-padrão)

A partir dos dados observados na TAB. 13, pode-se afirmar que todos os corpos de prova atingem a pega final em até 8 horas e é suficiente para o caso de uma mistura em escala real (Isiki, 2003). As soluções ácidas incorporadas em cimento apresentaram a melhor resistência a compressão axial (TAB. 13). Estes corpos de prova seriam os únicos aceitos perante a Norma NN 6.09, que estabelece o valor mínimo de resistência mecânica de $10 \mathrm{MPa}$. Isso pode ser explicado pela elevada concentração de sulfato, proveniente do $\mathrm{FeSO}_{4} \cdot 7 \mathrm{H}_{2} \mathrm{O}$, 
disponível nessas soluções e que foi precipitado nos ajustes de $\mathrm{pH}$ neutro e básico. $\mathrm{O}$ sulfato pode reagir com $\mathrm{O}$ aluminato de cálcio, presente no cimento, para formar a etringita $\left(\mathrm{Ca}_{6} \mathrm{Al}_{2}\left(\mathrm{SO}_{4}\right)_{3}(\mathrm{OH})_{12} \cdot 26 \mathrm{H}_{2} \mathrm{O}\right)$, material que preenche os poros do material cimentado, aumentando seu volume e resistência (Vichot et al., 2008). Essa reação ocorre normalmente durante a hidratação do cimento e a etringita formada sofre decomposição formando monosulfoaluminato. De acordo com Quennoz et al. (2008), somente após o uso de todo o sulfato, a etringita é consumida para formar o monosulfaluminato. A elevada concentração de íons sulfato da solução ácida pode ter impedido essa conversão, resultando em produto de resistência superior. O sulfato que é adicionado em todos os cimentos comerciais na forma de gesso $\left(\mathrm{CaSO}_{4}\right)$, tem a finalidade de retardar o tempo de pega e permitir a trabalhabilidade, pois sem ele o cimento endureceria quase que instantaneamente em contato com a água (Isiki, 2003). Assim, pode ser visto que o aumento da concentração do sulfato nas soluções ácidas também provocou aumento no tempo de pega.

Parte da solução remanescente da degradação das resinas foi evaporada e concentrada até atingir um volume com $40 \%$ do teor de sólidos. A resistência à compressão axial foi medida após 3 dias de cura, resultando num valor médio de $9 \pm 1(\mathrm{MPa})$, valor muito próximo do mínimo permitido em norma, $10 \mathrm{MPa}$ (CNEN, 2002). Como o tempo de cura adotado foi muito curto espera-se que o valor de resistência seja maior, pois, sabe-se que ele aumenta em função da hidratação do cimento com o tempo. Comparando esse processo com a imobilização direta, verificou-se que um aumento na capacidade de imobilização de resina no cimento. A solução concentrada continha o equivalente a $140 \mathrm{~g}$ de resina, que se fosse diretamente cimentada resultaria em 3 corpos de prova $(5 \times 10 \mathrm{~cm})$, diferente do resultado após a degradação, que gerou apenas 1 corpo. 


\section{CONCLUSÕES}

O Processo Oxidativo Avançado com reagentes de Fenton foi avaliado na degradação da resina de troca iônica. Quantidade final de resina, concentração e diferentes catalisadores, oxigênio dissolvido, Carbono Orgânico Total, temperatura, concentração de catalisador, análise morfológica e de grupos funcionais e a capacidade de imobilização da solução final foram os parâmetros estudados. O POA é uma técnica viável para degradação das resinas e é possível concluir que:

- A concentração do catalisador interfere na reação de oxidação, sendo 50 e $100 \mathrm{mM}$ as concentrações mais eficazes. Entretanto, a concentração de 50 $\mathrm{mM}$ foi a mais efetiva, por necessitar de menos catalisador comparada a de $100 \mathrm{mM}$ no tratamento de 10 gramas de resina.

- É possível degradar eficientemente as resinas sem aquecimento externo. A temperatura de $60^{\circ} \mathrm{C}$ se mostrou efetiva.

- O COT foi eficiente como parâmetro de reação para determinar as taxas de degradação das resinas.

- Nos catalisadores estudados, o $\mathrm{Fe}^{2+}$ e $\mathrm{Fe}^{2+} / \mathrm{Cu}^{2+}$ foram os mais adequados nos ensaios de oxidação.

- A determinação do carbonato de sódio não foi um parâmetro aceitável para avaliar a degradação das resinas, já que não houve correlação das massas de carbonato quantificadas com a massa de resina residual. 
- As resinas aniônicas e mistas apresentam maior dificuldade de degradação em relação as resinas catiônicas, devido a estabilidade de seu grupo funcional amina.

- A relação solução/cimento de 0,28 foi adequada para produzir um produto imobilizado que atende os limites estabelecidos em norma.

- Os processos de degradação e a evaporação permitiram a incorporação de uma massa 3 vezes maior quando comparada com a imobilização direta. 


\section{TRABALHOS FUTUROS}

- Avaliar as degradações das resinas de troca iônica quando catalisadas por UV ou Fenton heterogêneo, evitando a formação de lama (excesso de ferro na solução final)

- Uso de surfactantes (ex. CTAB, Triton X-100, SDS) em concentrações acima da CMC (concentração Micelar Crítica) para avaliação do efeito dos mesmos na reatividade do sistema testado.

- Avaliação e maior controle de impurezas (íons metálicos de transição) para identificação de possível efeito sinérgico no sistema reacional estudado.

- Fazer estudos com cimento resistente a sulfato. 


\section{REFERÊNCIAS BIBLIOGRÁFICAS}

AGUIDA, L. A.; TING, D. K. S.; SILVA, A. T.; LONGO, E. S.; FILHO, O. C. Identificação dos processos de corrosão dos elementos estruturais do reator IEA-R1 através da análise química da água. Fase 1 - Caracterização da água da piscina do reator IEA-R1. International Nuclear Atlantic Conference, INAC. IPEN-CNEN/SP. São Paulo, Brasil, 1999.

ALBERICI, R. M.; Construção de um fotoreator para degradação de compostos orgânicos potencialmente tóxicos. 1992, Dissertação (Mestrado), UNICAMP, Campinas, São Paulo.

ALBERICI, R. M.; Destruição de compostos orgânicos voláteis em fase gasosa por fotocatálise heterogênea. 1996, p. 112 Tese (Doutorado), UNICAMP, Campinas, São Paulo.

ALVES, J. F; Aplicação do Reagente de Fenton no tratamento de líquidos lixiviados de Aterros Sanitários. 2004. Dissertação (mestrado). Universidade Federal de Minas Gerais, UFMG, Belo Horizonte, Minas Gerais.

AMPHLETT, C.B. Treatment and Disposal of radioactive wastes. International Series of Monographs on Nuclear Energy. Division V, v.2, Pergamon Press, London, 1961.

ANDREOZZI, R.; CAPRIO, V., INSOLA, A., MAROTTA, R. Advanced oxidation processes (AOP) for water purification and recovery. Catalysis Today. 53, 51-59. Italy, 1999.

ANSTO. Management of Radioactive Waste in Australian. Australian Government, 2011.

ARAUJO, F. V. F.; Estudo do processo Fenton Heterogêneo utilizando hematita $\left(\mathrm{Fe}_{2} \mathrm{O}_{3}\right)$ como catalisador na descoloração de soluções de corante reativo. Tese de doutorado. Universidade Federal do Rio de Janeiro, UFRJ, 2008.

ARPANSA, Australian Radiation Protection and Nuclear Safety Agency. Predisposal Management of Radioactive Waste. Radiation Protection Series. n. 16. 2008. 
ASSOCIAÇÃO BRASILEIRA DE CIMENTO PORTLAND. BT-106. Guia básico de utilização do cimento Portland. São Paulo, 2002.

BENAVIDES, E.; SCHIMIDT, K.; Cementation Plant for Radioactive Waste. Waste Management Symposia, p. 1465- 146, v. 2, 1992.

BLESA, M. A. Introducción. CYTED, 2001. Disponível em < http://www.cnea.gov.ar/xxi/ambiental/CYTED/04intro.pdf > Acesso em 22/03/13.

BOU-DIAB, L.; FIERZ, H.; Autocatalytic decomposition reactions, hazards and detection. Swiss Institute for the promotion of Safety and Security. Basel Branch, 4002 Basel , Switzerland. Journal of Hazardous Materials, v. 93, 2002.

BIO-RAD LABORATORIES, INC. KnowitalIB Informatics System 9.5. Copyright C 2012.

BUXTON, G. V.; GREENSTOCK, C. L.; Critical review of rate constants for reactions of hydrated electrons, hydrogen atoms and hydroxyl radicals $\left(-\mathrm{OH} /-\mathrm{O}^{-}\right)$in aqueous solution. Journal of Physical and Chemical Data. 17, 513, 1988.

CANELA, M. C.; Identificação e destruição fotocatalítica em fase gasosa de compostos causadores de odor em efluentes. 1999, p. 138 (Tese de (Doutorado) - Unicamp, Campinas, São Paulo.

CAPONERO, J.; TENÓRIO, J. A. S.; Comportamento da lama de fosfatização no processo de produção do clínquer de cimento Portland. Departamento de Engenharia Metalúrgica e de Materiais da Escola Politécnica da Universidade de São Paulo. Congresso Brasileiro de Cerâmica. Florianópolis, 1999.

CATRINESCU, C.; TEODOSIU, C.; MACOVEANU, M.; BRENDLÉ, J. M.; DRED, R. L.; Catalytic wet peroxide oxidation of phenol over Fe-exchanged pillared beidellite. Water Research, v. 37. p.1154 - 1160. 2003.

CEGALLA, M. A.; BAPTISTA FILHO, B. D.; FÉLIZ, O. C. Estudo de sistemas para remoção de impurezas da água da piscina do reator IEA-R1. Fase 1: Projeto do Circuito Experimental. International Nuclear Atlantic Conference, INAC, 1997. 
CHEN, W. R.; WU, C.; ELOVITZ, M.; et al. Reactions of thiocarbamate, triazine and urea herbicides, RDX and benzenes on EPA Contaminant Candidate List with ozone and with hydroxyl radicals. Water Research, v. 42, n. 1-2, 137-144, 2007.

CNPq, Conselho Nacional de Desenvolvimento Científico e Tecnológico. Coop. Internacional. Disponível em http://memoria.cnpq.br/programas/coopint/cyted.htm>. Acesso em 22/03/13.

Calgon Carbon Corporation. The AOT Handbook, Ontario, 1996.

COMISSÃO NACIONAL DE ENERGIA NUCLEAR. 3rd Review meeting of the joint convention on the safety of spent fuel management and on the safety of radioactive waste management. Nacional Report of Brazil, October 2008.

COMISSÃO NACIONAL DE ENERGIA NUCLEAR. CNEN define medidas para reduzir efeitos da suspensão no fornecimento de molibdênio-99. Comunicação social CNEN. Disponível em < http://www.cnen.gov.br/noticias/noticia.asp?id=197>. Acesso em 05/09/2012.

COMISSÃO NACIONAL DE ENERGIA NUCLEAR, CNEN. Norma CNEN - NE6.05: “Gerência de Rejeitos Radioativos em Instalações Radiativas”, 1985.

COMISSÃO NACIONAL DE ENERGIA NUCLEAR, CNEN. Norma CNEN - NN 6.09: “Critérios de aceitação para deposição de rejeitos radioativos de baixo e médio níveis de radiação", 2002.

COMISSÁO NACIONAL DE ENERGÍA NUCLEAR. Glossário de segurança nuclear. Rio de Janeiro, RJ, Fev. 2011. Disponível em: <http://www.cnen.gov.br/seguranca/normas/pdf/glossario.pdf>. Acesso em: 10 jun. 2012.

CRUZ, R.M. Reativo de Fenton e Foto-Fenton em efluente de alta salinidade. 2000. Dissertação (Mestrado) - COPPE, UFRJ, Rio de Janeiro.

DOMÈNECH, X.; JARDIM, W. F.; LITTER, M. I.; Procesos avanzados de oxidación para la eliminación de contaminantes, 2004.

DONAIRE, P. P. R.; Desinfecção de águas utilizando radiação ultravioleta e fotocatálise heterogênea. Campinas, 2001. p. 130. Dissertação (Mestrado), UNICAMP, Campinas, São Paulo. 
ENDO, L. S. Tratamento de rejeitos radioativos compostos por solventes orgânicos: sistema TBP/DODECANO. 1991. Tese (Doutorado) - Instituto de Pesquisas Energeticas e Nucleares, Sao Paulo.

FABIANO B.; PASTORINO R.; FERRANDO M.; Distillation of radioactive liquid organic wastes for subsequent wet oxidation. Journal of Hazard Materials. v. 57, pp. 105-125. 1998

FENTON, H. J. H. Oxidation of tartaric acid in the presence of iron, Journal of Chemical Society. 65. 899-910, 1894.

FERREIRA, R. V. P. Biodegradação de rejeitos radioativos líquidos orgânicos provenientes do reprocessamento do combustível nuclear. 2008. Dissertação (mestrado) - Instituto de Pesquisas Energéticas e Nuclear. São Paulo.

FISPQ. Ficha de Informações de Segurança de produtos químicos. Peróxidos do Brasil.. Peróxido de Hidrogênio. IQBC Produtos Químicos Ltda. Revisão 27/06/2012. Disponível em < http://www.peroxidos.com.br/SiteCollectionDocuments/Fichas/H2O2 8 A 35 PE ROXIDOS.pdf>. Acesso em 01/04/2013.

GÁLVEZ, J. B.; RODRíGUEZ, S. M.; GASCA, C. A. E. BANDALA, E. R.; GELOVER, S.; LEAL, T. . In: CYTED. Eliminación de Contaminantes por Fotocátalisis Heterogénea, 2001.

GIUFFRE, M., ENSMINGER, D., NALBANDIAN, J., NAUGHTON, M. The economics of radwaste volume reduction strategies. Waste Management, v. 2: $p$. 31-35, 1984.

GOGATE, R.; PANDIT, B. A review of imperative technologies for wastewater treatment I: oxidation technologies at ambient conditions. Advances in Environmental Research. v. 8, p. 501-551, 2004.

GOLD, V.; LOENING, K.; SEHMI, P.; Compendium of Chemical Terminology, IUPAC Recommendations, Blackwell Scientific Publications, Oxford, 1987, p. 34.

GOSLAN, E.H., GURSES, F., BANKS, J., PARSONS, S.A.; An investigation into reservoir NOM reduction by UV photolysis and advanced oxidation processes. Chemosphere, v. 65, 1113-1119, 2006. 
GUISELLI, G. Remediação de solos contaminados com pesticidas organoclorados utilizando reagente de Fenton. 2001, $101 \mathrm{P}$. Tese (Mestrado) UNICAMP, Campinas, São Paulo.

HABASHI. F. A textbook of hidrometallurgy. Métallurgie Extrative Québec, Enr. Quebec, Canada, p. 375 - 405, 1993.

HABER, F.; WEISS, J.; The catalytic decomposition of hydrogen peroxide by iron salts. Proceeding of the Royal Society of London. 147, 332, Londres, 1934.

HELFFERICH, F. Ion Exchange. Toronto: General Publishing Company, 1995. 631 p. Disponível em: $<$ http://books.google.com.br/books?id=F9OQMEA88CAC\&printsec=frontcover\&hl= pt-BR\&source=gbs_ge_summary_r\&cad $=0 \# v=0$ nepage \&q\&f=false $>$. Acesso em: 18 set. 2012.

HIGARASHI, M. M.; Processos oxidativos avançados aplicados à remediação de solos brasileiros contaminados com pesticidas. 1999, p. 77 . Tese (Doutorado) UNICAMP, Campinas, São Paulo.

HIROMOTO, G.; DELLAMANO, J.C.; MARUMO, J.T.; ENDO, L.S.; VICENTE, R.; HIRAYAMA, T. Introdução à gerência de rejeitos radioativos. São Paulo: Instituto de Pesquisas Energéticas e Nucleares. Departamento de Rejeitos Radioativos, Rio de Janeiro, RJ, Brasil, 1999.

HUNG, L.C. Imobilização De Resinas De Troca lônica Em Polímeros. 1994. Dissertação (mestrado) - Instituto de Pesquisas Energéticas e Nuclear. São Paulo.

INTERNATIONAL ATOMIC ENERGY AGENCY. Application of ion exchange processes for the treatment of radioactive waste and management of spent ion exchanges, IAEA, Vienna, (2002).

INTERNATIONAL ATOMIC ENERGY AGENCY. Conditioning of low-and intermediate-level radioactive wastes. Technical Report Series. N. 222, IAEA, Vienna, 1983.

INTERNATIONAL ATOMIC ENERGY AGENCY, Classification of Radioactive Waste, IAEA Safety Standard Series, No GSG-1, 2009. 
INTERNATIONAL ATOMIC ENERGY AGENCY. Handling and storage of conditioned high-level wastes. Technical Report Series. N. 229, IAEA, Vienna, 1992.

INTERNATIONAL ATOMIC ENERGY AGENCY. Nuclear Technology Review. IAEA, Vienna, (2010).

INTERNATIONAL ATOMIC ENERGY AGENCY. Operation and Control of Ion exchange Processes for Treatment of Radioactive Wastes, Technical Report Series No. 78, IAEA, Vienna, 1967.

INTERNATIONAL ATOMIC ENERGY AGENCY. Options for the Treatment and Solidification of Organic Radioactive Wastes. Vienna, 1989. ( Technical Reports Series, 294). Review of the factors affecting the selection and implementation of waste management technologies. IAEA-TECDOC-1096. Ago. 1999. Disponível em: <http://www-pub.iaea.org/books/IAEABooks/1397/Optionsfor-the-Treatment-and-Solidification-of-Organic-Radioactive-Wastes>. Acesso em: 05 mar. 2012.

INTERNATIONAL ATOMIC ENERGY AGENCY. Radioactive waste management: An IAEA source book. IAEA, Vienna, 1992.

INTERNATIONAL ATOMIC ENERGY AGENCY. Storage of Radioactive Waste, Safety Standards Series, Safety Guide No. WS-G-6.1, Vienna, 2006.

INTERNATIONAL ATOMIC ENERGY AGENCY. The principles of radioactive waste management. Safety Series No. 111- F. IAEA, Vienna, 1995.

INTERNATIONAL ATOMIC ENERGY AGENCY. Treatment of Low and Intermediate-level Liquid Radioactive Wastes. Technical Report Series No. 236, IAEA, Vienna, 1984.

INSTITUTO DE PESQUISAS ENERGÉTICAS E NUCLEARES. Reator IEA-R1. Divisão de Comunicação Social, IPEN. São Paulo. 2002. (Folheto fornecido aos visitantes para visitas técnicas)

INSTITUTO DE PESQUISAS ENERGÉTICAS E NUCLEARES. Descrição do Reator. Disponível em: <http://www.ipen.br/sitio/?idc=263>. Acesso em: 14 jun. 2012. 
ISIKI, V. L. K. Avaliação do cimento Portland como matriz de imobilização de carvão ativo proveniente do reator de pesquisa do IPEN-CNEN/SP. 2003. Monografia - Faculdades Oswaldo Cruz, São Paulo.

JESUS, H. C. Estatística Aplicada à laboratórios de ensino. Laboratório de Química Analítica. Centro de Ciências Exatas, UFES, 2010. Disponível em < http://www.cce.ufes.br/dqui/lqa/extra/CEA.pdf>. Acesso em 16/08/13.

JIAN, X.; WU, T.; YUN, G. A Study of Wet Catalytic Oxidation of Radioactive Spent lon Exchange Resin by Hydrogen Peroxide. Environmental Effects. Nuclear Safety, v. 37, n. 2, April- June, 1996.

JUANG, R. S., LEE, T. S. Oxidative pyrolysis of organic ion exchange resins in the presence of metal oxide catalysts. Department of Chemical Enginnering, Yuan Ze University. Taiwan. Journal of Hazardous Materials. v. B92, 301-314, 2002.

JUANES, L. S.; BALLESTEROS, M. M.; ORTEGA, E.; CABRERA, A.; ROMÁN, L. M.; CASAS, J. L.; SÁNCHEZ, J. A.; Controlling dissolved oxygen concentration as a tool for economical efficiency improvement in a solar photo-Fenton treatment plant. $8^{\text {th }}$ IWA International Conference on Water Reclamation \& Reuse. Barcelona, 2011.

KOBAYASHI, Y., MATSUZURU, H., AKATSU, J., MORIYAMA, N. Acid digestion of radioactive combustible wastes. Journal of Nuclear Science and Technology. Japan Atomic Energy Research Institute. 865-868, Japan, 1980.

KIM, C., SAKATA, S. K., FERREIRA, R. V. P. MARUMO, J. T. Application of advanced oxidative process in treatment radioactive waste. International Nuclear Atlantic Conference - INAC 2009. Associação Brasileira de Energia Nuclear - ABEN. Rio de Janeiro, RJ, 2009.

KIM, H. Y; KIM, I. T; KIM, G.H; KIM, J.H; KANG, D.W. Wet Oxidation of Mixed Resins by Modified Fenton's Reaction with and Electrochemical Potential. Journal of Industrial and Engeneering Chemistry, v.13, no.5, (2007) 665-668. March 2007.

KINARD, F. Determination of the equivalent weight of an inorganic salt by cation exchange. Disponível em $<$ http://kinardf.people.cofc.edu/221LabCHEM/CHEM221L\%20lon-

Exchange\%20Equivalent\%20Weight.htm>. Acesso em 20/06/2012. 
KINOSHITA, K. HIRATA, M. YAHATA, T. NUCL, J. Pyrolysis and incineration of cationic and anionic ion-exchange resins: Identification of volatile degradation compounds. Journal Of Analytical And Applied Pyrolysis, Alemanha, v. 31, p.129-140, fev. 1995.

KOUZNETSOV, A., KNIAZEV O. Microbial treatment of ion exchange resins. Proceedings of the 8th Congress of Francophone Countries, v. 15, n. 86, p.427434, (2001).

KLAVARIOTI, M. MANTZAVINOS, D. KASSINOS, D. Removal of residual pharmaceuticals from aqueous systems by advanced oxidation processes. Environmental International, v. 35. 402 -417, 2009.

KWON, B. G.; LEE, D. S.; KANG, A. et al. Characteristics of pchlorophenol oxidation by Fenton's reagent, Water Research, v. 33, n. 9, 2118- 2118, 1999.

LAM, X. M.; LAI, W. G.; CHAN, E. K.; LING, V; HSU, C. C.; Site-Specific Tryptophan Oxidation Induced by Autocatalytic Reaction pf Polysorbate 20 in Protein Formulation. Pharmaceutical Research. v.28. p. 2543-2555. 2011.

LANGE, C. L.; ALVES, F. J.; AMARAL, S. C. M.; MELO JUNIOR R. W.Tratamento de lixiviado de aterro sanitário por processo oxidativo avançado empregando reagente de Fenton. Engenharia Sanitária e Ambiental. Rio de Janeiro. v. 11. n. 2, 2006.

Lei no 10.308, de 20 de novembro de 2001. Dispõe sobre a seleção de locais, a construção, o licenciamento, a operação, a fiscalização, os custos, a indenização, a responsabilidade civil e as garantias referentes aos depósitos de rejeitos radioativos, e dá outras providências. Diário Oficial da União [da República Federativa do Brasil], Brasília, DF, 21 Dez. 2001. P. 1 Disponível em: <http://www.planalto.gov.br/ccivil_03/leis/LEIS_2001/L10308.htm>. Acesso em: 15 jun. 2012.

LEYBROS, A., ROUBAUD, A., GUICHARDON, P., BOUTIN, O. Ion exchange resins destruction in a stirred supercritical water oxidation reactor. Journal of Supercritical Fluids. 51. p. 369 -375. 2010.

LI, J., WANG, J. Advances in cement solidification technology for waste radioactive ion exchange resins: A review. Journal of Hazardous Materials . v. B135. p. 443-448, 2006. 
LIMA, A. M., Tratamento de Efluentes Têxteis com Peróxido de Hidrogênio fotoativado com radiação UV. 1998. Dissertação (Mestrado) - PUC, Rio de Janeiro, RJ.

LIN, S.H.; LO, C.C. Fenton process for treatment of desizing wastewater. Water Research, v. 31, p. 2050-2056, 1997.

LUCAS, M. S.; PERES, J. A.; Decolorization of the azo dye Reactive Black 5 by Fenton and photo-Fenton oxidation. Dyes and Pigments . v. 7. p. $236-244$, 2006.

MATILAINEN, A.; SILLANPÄÄ, M. Removal of natural organic matter from drinking water by advanced oxidation processes. Chemosphere. v. 80. p. 351-365, 2010.

MARTíneZ, N. S. S., FERnÁNDEZ, J. F., SEGURA, X. F., FERRER, A. S. Preoxidation of an extremely polluted industrial wastewater by the Fenton's reagent. Journal of Hazardous Materials. v. B101. p. 315-322, (2003).

MARUMO, J.T. Avaliação da contaminação provocada por pára-raios radioativos de Amerício-241 descartados em lixões. Tese (Doutorado)Instituto de Pesquisas Energéticas e Nucleares, São Paulo. 2006.

MATTHEWS, R. Photocatalytic oxidation of organic contaminants in water: An aid to environmental preservation. Pure \& Applied Chemistry, v. 64, n.9, p. 1285 1290, 1992.

MIERZWA, J. C., HESPANHOL, I. Água na indústria - Uso Racional e Reuso. 1a edição. São Paulo: Oficina de Textos, 2005.

MORAES, J. L.; Estudo da potencialidade de processos oxidativos avançados, isolados e integrados com processos biológicos tradicionais, para tratamento de chorume e aterro sanitário. 2005. Tese (Doutorado), UFPR, Curitiba, Paraná.

NEAMTU, M.; SIMINICEANU, I.; YEDILER, A. et al. Kinetics of decolorization and mineralization of reactive azo dyes in aqueous solution by the $\mathrm{UV} / \mathrm{H} 2 \mathrm{O} 2$ oxidation, Dyes and Pigments, v.53, p. 93-99, 2002.

NEYENS, E.; BAEYENS, J. A review of classic Fenton's peroxidation as an advanced oxidation technique. Journal of Hazardous Materials, v. B98, p. 33-50, 2003. 
NOGUEIRA, R. F. P.; Fotodestruição de compostos potencialmente tóxicos utilizando $\mathrm{TiO}_{2}$ e luz solar. Campinas, 2005. p. 87. Tese (Doutorado), UNICAMP, Campinas, São Paulo.

NOGUEIRA, R. F. P. et al. Fundamentos e aplicações ambientais dos processos Fenton e foto-Fenton. Química Nova, v. 30, n. 2, p. 400-408, 2007.

NUKEM. Brochure Cementation. Cementation of Radioactive Waste, Junho 2007. Disponível em

$<$ http://www.nukemgroup.com/fileadmin/pdf/Brochure Cementation Juni 2007.pdf >. Acesso em 23/04/2013.

OLIVEIRA, I. S.; VIANA, L.; VERONA, C.; FALLAVENA, V. L. V.; AZEVEDO, C. M. N.; PIRES, M.; Alkydic resin wastewaters treatment by Fenton and photoFenton processes. Journal of Hazardous Materials. v. 146. 564-568, 2007.

PASQUALETTO, H. Níveis de radiação na superfície livre da piscina do reator IEA-R1. Dissertação (Mestrado). Instituto de Pesquisas Energéticas e Nucleares IPEN, 1978.

PIGNATELLO, J. J. Dark and photoassisted $\mathrm{Fe}^{3+}$ - catalyzed degradation of chlorophenoxy herbicides by hydrogen peroxide, Environmental Science \& Technology. v. 26. 1992.

QUEIROZ, L. G; FREIRE, L. F. A; ARAUJO, F. V. F; YOKOYAMA, L; CAMPOS, J. C. Estudo do processo Fenton e foto-Fenton no tratamento de lixiviados de aterros sanitários. XXVI Congresso Brasileiro de Engenharia Sanitária e Ambiental. Porto Alegre, RS, 2011.

QUENNOZ, A.; GALUCCI, E.; SCRIVENER, K.L. Calcium silicate - calcium aluminate interactions and their influence on cement early hydration. In: XIII ICCC INTERNATIONAL CONGRESS ON THE CHEMISTRY OF CEMENT, Madri, Jul $03-08,2011$.

RAITT, J. G. NUFFIELD ADVANCED SCIENCE. Chemistry ion exchange, a special study. Penguin Books, 1970. 
REYNOLDS, T. D., Unit Operations and Processes in Environmental Engineering, BC Engineering Division, Edition II, Boston, MA, 1982.

RIANI, J. C. Utilização de resinas de troca iônica em efluentes de galvanoplastia. Tese (Doutorado) da Universidade de São Paulo, São Paulo, 2008.

RIGG, T.; TAYLOR, W.; WEISS, J.; The rate constant of the reaction between hydrogen peroxide and ferrous ions. Journal of Chemical Physics. 22, 575, 1954.

ROCHA, A. A. Efeitos dos poluentes encontrados nos efluentes de uma galvanoplastia. Companhia de Tecnologia de Saneamento Ambiental (CETESB), Revista DAE, v. 42, p. 89-93, 1982.

SALGADO, B.C.B.; NOGUEIRA, M.I.C.; RODRIGUES, K.A.; SAMPAIO, G.M.M.S.; BUARQUE, H.L.B.; ARAÚJO, R.S. Descoloração de efluentes aquosos sintéticos e têxtil contendo corantes índigo e azo via processos Fenton e fotoassistidos (UV e UV/ $\mathrm{H}_{2} \mathrm{O}_{2}$ ). Engenharia Sanitária e Ambiental. v.14. n.1., 2009.

SIGMA ALDRICH ${ }^{1}$. AMBERLITE ${ }^{\circledR}$ IR120P Hydrogen Form. Catálogo. Disponível em:<http://www.sigmaaldrich.com/catalog/product/aldrich/216534?lang=pt\&region $=\mathrm{BR}>$. Acesso em 08/03/2013.

SIGMA ALDRICH ${ }^{2}$. AMBERLITE ${ }^{\circledR}$ IRA410 Chloride Form. Catálogo. Disponível em:<http://www.sigmaaldrich.com/catalog/product/aldrich/216569?lang=pt\&region $=$ BR $>$. Acesso em 08/03/2013.

SILVA FILHO, A. Tratamento Terciário de Efluente de uma Indústria de Refrigerantes Visando ao Reuso - Um Estudo de Caso. 2009..Dissertação (Mestrado). Universidade Federal do Rio de Janeiro - UFRJ.

SINGARE, P. U. Radioactive Tracer Technique in Characterization of Nuclear Grade Anion Exchange Resins Indion-102 and Indion GS-300. Department of Chemistry, Bhavan's College, Munshi Nagar, Andheri (West), Mumbai, 400058 , India. Journal of Nuclear and Particle Physics. 2(5). p. 119-125, 2012.

SHARP, J. H.; HILL, J.; MILESTONE, N.B.; MILLER, E.W. Cementitious Systems For Encapsulation Of Intermediate Level Waste. In: International Conference On Radioactive Waste Management And Environmental Remediation, 9 ${ }^{\text {th }} .2003$, Oxford, England: Proceedings Of Icem ‘03. p. 1 - 8. 2003. 
SHIMADZU. Total Organic Carbon Analyzer. TOC-V Series. Disponível em < http://www.shimadzu.com.br/analitica/produtos/toc/catalogos/toc-vw.pdf>, 25 de junho de 2012.

TEIXEIRA, C. P. A. B.; Destruição de compostos orgânicos potencialmente tóxicos utilizando fotocatálise heterogênea. Campinas, 1997, p. 88. Tese (Mestrado) UNICAMP, Campinas, São Paulo.

TEIXEIRA, C. P. A. B.; Estudo comparativo de tipos diferentes de Processos Oxidativos Avançados. 2002. Tese (Doutorado), Faculdade de Engenharia Civil, UNICAMP, Campinas, São Paulo.

United States Environmental Protection Agency. Handbook of Advanced Photochemical Oxidation Processes. December, 1998.

VARELA, N; VIEIRA, F. S; Cimento: Uma matéria-prima essencial no fabrico de argamassas. Congresso Português de Argamassas de Construção. 2005.

VEAZEY, G. W., AMES, A. L. Cement Waste-Form Development for IonExchange Resins at the Rocky Flats Plant. DOE Scientific and Technical Information. Los Alamos, New Mexico 87545, (1997).

VICHOT, A.; OLLIVIER, J.P. La durabilité des bétons. In: NONAT, A. L'hydratation des ciments. 2 ed., Paris, Presses de l'école nationale des Ponts et Chaussées, 2008.

VIEIRA, E. Estudo paramétrico da deformação de placas combustíveis com núcleos de dispersão $\boldsymbol{U}_{3} \mathrm{Si}_{2}-\mathbf{A l}$, 2011. Dissertação (Mestrado) - Instituto de Pesquisas Energéticas e Nucleares, IPEN, São Paulo.

ZAGORODNI, A. A.; KOTOVA, D. L; SELEMENEV, V. F.; Infrared spectroscopy of ion exchange resins: chemical deterioration of the resins. Reactive \& Functional Polymers 53. 157-171, 2002.

ZAHORODNA, M., BOGOCZEK, R., OLIVEROS, E., BRAUN, A.M. Application of the Fenton process to the dissolution and mineralization of ion exchange resins. Chemical Engineering Journal, v. 129, p.200-206, 2007.

ZAHORODNA, M., OLIVEROS, E., WÖRNER, M., BOGOCZEK, R., BRAUN, A. $M$. Dissolution and mineralization of ion exchange resins: differentiation between heterogeneous and homogeneous (photo-) Fenton processes. Photochemical \& Photobiological Science, p. 1480-1492, 2008. 
ZHANG, H. CHOI, H. J, HUANG, C. P. Optimization of Fenton process for the treatment of landfill leachate, Jounal of Hazardous Materials, v. B 125. p. 166174. 2005.

ZIOLLI, R. L; Fotodegradação da fração de petróleo solúvel em águas de mar sob ação da luz solar. 1999. Tese (Doutorado). Instituto de Química, UNICAMP, Campinas.

WALLING, C.; GOOSEN, A.; Fenton's reagent revisited. Journal of American Chemical Society. v.95, p.2987, 1973.

WHEATON, R. M. LEVEFRE, L. J. Fundamentals of Ion Exchange. Trademark Dow Chemical Company, 2000.

WOLFF, J. J. Ion exchange resins for use in nuclear power plants. Purolite-lon Exchange Resins. Revised and Updated, January, 2012. 